\title{
VIETNAMESE INTERNATIONAL STUDENTS' EXPERIENCES IN A NEW ZEALAND UNIVERSITY: A NARRATIVE STUDY.
}

\section{By}

HA THUONG VU

A thesis submitted to Victoria University of Wellington in fulfillment of the requirements for the degree of Master of Education.

Victoria University of Wellington, New Zealand 



\section{Table of Contents}

Abstract.........................................................................................v

Acknowledgements .......................................................................... vi

Chapter One: Introduction ..........................................................1

International students and studies of international students and international student

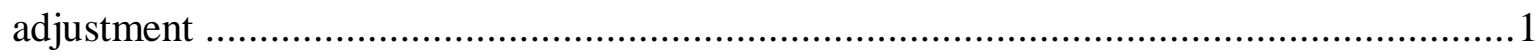

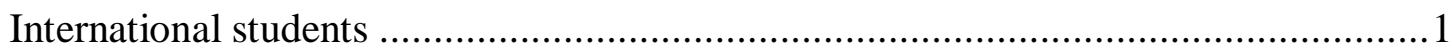

Studies of international students ............................................................. 1

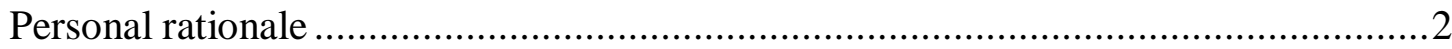

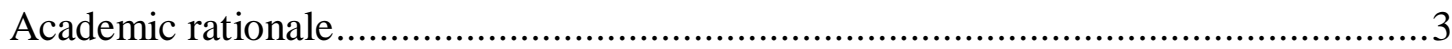

Location and context of the study ...................................................................

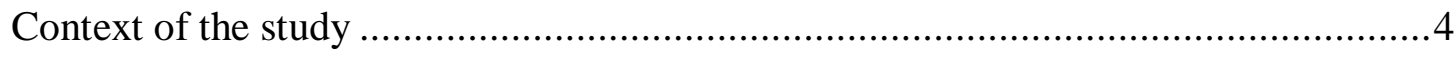

The Twinning programme- Ho Chi Minh City campus ...........................................5

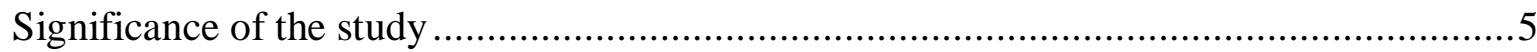

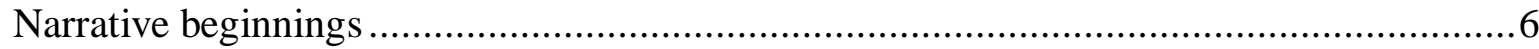

My stories of being an international student........................................................6

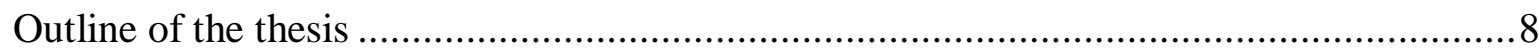

\section{Chapter Two: Literature Review and Theoretical Framework .......10}

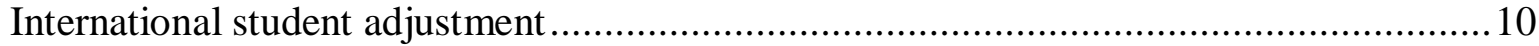

International student adjustment experience .................................................... 11

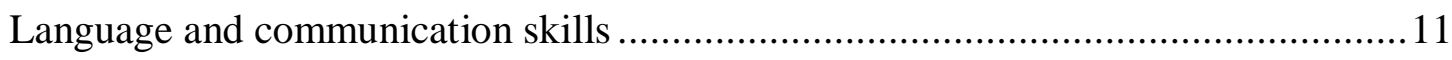

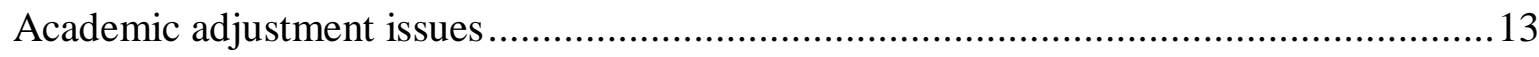

Adjustment strategies and help-seeking behavior ............................................. 16

Cultural difference in help-seeking behaviour.................................................. 17

Lack of knowledge about the host cultural behaviours ...................................... 18

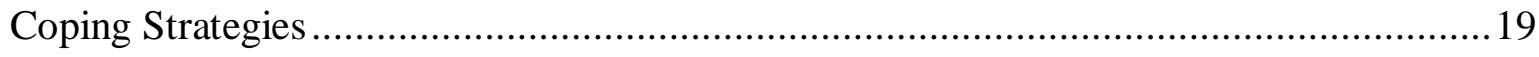

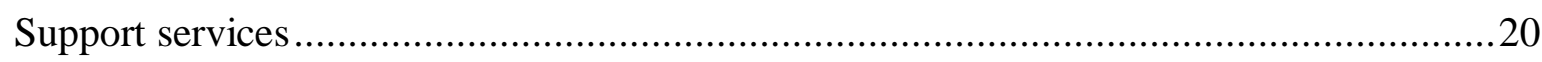

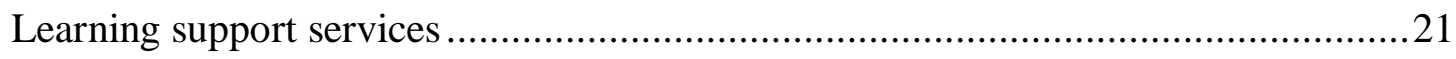

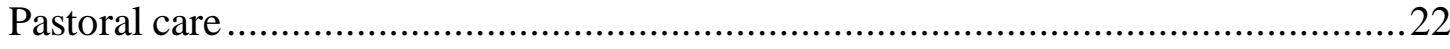




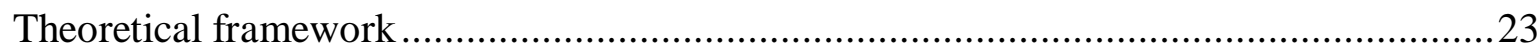

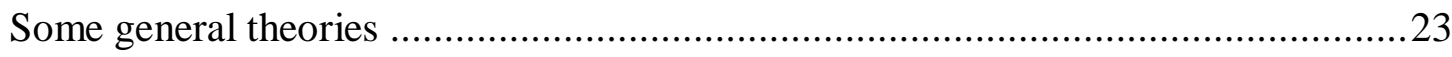

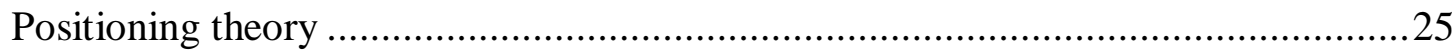

Chapter Three: Methodology ........................................................28

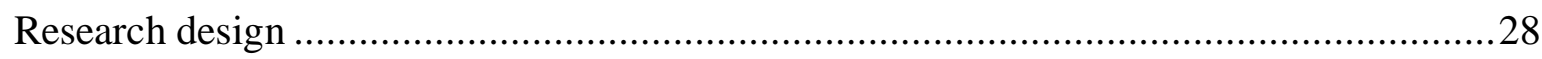

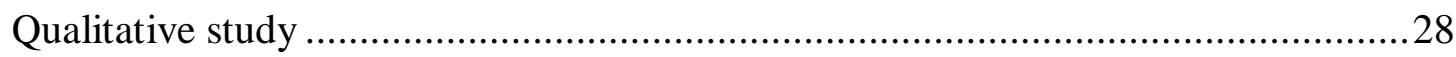

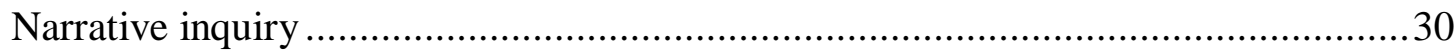

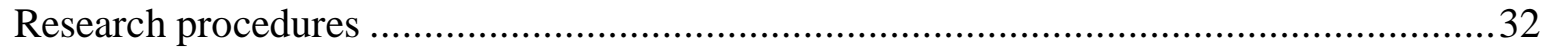

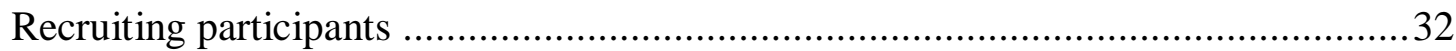

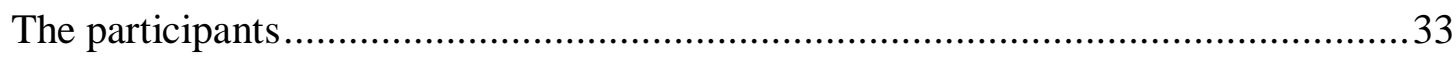

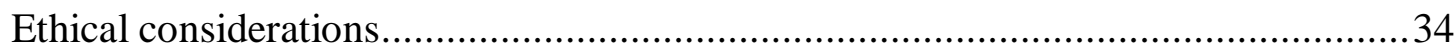

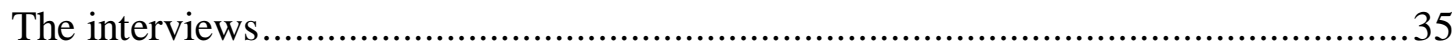

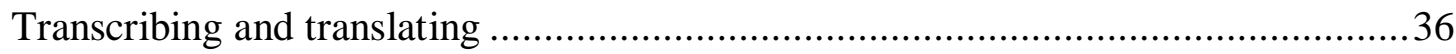

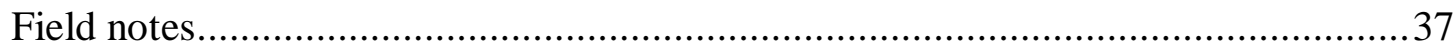

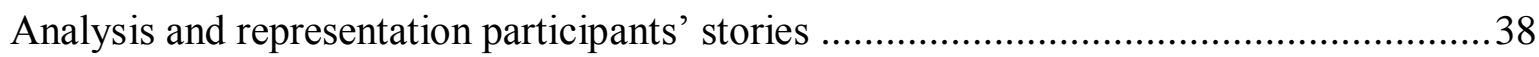

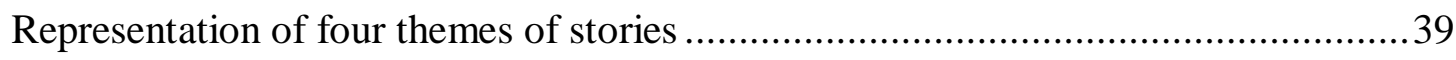

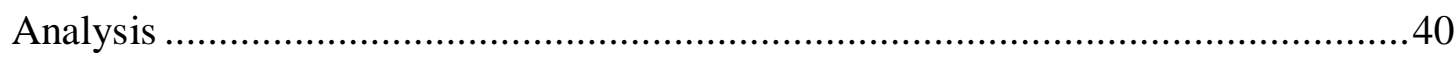

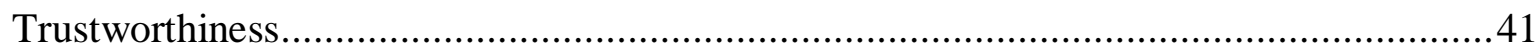

Chapter Four: Coming to New Zealand and Beginning to Study ..43

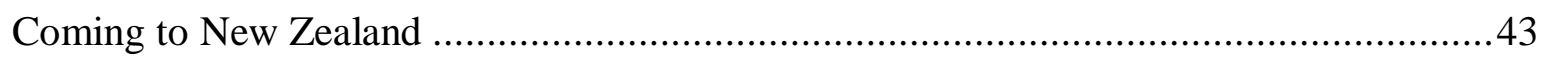

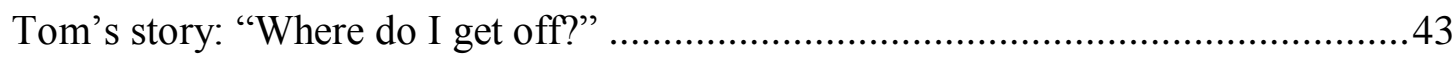

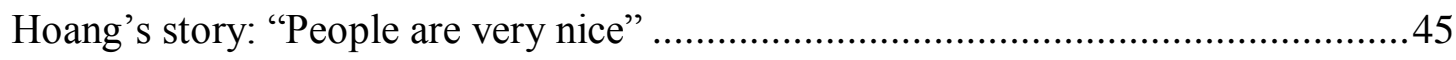

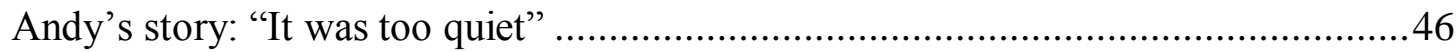

Hai's story: "It was a panic trip" .............................................................................48

Beginning to study at Victoria University .......................................................................49

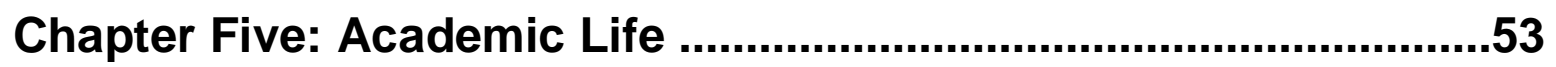

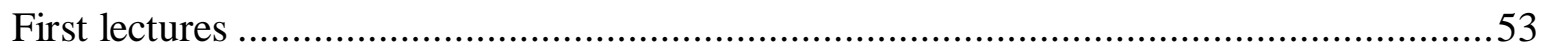

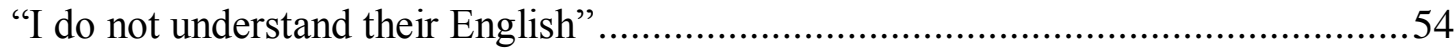

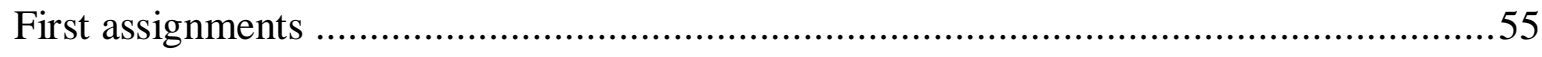

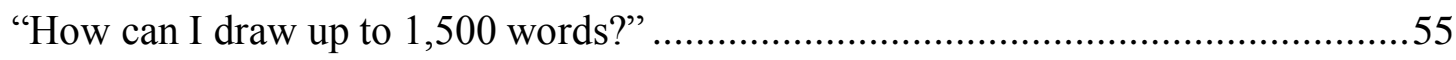




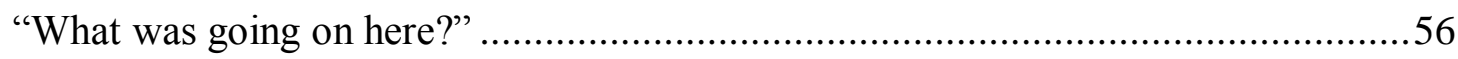

Learning style and relationship with academic staff ...................................................58

"Why did I spend thousands of dollar there then I had to self study?" ........................58

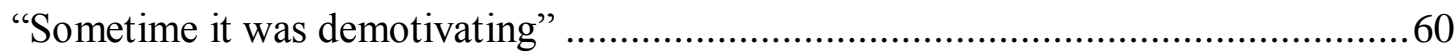

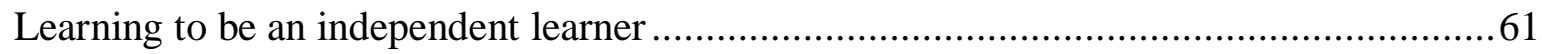

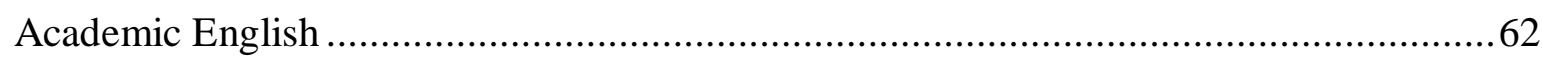

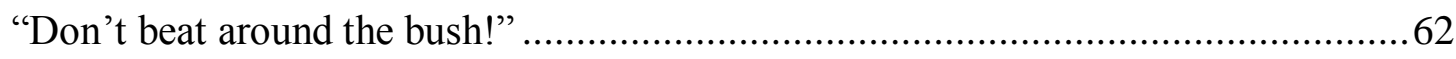

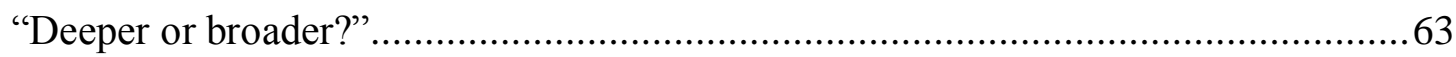

“Appropriate or inappropriate?" ................................................................................64

"Do not take notes on everything said by the lecturer"...............................................64

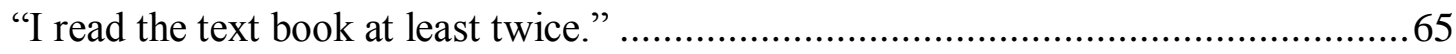

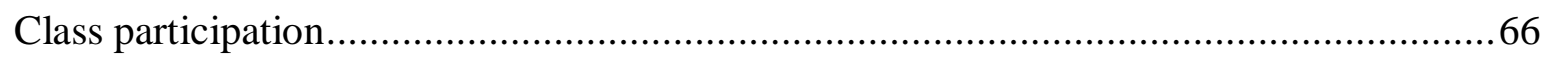

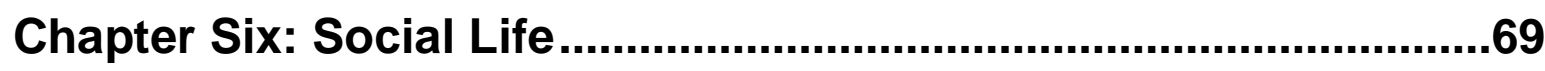

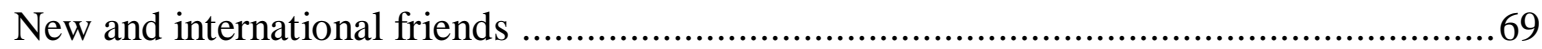

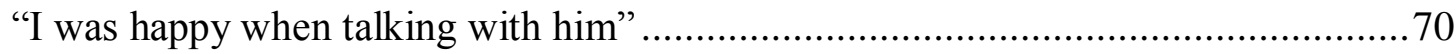

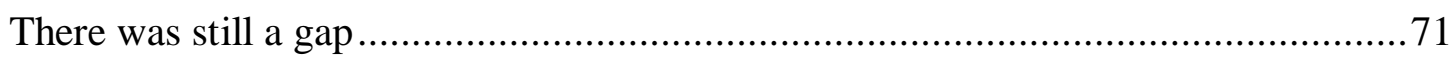

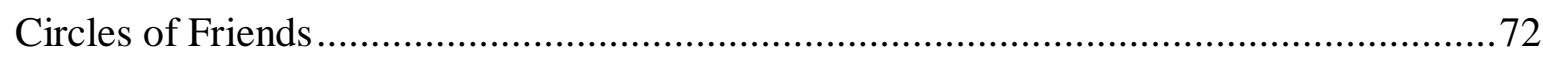

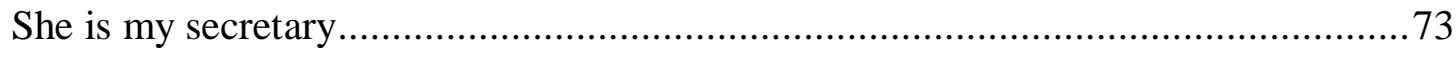

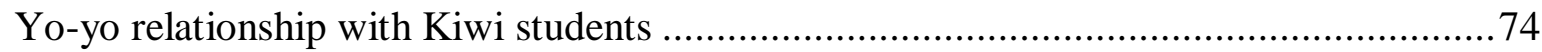

"They were co-operative students" ........................................................................74

They are more critical than me …………............................................................ 75

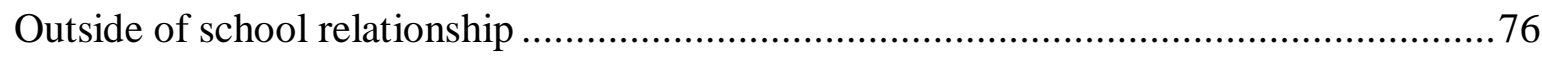

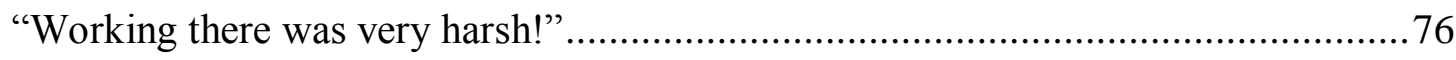

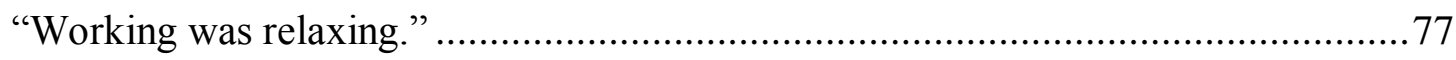

Chapter Seven: Three "Big" Stories of Participants......................79

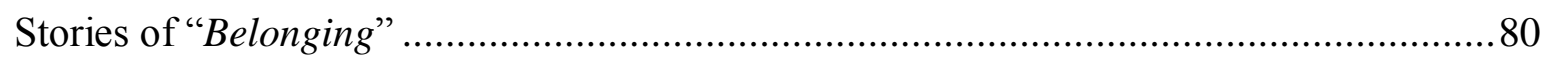

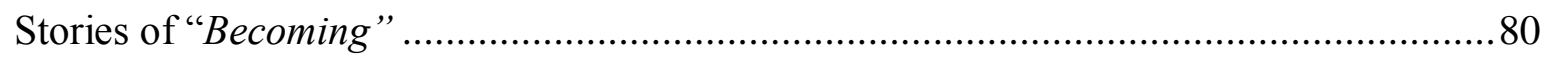

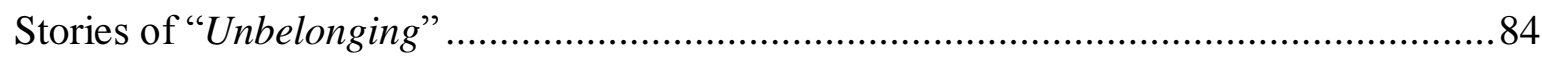

Chapter Eight: Discussion and Conclusion ....................................87

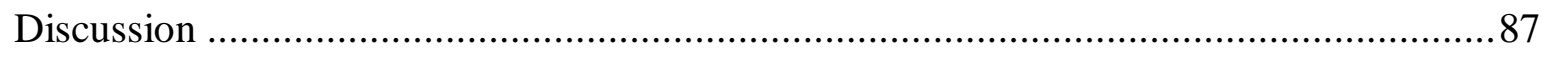


Stories of adjustment .......

Students experience their academic life, language and communication issues and social interaction in New Zealand. .88

The problems and benefits they experience at VUW. .91

Coping with their problems ........................................................................ 93

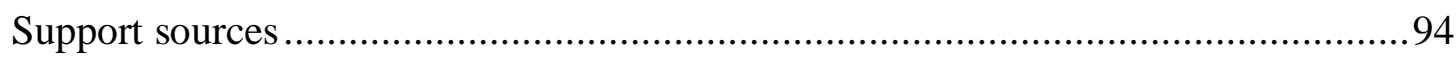

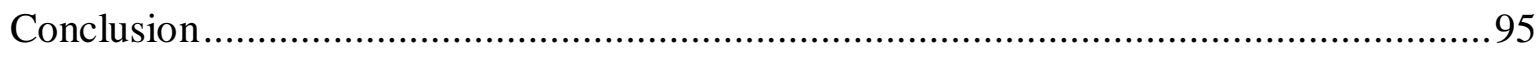

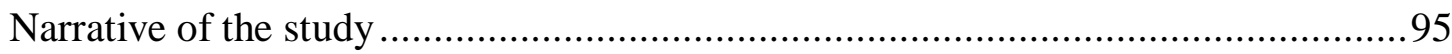

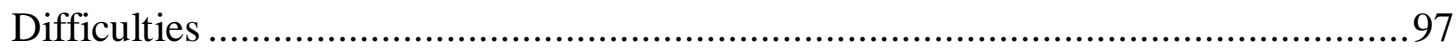

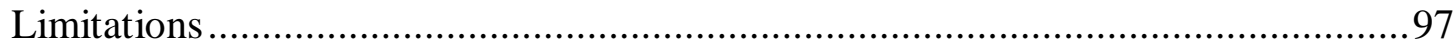

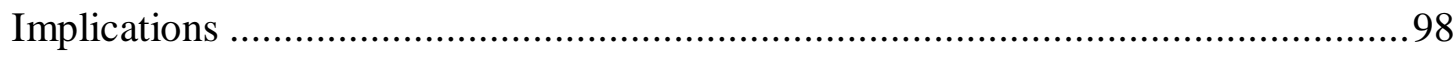

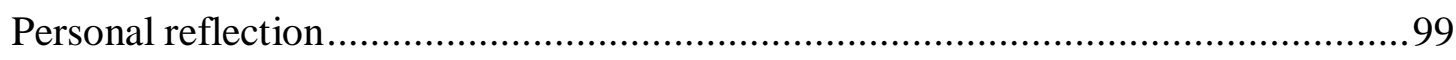

Final reflection on stories of the adjustment process ....................................... 101

References...................................................................................103

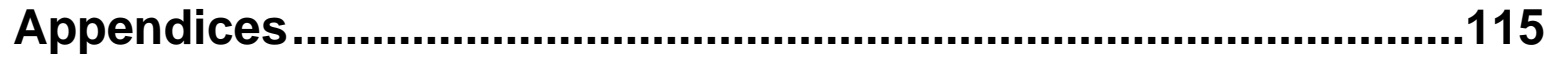




\section{ABSTRACT}

This narrative study explored the adjustment experiences of six Vietnamese international students at Victoria University of Wellington, New Zealand. Data for the study were based on two sources; in-depth interviewing and the researcher's field notes. Each of participants was interviewed twice on their adjustment experiences in New Zealand. Thematic analysis was applied to their stories and positioning theory provided a theoretical lens to further analyze and interpret the participants' stories.

The findings of the study indicated that the participants experienced many new and different things. Most experienced a stressful academic environment during their first few weeks but they felt better as time passed. The most common challenges they faced related to language issues. Difficulties came from differences between cultures with a mismatch between the participants' previous learning experiences and teaching and learning in the new environment. The participants felt stressed by the amount of self-directed learning expected. These challenges brought benefits such as becoming independent and selfregulated learners. After one trimester one participant had happily adapted and thought of a future life in New Zealand. Three participants had gradually adapted and come to enjoy their new life Two of the six students were clear that they did not belong in New Zealand and wanted to finish their degree and then go back to Vietnam.

The study concluded that the participants had diverse difficulties studying and living in New Zealand, mostly related to the different academic environment, language and culture. The participants used various coping strategies to deal with their challenges in the new environment and the main source of their support was from friends and families. 


\section{ACKNOWLEDGEMENTS}

Two years passed with many experiences of study overseas, many people have helped and encouraged me.

Many thanks to my supervisor Dr Stephanie Doyle who encouraged, supported and guided me from the beginning. She provided me with valuable advice and comments. I owe her special thanks.

My thanks to Dr Sue Cornforth who helped with narrative inquiry research and positioning theory, and to Dr Carolyn Tait who listened to my research stories. They were helpful and I always felt welcome when I met them.

My thanks to the Ministry of Education and Training of Vietnam who gave me a scholarship to study in New Zealand. I thank my school in Dinh Tien Commune, Yen Dinh District and the Committee of Yen Dinh District, Thanh Hoa Province, Vietnam for supporting my decision to pursue higher education abroad.

My special thanks to my husband- Viet Nguyen and our son- Tuong Nguyen. My husband encouraged me a lot to apply for the scholarship and then he shared housework with me so that I had time for my study. I owe our little son a big thank because he was a good boy, encouraged me to finish soon.

My thanks to the Vietnamese Student Association in Wellington (VSAW), they are a warm and united association for all Vietnamese students. They introduced me to the members so that I could recruit enough participants. I would like to send my special thanks to the participants of the study. I thank them for their stories which were the soul of my study. 
My thanks to my family, my "in-law" family and my friends. I left them for almost two years but I always received encouragement and good wishes from them. I thank my Vietnamese friends at VUW, my international friends and my Kiwi friends with whom I shared many good experiences during two years of studying in Wellington. I specially thank my thesis writing group friends: Liz, Lana and Kalyan, they always provided me with valuable advice. Thank you to all these friends who helped my life in Wellington be meaningful and unforgettable. 


\section{CHAPTER ONE: Introduction}

\section{International students and studies of international students and international student adjustment}

\section{International students}

International students are 'transient visitors' to new and different academic communities and are increasingly a feature of the social, cultural and academic life of many countries (Montgomery, 2010). International students have been referred to as overseas students (Beaver \& Tuck, 1998) or foreign students (Altbach, 2004). The number of international student all over the world has dramatically risen from 1.7 million in 1999 to 2.1 million in 2003 (Asteris, 2006) and the number is predicted to reach 5.8 million around 2020 (Asteris, 2006). International students come from different cultural backgrounds, educational systems and with different expectations and purposes. Most international students do not speak their first language as the host countries (Chalmers \& Volet, 1997). These students play an important role in the educational export industry (Burrel \& Kim, 1998). They bring money to institutions and communities and contribute to the diversification of communities in the countries they are studying (Gillard, 2009as cited in Tran, 2009). In 2004,

international students spent US \$13.3 billion in the United State on tuition fees and living expenses (Zhao, 2007). Most of them come from developing countries, with some seeking a professional credential (Beaver \& Tuck, 1998) and many just simply seeking international qualifications. With these qualifications they hope to get well-paid jobs when they go back to their countries. After graduating, they will play an important role in academic cooperation and connection between countries (Rai, 2002).

\section{Studies of international students}

When arriving in a new country with different cultures, language and customs, many people find it difficult to know where to start the new journey that will lead to success. The international student's journey to achieve goals in a new educational environment seems to be very hard. One of the most important elements of a successful journey is how an international student adjusts to a new life in a host country. 
Much has been studied about international students' lives and their adjustment experiences (Erichsen, 2011; Hsieh, 2007; McClure, 2007). There has been research focused on aspects of international student experience such as academic life, language and communication issues, culture shock, accommodation and financial problems. In her qualitative study, Erichsen (2011) collected data through "multiple semi-structured, in-depth interviews" with seven participants to understand "the international students' learning and personal change" (p. 109). Hsieh (2007) used narrative inquiry as her methodological approach to investigate one Chinese international student's stories which would explain why she was silent in her American classes. Such studies deepen knowledge of the international student experience. Understanding international students' life and their adjustment process is not only important to the educational policy makers but also to institutional staff and the students themselves.

\section{Personal rationale}

In narrative inquiry the researcher's story is an integral part of the process and the product. It positions the researcher in the study, and helps explains how the researcher came to conduct the study. Here is my story. I was born and raised in a small village of a poor rural area of Thanh Hoa Province, Vietnam and trained to be a teacher of English. Before I came to New Zealand I taught English in a secondary school where English was taught as a foreign language that students studied as a compulsory subject. The decision to apply for a study abroad scholarship came from my husband who was an international student for more than ten years. He encouraged me to find a chance for myself so that I could study in an English speaking country and our small family could live together in a different country. Time passed, and I became an international student for nearly two years with many experiences which I had never had before. My life was filled with joys, happiness, struggles and tears that I would never forget. I had not had any preparation for my journey so that I underwent many frustrating moments, which really discouraged me. I wondered about how other students like me experienced their life in New Zealand, what difficulties they faced and how they overcame. Finding the answers for these questions attracted me very much.

I brought to New Zealand my expectation that I would make friends with many Kiwi students but I could not. I knew Kiwi students but we just were classmates and school 
mates. I had many difficulties with language issues. It took me lot of time to develop my language proficiency. After more than a year, I found that, New Zealand became my dream place which I found peaceful, safe and secure. Moreover, it was a good place for my son to get his education. I had come to love New Zealand. I really wanted to explore how other Vietnamese students experienced their life in New Zealand. That motivated me to carry out this study.

\section{Academic rationale}

In reviewing the literature, I read many studies on international students and found that there were few studies of Vietnamese students. There were a small number from the United States (e.g., Do, 2006; Heggins \&Jackson, 2003); Australia (e.g., Tran, 2007, 2011; Tran, 2009), and the United Kingdom (e.g., Kuo, 2006). I did not find any studies of Vietnamese international students in the New Zealand context though there are a number of studies on Asian students but these studies focus on Chinese (Hong Kong, Taiwan) or Indian, Indonesian and Malaysian students (Ho, Holmes \& Cooper, 2004; Ho, Li, Cooper \& Holmes, 2007).

After reviewing the literature on international education, I wanted to learn more about the experiences of Vietnamese students in New Zealand. I decided to study the experiences of Vietnamese undergraduate students in adjusting to a new academic and social environment, including the problems they encountered and their coping strategies during their first months in New Zealand. The central question of this study is "What is the story of the adjustment experience?" and this is underpinned by narrative inquiry. I believed that with in-depth interview methods I would be able to encourage students to tell their stories. Then, I could understand what these students experienced during their study. I hope this research will be able to contribute to the literature on the international student experience and to the policy making process of the host university so that they can provide necessary support services to assist their international students (Kaur, 2006) in particular, this research seeks to answer these research questions:

1. What are the adjustment stories of six Vietnamese international students at Victoria University of Wellington? 
2. How do these students experience their academic life, communication and social life in New Zealand?

3. What are the problems and benefits they experience?

4. How do these students cope with their problems?

5. Where do they get support from?

Qualitative in-depth interviews were used as one of the data collection methods that helped me explore the stories of the participants. Besides that, I took field notes during the research journey in which I wrote down what I experienced when I was working in the field. These two ways of collecting data brought to me many interesting stories of the participants about their first impression of coming to New Zealand, their experiences of preparing for their life in Wellington, their experiences of the first lectures, assignments, tests and exams.

\section{Location and context of the study}

\section{Context of the study}

New Zealand, together with United States, The United Kingdom, Australia and Canada, has been receiving increasing numbers of international students during the last two decades (Andrade, 2006; Foot, 2009; Li, Chen, \& Duanmu, 2010).

This study was conducted in 2012. I chose Victoria University of Wellington (VUW), New Zealand as the location of my research for two reasons: (1) New Zealand is a popular destination for study abroad (Ho, Li, Cooper, \& Holmes 2007); (2) Victoria University of Wellington is where I was pursuing my degree; (3) This is the university where many Vietnamese international students were.

The international students at Victoria University come from 90 countries (VUW 2012). International students bring many cultural features to contribute to the multicultural picture of New Zealand. Similar to other English speaking countries, New Zealand education is rooted in Western educational philosophy. That is why the New Zealand educational system is different from that of Asian countries, which is challenging for Asian students. In that context, I determined to explore how Vietnamese students engage in a new 
environment and adjust to it. In 2012, VUW had 21,000 students in total of whom 3000 were international students.

\section{The Twinning programme - Ho Chi Minh City campus}

Victoria University has four campuses in Wellington. The university has a campus in Ho Chi Minh City (Vietnam) which was set up in 2004 (VI HCM prospectus 2012-2013). Students who enroll in a Twinning programme will study for 12 to 18 months in Ho Chi Minh City then transfer to the Wellington campuses (VI HCM prospectus 2012-2013). The students, who are eligible to enroll in this campus, will select from nine -100- level courses to five- 200-level courses to study and finish at least seven courses before transferring to the Wellington campuses. But not all the students who have enrolled in HCMC are eligible to transfer to Wellington to finish their degree. The format of the training programmes, courses, textbooks, exams, and tests used in the Twinning programme originate from the Wellington campuses . The students who want to enroll in the HCMC have to achieve 5.5 points on the IELTS (International English Language Testing System) and then 6.0 of IELTS to transfer to the Wellington Campuses or they need to achieve at least three skills with 4 and one skill with 3 of the EPP scores (English Proficiency Proramme). Five of the six participants were from HCMC and they had finished from seven to ten courses in Vietnam. These students had one year and a half at VUW to finish their study.

\section{Significance of the study}

This study of Vietnamese international students using narrative inquiry adds to the literature on the international experience. Specifically it adds to the small number of international studies on Vietnamese students, and locally it adds to the small but growing literature on international students. The use of narrative inquiry provides the opportunity to look in depth at the lived experiences of a group of students. The findings are likely to be informative for New Zealand universities (particularly Victoria University), for policymakers and those involved in preparing to send students abroad. The findings will be very useful information for the Twinning program administrators and lecturers when preparing for their students' transfer to VUW. The findings may be used to inform preparation courses for students who are going to study abroad so that they can learn about the 
challenges they may face, and the coping strategies that may be applied in the future study journey.

This study provides information about the relationship between academic staff and international students for New Zealand universities and has the potential to help academic staff to be more cross-culturally aware.

\section{Narrative beginnings}

Before being approved to carry out this study, I had to finish a Postgraduate Diploma in Education and Professional Development for which I completed four 30-point courses. These courses provided good knowledge and skills for developing learning and teaching skills, motivating students to learn, teaching in a diverse classroom, studying many theories in human science and research methods. One of the most important courses was Research Methods in Education for which a mimimum of a $\mathrm{B}+$ was a was a prerequisite for enrolling for a Master's thesis. I tried very hard to finish all the courses and get my Diploma so I could start this study journey.

The one year of coursework sharing with new friends and lecturers helped me recall experiences I had when I worked as a teacher in Vietnam. I was very interested in a course The Critically Reflexive Practitioner which introduced me to the main theories in human science such as Critical theory, Feminist theory, Post-colonialist theory or Poststructuralism theory. Through this course, I became familiar with the term "narrative" and with the idea of using the lenses of post-structuralism to look at personal behavior. The new knowledge and experience I gained while studying this course helped me to conduct the current research. It helped me decide that my research would be a narrative inquiry study using the lenses of positioning theory. In the next section I tell my stories of the experience of being an international student.

\section{My stories of being an international student}

My stories might be similar to the stories of other international students studying in New Zealand. Living in Wellington was wonderful time and it was a nice dream and special to me, a person who never has gone far away from her village. I had anticipated that 
I would face many difficulties and have to struggle to pass all the courses. Luckily, I got much encouragement from my family, friends and teachers. I was aware that studying in a second language is very challenging. I was a very unconfident student in 'diverse' classrooms for the first few classes. I could see that, not only for me but for many other international students, especially Asian students, studying in a multicultural environment is challenging. We are sometimes very passive in the classrooms. For me, reasons were language deficiency; lack of oral skills and my traditional learning style (for example not questioning authority). I had to try as much as possible to be active in my classes and I had to control the scary feeling of making mistakes. Despite my feelings about participating in the classroom, my Kiwi classmates and lecturers strongly encouraged me. They also valued my contribution. Their kind attitude helped me feel more and more confident. They helped me to deal with academic issues and advised me to take advantage of institutional support services.

I would never forget my first class at VUW, and although nearly two years have passed I still feel it as if it were yesterday's class. The class started at 4.30 in the afternoon and finished at 7.30 in the evening, it was very strange timetable to me. I came to the campus at $4.00 \mathrm{pm}$ with my husband but we could not find the building of the classroom. It took me 30 minutes to run from one building to another, upstairs then down, I felt lost and was scared that if I was too late, the lecturer would be angry and punish me. Luckily, I met a cleaner who was very helpful and who enthusiastically took me to the classroom. The lecturer was very surprised at my presence because she had not been informed that she had one more student. On that day, I finished enrolling in the morning and came to the class in the afternoon. I had no time to prepare for my class. I remembered that, I was very worried about what would happen in the lecture. The lecturer and classmates welcomed me very warmly, and then we introduced to each other. I was nervous when the lecturer asked me to be the first talking about ourselves. I was very embarrassed at that moment; it took me some minutes to think about what I should say. I asked myself "would they understand my English?" and at last I had a small talk but I did not know how much the lecturer and other students understood. 
Successful academic achievement is very important to me so I spent all my time and energy on studying. Then I realized that developing social and communicational skills were very important too. I decided to improve them. I tried to take part in many social activities. I wanted to show that I belonged to the community. My Kiwi and international friends always welcomed me with warm hugs and they called me a "warm hearted woman". I learned how to greet people and start a conversation in Kiwi style. Sharing in a group of friends was a good strategy for developing my English. When I went out, I tried to talk with strange people, it was hard but useful. I also took time to practice English with my Kiwi flat mate. The Kiwi accent was very different from the English which I had studied at the university, initially, it really challenged me. In my first classes, I did not understand what the Kiwi classmates discussed especially when two Kiwi students talked to each other. I was very upset.

Coming from a different cultural background, I have brought different experiences to New Zealand such as education, economic and social and I hoped to have good experiences in the host country. Sometime, my opinion was highly welcomed because my Kiwi classmate said "Your opinions bring new perspectives to that issues that we never heard or thought of'. Besides sharing my understanding about some academic issues with my classmates, I was motivated to learn new things in classrooms, living situations and social interaction. I tried my best to adapt to the new environment. I wanted to succeed when living and studying in New Zealand and I have experienced many good things though I have my own difficulties such as language, critical thinking skills, short of time for social activities and different philosophical back ground; I have tried a lot and step by step I have nearly reached my dream. The stories of my experience of being an international student in New Zealand will be longer, richer and deeper when I finish this study journey.

\section{Outline of the thesis}

The thesis is written as a research report that consists of eight chapters. Chapter two provides the literature on international student studies and the theoretical framework. The literature review focuses on common issues pertinent to the study of the international student experience such as language and communication skills, academic adjustment issues, cultural adjustment issues and adjustment and help-seeking and behavior. In that chapter, I 
review theoretical frameworks applied in the study of international students. In chapter three I present the methodological approach of this study, the methods I applied to carry out the study. Chapter four presents stories of coming to New Zealand and beginning to study at VUW. The stories are the participants' experiences of travelling to New Zealand, their first feelings and impressions of Wellington and preparing for their study, including through activities such as orientation. Chapter five focuses on the stories of the participants' academic life. That chapter consists of stories about their first lectures, assignments, their relationship with academic staff or other students in academic context. Chapter six recounts the stories of social life of the participants. The stories are their experiences within their circle of friends, the process of making friends and their relationship with Kiwi students and people. It includes cultural issues encountered when the participants were in outside the university context such as in their living accommodation, work places and the community. Chapter seven draws on my analysis of the participants' narratives which resulted in identifying their shared and distinct stories. From these I developed three "big stories": "Belonging" stories, "Becoming" stories and "Unbelonging" stories. Chapter eight presents my discussion and conclusion of the research. 


\section{CHAPTER TWO: \\ Literature Review and Theoretical Framework}

\section{International student adjustment: Definitions and models}

Much has been written about the "adjustment" of international students but there is no generally agreed definition of adjustment. Studies explain adjustment using diverse models. I will briefly discuss selected studies which directly address adjustment.

According to Lysgaad (1955), there are three stages of adjustment that create an U-shaped curve, starting with positive feelings, then maladjustment and in the final stage adjustment is reached (as cited by Brown \& Holloway, 2007). In the W-curve model the process of adjustment was divided into four stages (Oberg, 1960): First the Honeymoon stage of fascination, then the second the Crisis stage is one of hostility and aggression, the third is the Recovery stage where the visitors feel more used to the new cultural environment and develop a sense of humor; and the fourth is Adjustment stage where the adjustment is completed. In their study, Brown and Holloway (2007) review many other models of adjustment and argue that the common of them are "the first stage as a time of excitement and a positive frame of mind" (p. 34). For others, the adjustment is an ongoing process where day-by-day visitors feel a little bit more adjusted to the new environment. One of the most common definitions of adjustment was developed by Ramsay, Barker and Jones (1999), and that is the fit between students and the academic environment. Research on adjustment has been designed to explore the issues that might affect international students such as learning styles, study habits, language and communication proficiency and cultural competence.

Cross-cultural adjustment is another term the scholars use to frame the international student adjustment experience and it seems to be a commonly used concept in studies of international students. There are two fundamental types of cross-cultural adjustment: psychological and sociocultural. Psychological adjustment refers to the "psychological well-being or satisfaction" of international students with the new and different culture. Sociocultural adjustment refers to their "social skills", "the ability to fit in or negotiate aspects of the host culture' (Ward \& Kennedy, 1993, p. 222). Ward and Kennedy found 
that both quantity and quality of interaction with the host nationals affect positively on cross-cultural adjustment. That finding was supported by Cross (1995) who found that friendships with host country nationals predicted successful adjustment. That was because more frequent interaction with host friends provided more opportunities for international students to learn more about culture (Cross, 1995). Similarly, Caligiuri (2000), found that the greater number of relationships that the international students set up with the host nationals the more chances they had of successful cultural adjustment. Openness and sociability are two characteristics international students require to set up such relationships (Caligiuri, 2000). But, making friends with the host nationals is not easy due to factors including low language proficiency and the receptiveness of the nationals (Wards \& Kennedy, 1993).

\section{International student adjustment experience}

Together with the increasing numbers of international students globally, a large number of studies have been conducted to explore every aspect of their life abroad. The literature on international student adjustment issues has been categorized into two main areas: (a) those that identify factors influencing adjustment; (b) those that identify the relationship between these factors and academic achievement (Andrade, 2006). This review will be developed by following the first area of international student that will review many factors affecting the international student adjustment such as language and communication skills, academic adjustment issues or cultural adjustment.

\section{Language and communication skills}

Language has been identified as a significant problem for international students (Do, 2006; Lee, 2007; Townsend \& Poh, 2008; Zhang \& Mi, 2009). Most international students are non-native speakers of English; and language may cause difficulties in both academic and social adjustment. For example, due to the lack of English proficiency, international students feel anxious about speaking and may not participate fully in class activities (Lee, 2007). Studies have reported English language level as positively related to the level of oral participation of international students in the United State universities. Lack of oral fluency in English affects student engagement in tutorials and seminars because they may be afraid 
of taking part in group discussion and of asking for assistance. According to Ryan and Twibell (2000), some international students report that they cannot state their point of view in discussions with peers because they take a longer time to formulate the ideas they want to contribute and their peers do not wait and instead move on to other topics.

In a guide for Australia lecturers on working with international students the authors made the point that the voice of international students may not heard because of poor spoken English and consequently those students become known as the quiet members of the class (Ballard \& Clanchy, 1991). Besides facing difficulty in communicating in the classroom, international students have difficulty in reading, understanding material, instructions and lectures (Townsend \& Poh, 2008). That was supported by Zhang and Mi (2009) who found that Chinese international students in Australian universities had problems with language and the problem seems to be a strong emphasis on the three skills of listening and speaking, and writing. Those students not only had difficulties with understanding the lectures and stating their opinions due to low listening and speaking skills but also struggle with their writing. Most of them even cannot improve their English writing skills even after their time of degree finished (Zhang \& Mi, 2009).

Birrel (2006) found that 34 percent of 12,116 international students graduating from these universities in 2005-2006, did not have the English standard needed for admission to university in a survey which investigated factors that affect international student English skills in Australia. International universities/institutions may require their international students to have an English certificate (TOEFL or IELTS) before coming to the host countries but some make provision for international students to attend language courses in the host country to get certificates then enroll to study (Birrel, 2006). Many students learnt English in their home countries and prepared for their study abroad journey and they were disappointed with what they had studied because it did not help in the new educational environment. For example, Vietnamese international students reported that in Vietnam too much attention was paid to English grammar but little to oral communication so few students were confident of their speaking and discussion skills in English (Do, 2006). That was supported in 2011, the British Council and APOLLO Educational Centre conducted a study in twenty countries about the reality of learning and teaching English language to get 
the international standard which found that that skills of reading and writing of Vietnamese students were at the eighth position of 20 but the skills of listening and speaking were in 18 and 19 in the rank of 20 countries (Hoang Thuy, 2011). If those students study abroad, they might have the same difficulties with the students in Do's (2006) study. Lack of confidence in speaking English was also identified as factor preventing many international students in the United State from making friends with American students (Mori, 2000). Many local students did not want to be friends with their international counterparts. Sometimes international students did not understand what their native classmates were talking about but they tried to smile (Do, 2006). Sometimes they misunderstood or misinterpreted when they communicated. They had a real feeling of "not being as good" (Osmond \& Roed, 2010, p.115).

Moreover, the barrier of a lack of English language proficiency may also influence the adjustment process and may impede international students' in their interactions within the new community (Poyrazli \& Grahame, 2007). Students may not be able to access the community to help with understanding the culture and to get assistance from the other community's members. Furthermore, not only do students of non-English background face difficulties but native speakers of English may have language difficulties related to accent, and differences in the formal and informal English of different countries (Mori, 2000).

\section{Academic adjustment issues}

The literature on academic adjustment focuses on the links between factors related to academic adjustment. Researchers may be interested in investigating factors affecting a successful academic adjustment (Andrade, 2006). Some others may explore the strategies that international students apply in order to ensure good academic achievement.

The factors challenging international students' in their academic adjustment may include the education system, the learning environment, lecture styles, academic tasks, classroom discourse, assessment and evaluation, relationship between students and lecturers. Burrell and Kim (1998) claim that international students must adapt to an academic culture in order to be successful. One of the factors related to the academic performance of international students is the form of academic tasks. Doing a research paper or a report and writing an essay may be challenging for Asian students such as to Vietnamese students, as their 
achievement has always been assessed and evaluated by teachers through tests and exams so that when they study in a Western educational system with different forms and process of assessment such as essays, critiques, and presentations that puzzle them; it takes time to adapt (Arkoudis \& Tran, 2007). Peer assessment, group assessment and portfolios (Dochy, 2001 as cited in Tait, 2010) are unfamiliar to Vietnamese and Asian students. International students bring their traditional learning strategies to the new academic environment which may not match the requirements and expectations of a Western educational context (Arkoudis \& Tran, 2007). Another factor identified as being challenging for international students when writing essays is a lack of critical thinking skills. Students might be aware of the importance of critique in writing but sometime they may not know how to go about it and they might only focus on other scholars' comments about the studies they read rather than evaluating content for themselves (Arkoudis \& Tran, 2007). Many Asian students are unfamiliar with how to write an argument and criticize the work of others. Asian students may tend to write indirectly and they are not accustomed to analyzing the strengths and weakness of an argument (Holmes, 2004)

Poyrazli and Kavanaugh (2006) suggest that "host language fluency plays a key role in successful academic performance" (p.770). In their correlational study, which investigated 149 post graduate international students Poyrazli and Kavanaugh found that "students with lower levels of academic achievement reported lower levels of English proficiency and more overall adjustment strain" (p. 1). Furthermore, they supported their claim by citing Stoynoff's study (1997) which reported a positive correlation between TOEFL scores and successful academic achievement. Ying (2003) likewise claimed higher English writing skills predict higher academic achievement. Other studies have established that language ability has a correlational relationship with academic achievement (e.g., Ellis, 1993). In contrast, there are studies that seem not to support these claims, for example Do (2006) points out many of Vietnamese international students in his study reported that though they did not have strong oral/verbal communication, listening, pronunciation or reading comprehension skills, they did not have academic difficulties.

Different classroom discourses and environment were two of the predictors that affected international student academic engagement in Lee's (2007) survey in which she explored 
the factors affecting East Asian students' oral participation in US university classrooms. In Western academic culture, "students' demonstration of critical thinking abilities, problemsolving skills, and assertive oral participation are highly valued and rewarded" (Lee, 2007, p.29). Whereas, East Asian culture "values indirect and passive communication styles" (Makino \& Takemura, 1993 cited in Lee, 2007, p.29). That was why students from East Asian countries may be unfamiliar with group discussions and interacting with lecturers. The lack of oral performance skills may create difficulty for international students in negotiating meaning and arguing with other members of the group. In her study, Lee suggested that the Eastern Asian students avoid engaging in academic activities in the classroom because of their "fear of negative evaluation" (p. 33) by peers or their instructors. They chose to withdraw from or tried to avoid participating in class discussions.

Butcher and McGrath (2004) suggest that international students have become "a significant part of New Zealand's education system" (p.544) and they identify common academic needs in order to help academic staff understand their international students. One of the difficulties Asian students face is the ability to response to the Socratic mode of teaching because they have been educated to listen and not to question authority with a "rote-learning style". However, Butcher and McGrath do not provide sufficient information to help readers understand clearly the nature of what constitutes rotelearning style and how this leads to a mismatch between academic staff and international student expectations. Kingston and Forland (2008) explored the contradiction between Confucian and Socratic traditions in learning and teaching, and provided salient exemplars. For example, Eastern or Confucian original students inherit a Collectivist orientation in contradiction to Individualist orientation of Western students (Kingston \& Forland, 2008). That leads to different academic learning approaches such as divergent (Western students) in contrast to the convergent approach of Eastern students, deep learning style versus surface style. . Western researchers tend to position these different orientations as resulting in qualitatively different outcomes.

International students and academic staff relationships have been linked to student academic performance. In a Western classroom, Eastern students are seen as "passive learners" (Chalmers \& Volet, 1997) because in their traditional education systems they 
are educated to obey and listen to their teachers, and they may lack autonomy (Kingston \& Forland, 2008). In a co-operative and supportive classroom where the gap between teachers and students is not big (Do, 2006) teachers encourage students to question and argue during the lectures. Asian students are afraid of making mistakes so they may remain silent. Do suggests that not being confident with the host language may prevent international students from establishing close relationships with teachers. Others point out that the reasons for not developing such relationships may come from the host teachers. Teachers may lack understanding of the culture, academic, religious or learning styles of their international students (Butcher \& McGrath, 2004). International students may perceive that some lecturers do not care about them (Kingston \& Forland, 2008). The gap between international students and academic staff may be created by a mismatch in their expectations.

However, not all international students have negative opinions of their lecturers or tutors/mentors, some view their relationships positively. . Kingston and Forland (2008) found that students enjoyed their tutorials and the teaching styles of lecturers and tutors. The lecturers also commented positively on international students reporting that the international students were hardworking, well-disciplined and highly motivated.

\section{Adjustment strategies and help-seeking behavior}

In this section, rather than reviewing the cultural aspects influencing international student adjustment I discuss the role of cross-cultural adjustment and the ways students adapt to a new culture and learn to be competent in their new academic environment.

Cross (1995) argues that, international students prefer interdependent self-construal coping, which is rooted in the collectivism of East Asian culture. To explain what interdependent self-construal is, Cross cited Markus and Kitayama's (1991) example that the tasks for individuals with an interdependent self-construal "are to fit into relationships and to pursue a sense of belonging with others" (Cross, 1995, p. 675). That means they attempt to adjust to a social situation by focusing on changing the self rather than changing the situation. Cross suggested that international students derive meaning from the situation and change their expectations in order to adapt; and that they tend to accept the situation as it naturally exists (Cross, 1995). Self-construal has a direct effect 
on well-being and with psychological adjustment, and it appears that many students use this type of coping strategies (Cross, 1995).

\section{Cultural difference in help-seeking behaviour}

International students may face common problems during their study but the ways they solve their problems will vary. Many will seek help from institutional support services, others will choose personal strategies; some may actively try to find the best solution for their issues but some do not do anything and just waiting hoping that things will change.

In a study of postgraduate international students in Singapore universities, McClure found three kinds of coping strategies: "self-determination, collegial support and strategies" (McClure, 2007, p.205). With self-determination the international students "develop high degree of independence" (p.205) in solving problems. The students in McClure's study reported that they had changed their approach in order to be more independent in learning. In another study (Do, 2006), Vietnamese students employed this kind of independent coping strategy when they dealt with personal issues such as their relationships with lecturers, friends or flat mates. They preferred not to use the counseling services provided by the institutions (Do, 2006) because they did not want to talk about themselves, and they did not think counselors would understand or could help them. The research suggests that Asian students, especially Vietnamese students, may rarely talk about their personal issues because they believe own problems should never be revealed to others. They try to deal with their problems by changing their ways or else they do nothing and just accept the situation (Do, 2006).

Some specific strategies of self-determination identified in previous research is for students to spend more time studying in the library, reading more and writing more in order to get fluent and improve comprehension skills by practicing more (Choi, 2006). Especially with language issues, Asian students may choose to work harder (Choi, 2006; Hellsten, 2002); other effective self-determined strategies reported included managing their time and listening to the radio, or watching movies/news to improve language skills (Choi, 2006; Do, 2006). Another example of a self-determination strategy to solve personal problems was shortening the stay in host countries in order to deal with financial issues (Do, 2006). 
In contrast, some international students in the US decided to transfer from three-year bachelor programs to four year programs in order to have time for "practical training" so that they can work legally with their Visa status in the US. If they do not take the risk by doing that, then they deal with financial troubles by competing with the "employment eligible native students for on-campus employment that is already on short supply" (Do, 2006, p.18).

Other sources of help that international students seek include friends and family. In an Australian study on international students, Asian students reported that they go to their friends to share personal problems such as homesickness, loneliness, or isolation because they did not think international officers or counselors could help (Hellsten, 2006). Because of cultural reasons, Vietnamese students are not accustomed with talking about personal or emotional issues to do with their friendships or partnerships. They may sometimes talk with their close friends and their parents who typically are the major sources of support for their emotional needs (Ho, Li, Cooper \& Holmes, 2007). A comparative study of Australian domestic and international studies found that majority of international students obtain financial support from parents contrary to domestic students who receive finance from employment (Khawaja and Dempsey, 2008).

\section{Lack of knowledge about the host cultural behaviours}

International students have a tendency to make friends within their same nationality students (Do, 2006) or with group of other international students. They do that because they believe, international students can understand each other more and they might be in the same situation so they help to deal with difficulties (Ho et al., 2007). These groups of international might gather and discuss their issues and to support each other. The findings of a number of studies indicate that it is common for international students to deny using available services on campuses (as Mori, 2001; Cheng et al., 1993 as cited in Khawaja \& Dempsey, 2008). There is evidence that some international students prefer to find own solutions for their problems or else to asking friends and family for advice (Johnson, 1993; Scheider \& Spinler, 1986) instead of taking advantages of institutional support services. However, what types of services international students choose to use or not use and reasons why they may like to, or conversely why they may not like to use a service are very 
interesting question that should be answered in more detail. It might be that is some instances international students are not provided with full information of campus services so they do not know how to get access to these services. Elsewhere, the reasons of not using services come from the services themselves such as knowledge and attitudes or lack of cross-cultural communication skills of service' officers (Johnson, 1993; Scheider \& Spinler, 1986). These implications should be studied more in order to understand well the quality of the services and encourage international students take advantage of their universities services during their study in the host countries.

\section{Coping Strategies}

As mentioned above, different cultures pose difficulties for newcomers in adaption; and many international students face difficulties studying overseas. Choi's study (2006) identified eight proactive strategies for adjustment: "finding a mentor, hard work, stress control, finding your focus or goal as early as possible, learning the language and culture of the host country, perseverance, building up background knowledge and, lastly, communicating needs" (p. 3). Choi provided examples of international students finding advisors/mentors to support the claim that finding a mentor/advisor is one of the most effective strategies of achieving academic success in new academic environment.

Arkoudis and Tran (2007) studied the experiences of two Chinese postgraduate students in Australia to reveal some meaningful information about international academic writing in higher education. In order to meet the lecturers' requirements in writing essays, these two students used different strategies such as interpreting the lecturer's preferences or asking for the lecturer's advice (Arkoudis \& Tran, 2007). They learnt that their writing needed to be more direct, and they should not "beat around the bush" (Arkoudis \& Tran, 2007, p. 164). Getting help from lecturers was the strategy applied by Vietnamese international students in Do's (2006) study in the US when they have assignments or tests.

Beaver and Tuck (1998) argue that for Asian students, finding extra study assistance, facilitating social interaction and simplifying assignment instructions are the three of the most important strategies to achieve personal learning goals. Beaver and Tuck conducted a 
survey of three ethnic groups, including Pakeha ${ }^{1}$, Asian and Pacific Islander students in New Zealand. The findings from this study were that the Pacific Islander and Asian groups believed extra study assistance to be a very critical strategy (Beaver \& Tuck, 1998). However, although Beaver and Tuck's survey explored how the three groups of students rated the importance of strategies; they did not provide full explanations of those strategies. Chinese international students in Tait's (2010) study used surface learning strategies to prepare for multiple-choice assessment format and deep learning strategies when they prepared for an essay format assessment. Surface learning refers to rote memorization, to just remember the "facts and details rather than understanding important concept" that the learners have a desire "to do the work that is needed to pass" (p. 264). In contrast, deep learning strategies refer to the intrinsic interest which comes from "a desire to develop competence in the subject being studied" (p.264). In her study, Tait found that Chinese students tended to practice with previous tests before the exams and use rote memorization to predict questions. They sometimes gained understanding, but many choose to use memorization without understanding, just doing the tests and passing the courses.

International students from diverse cultures may have different strategies and help-seeking behaviors, but it appears that strategies need to be flexible for students to adjust to a new environment. International students play important roles in both academic and economic fields in their host countries. They should be provided with culturally appropriate services to support them in overcoming difficulties and to achieve success in their study journeys. Self-regulated adjustment strategies come from within individual students and these strategies might lead to success but sometimes they do not. External strategies are provided by the institutional support services or social support services these should be well-prepared to serve the students in order to be successful.

\section{Support services}

Support services are another favorite topic of academic scholars when doing research of international students. In this section, I will discuss some types of services to see the benefits they bring to international students when they study in different countries.

\footnotetext{
${ }^{1}$ Pakeha- the word refers to New Zealanders of European descent.
} 
Furthermore, I want to review the literature on this topic to understand what kinds of support international students acknowledge, take advantage or even they do not know and never use during their adjustment progresses. The fundamental question when providing international students support services is "what do the international students need?" which can help institutional administrators, educational exporting policy makers prepare and provide good and suitable services which serve the students best.

\section{Learning support services}

Learning support services provide vital assistance, which are offered by the host institutions in order to help international students achieve academic success. They are set up for both domestic and international students to assist with their academic issues, such as language proficiency improvement, exam skills, writing, critical thinking, and proof reading.. The staff of these services may be lecturers or student volunteers who can help in peer activities. Typical support learning support services provided by Australian universities include "Study skills, Communication skills, Academic literacy, Academic grammar, Study preparation and Online Student Support Centre” (Hussin, 2007, p. 364). Hussin (2007) designed a survey on the learning support and development staff from 12 universities in Australia which have large transnational programs. In total, 15 staff members participated

in the survey. The participants answered a questionnaire in which they rated the effectiveness of the support services which assisted off-shore students of Australian universities. Off-shore students are international students who study at a distance and are not on campuses in Australia. The findings show that, these services sound great, but the fact that there were no students involved in Hussin's survey made it difficult to evaluate the effectiveness of these services from both points of view. However, some respondents indicated that overseas postgraduate students used email consultation for their theses writing and rated it as very effective. The students sent passages from their theses to academic advisors to get comments. Furthermore, the most meaningful information of this study, I think, is the focus on plagiarism; Hussin questioned the staff about "support services which focus on assisting students to avoid plagiarism" (p. 366). The findings show that the strategies the support advisors used were structuring paragraphs used sourced information, paraphrasing, using other people' ideas and developing citation techniques 
(Hussin, 2007). In addition to this strategy, some institutional staff stated that providing examples of plagiarism and having students practice was a very important strategy which helped them understand "the educational aspects of plagiarism" (p. 366).

For international students, language proficiency improvement is one priority for academic support services. The programs of developing English language proficiency may focus on writing and conversation (Burrell \& Kim, 1998). Some examples of services are "Thesis Writers' Circles" (Larcombe, McCosker \& O’Loughlin, 2007) where postgraduate students send a piece of their writing to other members and receive feedback from others; conversation groups (Casazza \& Silverman, 1996 as cited by Burrell \& Kim, 1998); language courses and language buddy program (VUW international prospectus, 2012).

\section{Pastoral care}

Butcher and McGrath (2004) focused on academic and social and financial needs of international students in New Zealand. For example, some of the academic needs are "proficiency in English and ability to understand textbooks and their lecturers" or "their difficulty in comprehending questions, assignments, and research skills" (p.545). Social needs are those that may originate in feelings of being "ambivalent about their relations with host nationals and that may perceive discrimination" (p.545). Based on the needs of international students Butcher and McGrath argue that pastoral care which is divided into two subtypes: reactive and proactive care, should be a good response to help students better. If 'reactive care is 'intervention care' which can help in a crisis (such as accidents, illness, and culture shock), 'Proactive care' seem to do a better job because the care help to anticipate students' needs, potential problems, or "it articulates and addresses expectations; it provides education and information" (p.548). 'Academic orientation', 'learning support', 'friendship programs, 'social events' or 'recreational activities' are examples of proactive care services. 


\section{Theoretical framework}

The literature on international student issues is shaped around different theoretical frameworks such as cultural shock (e.g., Brown \& Holloway, 2008); sociocultural theories of learning (e.g., Ali, Rohindra \& Coll 2006); cross-cultural adjustment (e.g., Brown (2009); acculturation theory (e.g.,Tran, 2009); transformative learning (e.g., Erichsen, 2011; Crabtree, 2008); positioning theory (Arkoudis and Tran, 2007; Tran,2011; Rizvi,2005). In this section, I will review some general theoretical frameworks, which have been applied in the research of international students and then focus on the theory of positioning to develop my own theoretical framework for this research.

\section{Some general theories}

The Culture shock model developed by Lysgaard's (1955) is well-known as the "U-shaped curve" (cited in Brown \& Halloway, 2008; Lewthwaite, 1996) (was discussed in page 16 of this thesis). The U-shaped curve model is explained in three stages with the first being when the student is on the "honeymoon high" and then the second is turning down to the "bottoming out resulting from maladjustment" and the third is the climbing up and out to “cultural acceptance and adaptation' (Lewthwaite, 1996 p. 168). Five years after Lysgaard's (1955) model, Oberg (1960) defined culture shock as "a medical condition which afflicted all who crossed culture" (cited in (Lewthwaite, 1996 p. 168). According to Oberg (1960), adjustment is developed over four stages instead of three stages, and Oberg called this the "W-curve model" which was utilized by Gullahorn and Gullahorn (1960) and Brown (1980) (cited in Brown \& Halloway, 2008). Both models depict an initial stage of excitement, and positive feelings and followed by culture shock. A number of scholars have used culture shock as a construct in investigating and discussing the issues influencing international student during their adjustment journey to a new culture.

Cross-cultural adaptation is a complex process (Lewthwaite, 1996) which can help in understanding adjustment as "a cyclical and recursive process of overcoming obstacles and solving problems" (p.170). Cross-cultural communication theories have been used in a number of studies (e.g., Brown, 2009). In her study, Brown found that successful communication was the key factor which promised the successful adjustment of an 
international student. In another study, Nieto and Booth (2010), stressed the level of cultural competence as an essential factor in deciding the level of feeling welcomed and comfortable in a new environment. The authors suggest that international student adjustment was not only influenced by the level of cultural competence of the host instructors, but also by the cultural competence of the international students (Nieto \& Booth, 2010).

Another theory commonly used in studies on international students is that of transformative learning theory. Mezirow's Transformative learning theory (1997) theory is used to explore the leaning process, meaning making process or cultural adaptation of international student. For example, Erichsen (2011) used transformative learning theory to investigate and analyze the learning process of international students and explain how students change while studying abroad.

Social learning theory is another example of the theoretical framework of this area. This theory was applied by McLeod and Wainwright in a study in 2009. This theory can help focus on individuals' locus of control perspective which international students bring into a new experience of traveling abroad; these students will learn why they are a part of the programs (McLeod \& Wainwright, 2009). The findings of this study reveal that what the students learnt will help them to determine how to behave (in new environment-new classroom, new community, and new culture) and how much they enjoy.

In one study of Vietnamese students in the US, Do (2006) used the theory of person/environment Interactionism. This theory was used to explore seven adaptation aspects in case studies of eight Vietnamese international students (Do, 2006). It can help "to examine the interaction and the degree of congruence between the Vietnamese students, their needs and the college environment" (p.2). This theory is not often used in the area of international student experiences.

Above section is the summary of some theories applied in the topic of international student issues. Some are very often used such as culture shock or cross-cultural adaptation but some are not. The following section I will review some studies which use different theory 
as framework call positioning theory and discuss the anticipating of using this theory as my theoretical frame work for the present study.

\section{Positioning theory}

Positioning theory explains the cognition process of people when they judge themselves or others in discursive practices. Within a particular discourse and moments through their own or other utterances, individuals create their subjectivity by negotiating with others. Positioning theory also points the effort that participants (in conversations) try to 'resist' or 'refuse' judgments from other participants (Harré \& Langenhove, 1999). Through the lenses of position theory participants are seen to construct their identity by 'intentional actions of speech' and reconstruct if they are not satisfied by negotiating with others in their conversations. Participants will directly or indirectly indicate/create who they are and who they want to be by creating dominant discourses which might change during a conversation (Winslade, 2005). According to Winslade (2005) "each utterance must necessarily be situated in discourse simply because it uses discursive material (words and meanings) in order to make sense" (p.352). People present themselves and others during their narrations which are "communicative production" consists of "storyline" and their presentations create "discursive positions" (Hollway, 1984 cited by Harré \& Langenhove, 1999).

People engage in discursive practices within discourse to negotiate where they stand in relation to others in their storyline, accept new places to stand, ways of re-presenting themselves and/or create new storylines (Harré \& Langenhove, 1999). It is said that people live in fragmented pieces of experiences which are called "episodes". All skills depend on the capacities of producing words/sentences and also to shape the episodes of social life (Harré \& Langenhove, 1999). Further, Harré and Langenhove argue that not only what people do but "also what we can do is restricted by the rights, duties and obligations we acquire, assume, or which are imposed upon us in the concrete social contexts of everyday life" (p. 5). The social life of anybody can be retold in lived stories which might be follow a dominant storyline of the storyteller's life or they might be retold in episodes in which storylines are changed in different situations, contexts and times. Considering the coherence and incoherence of storylines, Harré, Moghaddam, Cairnie, Rothbart and Sabat 
(2009) use the concept of "Frame" which is important to understanding the emerging challenges of storylines. They argue that the shifting of one frame (storyline) to another sometimes involves "breaking the frame" sometimes occurs without breaking the frame (Harré et al., 2009). To understand how people present themselves not only depends on their speech acts in their storylines but also in recognizing when and how they change their storylines. People try to become autonomous when they talk about themselves and others. That is the way of seeing the inner world as well as social world in which the storyteller positions themselves as autonomous actors. They will decide in what ways they want to present themselves by controlling the stories they tell others Research investigating stories of experience is not an exception. Harré et al.,(2009) suggest that researchers need to be well aware of the different points of time, personal emotion, and what rights and duties the participants occupy will affect their storytelling (including how they present themselves in relation to others and what sort of 'other' they invite those they are communicating with or about to be) because they know what they will tell others. The researcher/listener understands their stories by following their speech acts which let the researcher/listener know the illocutionary force of each sentence they speak. These things help to shape their stories they tell about who they are and want to be, and how they want/allow others to be (Harré \& Langenhove, 1999). Sometimes the researcher/listener can offer participants new points of entry in conversations but they have the rights to refuse or protect and form their ideal subjectivity.

In a discussion on how Chinese students negotiate their academic writing, Arkoudis and Tran used positioning theory to investigate how students position themselves and how academic lecturers position their students in the context of academic writing (the first essay). They usethe term moral agency defined by Harré and Van Langenhove (1999) as social and purposeful action (Arkoudis \& Tran, 2007). For example, one student in the study positioned herself as "someone willing to adapt her writing to suit the requirement of the lecturer" and her lecturers positioned this student as "someone who need to learn more about referencing rules in academic writing in the university" (p.165). This theory works well within this study, the context and the findings reveal that students and their lecturers do not agree on students' positions (Arkoudis \& Tran, 2007). This study suggests positioning theory as a theory for investigating international student stories in which the 
researcher(s) can understand the stances the students take to talk about themselves (position themselves) (Davies, 1991) in their "purposeful action" when talking about their experiences. Furthermore, when exploring their stories we can see how they might be positioned by others (lecturers, friends or other institutional staff) and how they can accept or resist these new positions as well as how they may change through the time (Davies \& Harré, 1990). By listening to the international students' storylines we can investigate the participants' process of developing their own subjectivity through language, through acceptance or resistance of "powerful discourse" (Koehne, 2006, p.242). The researcher(s) are required to pay attention to which is the dominant discourse used when the students talk about their experiences. According to Hollway (1984), initially, positioning theory was developed as a tool, which, helps to explore 'dynamic inter-personal relations" in which "selves were given" (cited in Harré, Moghaddam, Cairnie, Rothbart \& Sabat, 2009 p. 25). At an inter-personal level (one student-participant has relations with others) positioning theory can help to explore the student-participant's selves. I believe that positioning theory can help me explore international student's positions that form their subjectivity and agency and the way they become autonomous. 


\section{CHAPTER THREE: Methodology}

In this chapter, I describe the methods used in this research. In the first section I describe the basic characteristics of the qualitative case research with a narrative inquiry lense. Then, in the second section, I describe the methods and techniques used to carry out this research.

\section{Research design}

In this section, I discuss the methodological framework underpinning my research namely that of qualitative research using narrative inquiry.

\section{Qualitative study}

Qualitative research has become an important mode of inquiry for the social sciences (Marshall \& Rossman, 2006) such as education, social work or management. According to Merriam (1998), qualitative research "is an umbrella concept covering several forms of inquiry that help us understand and explain the meaning of social phenomena with little disruption of the natural setting as possible" (p.5). The major objective of qualitative research is "exploration" or "discovery" and qualitative researchers are not interested in generalization of findings (Johnson \& Christensen, 2008), but are typically interested in understanding the meaning which is constructed by individual's interaction with their social world, at a particular point of time and context (Merriam \& Associates, 2002). Qualitative research can provide the 'richly descriptive' information needed to answer research question(s). Sherman and Webb argue that qualitative research "implies a direct concern with experience as it is "lived" or "felt" or "undergone" (cited in Merriam, 1998, p.6).

Many social science researchers have chosen to take advantage of the strength of qualitative research. Though how and why to select one approach over another are difficult questions. Merriam (1998) identified five main types of qualitative research, consisting of basic qualitative research, ethnography, phenomenology, grounded theory and case study. Others have suggested similar grouping (e.g., Johnson and Christensen, 2008). Creswell, Hanson, Clark and Morales (2007) added narrative research to their classification of types 
of qualitative research. What phenomenon affects a researcher's selection of one approach over another is an important question that should be well answered before designing a qualitative study. Each type can be identified and distinguished from the other type but they share the "essential characteristics of qualitative research" (Merriam, 1998).

This is a narrative study. The study was designed to explore the adjustment experiences of Vietnamese international students in a New Zealand university. A qualitative study allows us to "gain an in-depth understanding" of which we are studying (Merriam, 1998, p.19). I wanted to "understand the meaning people have constructed about their world and their experience" (Merriam etal., 2002, p. 4). In this study was the meaning Vietnamese students had constructed during their first months in a New Zealand university. They were selected partly because I am Vietnamese and also because the Vietnamese student group is one of the biggest at the University. The literature review identified the relative lack of research on the Vietnamese student experience in a New Zealand setting. I wanted to get an intensive, holistic description of the student experiences. I assumed that the students would have diverse experiences of life in a foreign country and that; it would be interesting to explore these differences.

Qualitative research design is "a powerful tool" (Merriam et al., 2002) to help answer to research questions, and suited my desire to know more about international student life. This study was designed in order to answer the central question "What is the story of the adjustment experience?" and is underpinned by narrative inquiry to address sub-questions:

1. What are the adjustment stories of six Vietnamese international students at Victoria University of Wellington?

2. How do these students experience their academic life, social interaction and language and communication issues in New Zealand?

3. What are the problems and benefits they experience?

4. How do these students cope with their problems?

5. Where do they get support from? 
The aim of this study was to explore students' stories of life so that I used a subtype of qualitative research - narrative inquiry as the lenses for data collection and analysis. In the next section I discuss narrative inquiry.

\section{Narrative inquiry}

According to Polkinghorne (1995), narrative inquiry is not new to qualitative researchers and it is defined as a "subset of qualitative research designs in which stories are used to describe human actions" (p.5). Narrative is the primary form which people use to make their experience meaningful. Narrative is a powerful vehicle through which "other people's experiences can be understood and shared" (Kanno, 2003 cited in Hsieh, 2007). People live by their stories which are formed by their experiences in the past, in the present and help to form their future stories (Clandinin \& Connelly, 2000). Clandinin and Connelly also argue that, narrative "is the best way of representing and understanding experience" (p. 18). People talk about their experiences in the form of stories, in which their experiences make sense to them. According to Creswell et al. (2007) narrative research studies the life experiences of individuals over time. Narrative research is a type of research that consists of obtaining and then reflecting on people's lived experiences (Josselson, 2007). Furthermore, Sikes and Gale (2006) identify the essential characteristic of narrative research was concerned with stories. Casey (1995) defined narrative research as "an overarching category" (p.211) which includes many types such as autobiographies and biographies (recited by Casey, 1995); life writing (L. M. Smith, 1994); personal narratives (Personal Narrative Group, 1983); ethnopsychology (Freeman, 1992); and so forth. The many subtypes of narrative research share in common that narrative inquiry is "an interest in the way that human beings make meaning through language" (Casey, 1995, p. 212, also see Riessman, 1993). Polkinghorne (1995) identified two types of narrative research, pragmatic and narrative modes of thought (based on Bruner's types of cognition). In the first type, new pragmatic typologies or categories are produced from stories as narrative data. In the second type, based on narrative data, the researcher produces stories (Polkinghorne, 1995).

Experience is a key term in narrative inquiry. This term helps us think of what happened, to understand how the participants negotiated their stance and made meaning at a particular 
point of time and in a particular context. As a narrative researcher I was very interested in the lived experiences of the six students reflected in their different stories. In narrative research, collecting data is an activity that involves having participants tell their stories (Clandinin \& Connelly, 2000). In my research, I wanted the outcome to be the adjustment stories of the participants. In order to do a robust analysis which helped to produce stories from the narrative fragments of participants, I used the thematic analysis model from Riessman (2005) because the data were the narratives of personal experiences. Thematic analysis, according to Riessman (2005), is one of four narrative analysis modes which focuses on the content of the texts. In thematic analysis the narrative fragments are organized by themes. Applying thematic narrative analysis, the research emphasizes "the told" - consisting of events and cognitions "to which language refers" (Riessman, 2008, p. 58). Language is considered as a resource in which the researcher interprets what is said by focusing on the meaning that the participants intended in the conversation (in interviews). This mode of narrative analysis allows the researcher to theorize across a number of narratives to find common thematic elements (Riessman, 2005).

In this study I applied the five-level model of Representation experience in narrative research (Riessman, 1993). The first level is attending to experiences, it was the time I experienced my international student life at VUW. The researcher encourages the participants to engage in storytelling. This is the second of the five levels. 


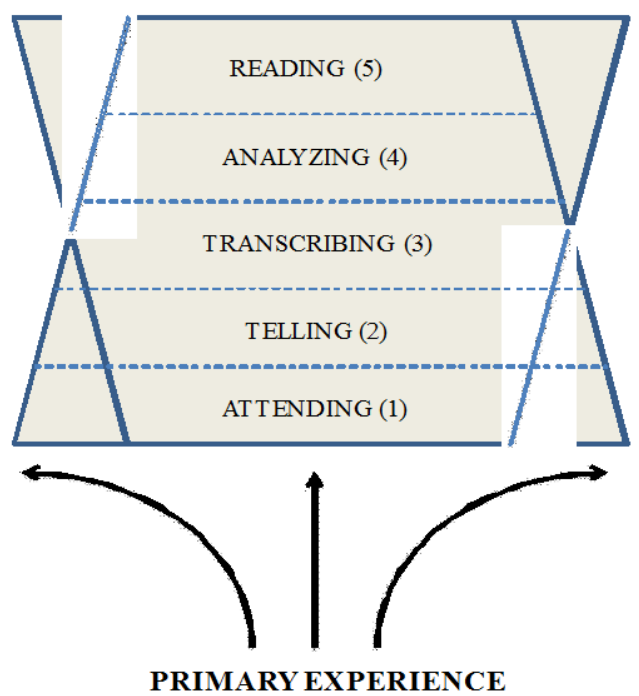

Figure 1: Levels of Representation in Research process (Source: Riessman, 1993)

The third level is that of transcribing experience. An audio recording is the best choice to capture the conversation (Riessman, 1993) which is their transcribing. Transcription is not only the process of transforming spoken language into written language but is also the process of interpreting what the researchers hear and share with participants. After that, is the fourth level that of analyzing experience. At this level, the researchers have to identify the "critical moments" (Riessman, 1993) which help to identify what were the foci of the participants' stories, and identify the 'the similarities across moments" into a summary of experiences. It is a process in which a story is constructed in a collaboration between the participants and researchers and "becomes fixed in a written text" (Moen, 2006, p. 62). And the last level, reading experience, is when a written report is finished and offered to the readers.

\section{Research procedures}

\section{Recruiting participants}

After getting Ethics approval (discussed later in the section of ethical considerations), I worked with the Vietnamese Student Association in Wellington (VSAW) committee to 
understand the population of students at Victoria University. I learnt that approximately 200 Vietnamese students participated in VSAW activities and were members. I had the VSAW committee post my research information sheet and expression of interest form (see appendix A and B) on their website. The information sheet outlined the research, the rights of participants and the research procedure. I invited interested students to contact me via email. Some of the students volunteered at once and they set up a time to meet me. Other students emailed and asked me for more details of the research. The student volunteers filled in the expression of interest form (see appendix B) and the demographic information form (see appendix C). They sent the completed forms to me and we arranged a time to meet. I did not organize a group meeting of interested students for cultural reasons. Vietnamese people dislike others knowing their personal stories especially about any struggles, frustrating times or sad experiences. After two weeks of posting information on the research, I had total 10 volunteers. They emailed me their interests of participating in my research. Based on the information of the time spent studying in New Zealand I selected six students who had studied less than a year to be my participants. I emailed the four remaining volunteers to explain the reasons they were not selected and thanked them for helping me.

I met each participant three times during the research: the first time to introduce the research and to seek their consent and to have consent form signed; the second time and the third time for interviewing. Contact with the students was by email and sometimes by cell phone. They all lived around Wellington city.

\section{The participants}

The participants in this study were six Vietnamese international students at Victoria University of Wellington. The six first year students are fulltime commerce students. According to Chase (2005) and Creswell (2007) in narrative inquiry research the common focus is on gathering in-depth data, and this is usually with a small number of participants, hence the small sample size. The participants were selected by using a purposeful sample selection method. According to Merriam (1998), this kind of sampling technique "is based on the assumption that the investigator wants to discover, understand and gain insight and therefore must select a sample from which the most can 
be learnt" (p. 61). The selection criteria were participants needed to: (a) be enrolled in an undergraduate program; (b) have been in New Zealand from five months to one year; (c) be in their first year at university in New Zealand and (d) ideally, that $50 \%$ of the participants will have done some courses at Victoria University in Vietnam (in the Twinning program at HCMC), and 50\% have not done any courses in Vietnam. Of the six participants, five came from the Twinning program and one did not. I could not find as many students who had not come from the Twinning as I had expected, or some had been here too long or were in their third year at VUW. The students volunteered to do interviews with me and they were very open to tell me what they had experienced. They had been in Wellington from five to 12 months at the time of the first interview. One participant came from the North of Vietnam and the other five participants came from the South of Vietnam. Two of the participants previously lived in a hostel but had moved out to share flats with other Vietnamese students while the other two were living in the $\mathrm{Hall}^{2}$ during that time. One of the participants had initially been in a home-stay with a New Zealand family. The participants aged from 18 to 21. Two participants were female and four of them were male.

\section{Ethical considerations}

The ethical issues of a study refer to participant safety and protection (Walliman, 2001). In narrative research, according to Josselson (2007) the assurance of confidentiality and privacy to participants is central concern of the researcher. The participants were provided an information sheet. I answered their questions such as why I wanted to interview them, how their stories were used or whether they could read their stories when I finished. I explained carefully to the participants as to their involvement, their right to withdraw, to refuse to answer any sensitive questions or withhold information they did not want to be used in the research. They were informed of the steps, time required content of the interviews and they would be audio-recorded. They signed a consent form to agree to participate in the research. During the interviews, the participants used the names of friends, lecturers or school and flat mates, I did not use these names to protect their privacy.

\footnotetext{
${ }^{2}$ In New Zealand, hostel is sometime called the hall of resident.
} 
Occasionally, I came across a participant with their friends I did not let those people know the researcher-participant relationship. Each participant created their own pseudonym.

I did not hold a participant focus group to discuss about my findings for two reasons. First was to protect their privacy. Vietnamese people do not like talking about personal issues with others. Second was I did not have time to hold this activity and I wanted to focus on the research right after getting feedback individually from participants.

\section{The interviews}

Qualitative interviewing aims at exploring "qualitative knowledge in normal language" (Kvale, 2007), that is about human experiences or 'lived' stories; it does not focus on quantification. A qualitative interviewer encourages interviewees to describe and explain instead of confirming or selecting items. Questions in qualitative interview are more openended and unstructured and the questions tend to have an exploratory role (Merriam, 1998). In my study, I tried to ask open questions in order to get as much information as possible.

According to the participants' agreement, I interviewed some participants in the student café, with others in the library and with one at his flat because he was not well enough to travel. The study room of the library was the most suitable place to conduct the interviews because it was quiet and private.

I interviewed each participant twice and in total I did 12 interviews. It took me from an hour to 90 minutes to listen to the participants' stories in the first interview. In the first interview, I asked some opened-ended and general questions. I invited participants to tell me about their stories of their adjustment experience in as much detail as possible. During the interview, I tried to pay close attention particularly to how students negotiate the meaning of their experiences. I checked with them as to whether I understood their examples and stories properly by asking "Do you mean...?" and "can you explain/provide some more details....?" The participants provided many experiences of their first months living and studying in New Zealand. Some probes such as "tell me more"; "how was it happened", "how did you feel" or "how did it mean to you" were provided during the interviews to help the participants to tell more about themselves. The second interview took place around four weeks after the first one. In that interview session, I concentrated on 
getting more detailed information which could build up the participants' main stories of their adjustment. It depended on which stories the participants told me in the first interview, I would decide what questions to ask each interviewee. I tried to make my understanding of their experiences clearer with rich information which helped me create narratives for each participant that accurately reflected their stories. It took me from 30 minutes to an hour to carry out the second interview. All the interviews were taped recorded.

\section{Transcribing and translating}

I tried to transcribe the interviews as soon as possible after each. After finishing transcribing, I summarized the stories of the six participants. I sent each individual summary to each of participants to get their feedback. Then, I read and reread the transcription and the summaries (with feedback from participants). Based on the summaries, I developed the questions for the second interview.

All the interviews were conducted in Vietnamese. Though all six participants' English was at least good enough for them to be accepted to study at VUW, I wanted to interview them in Vietnamese for two reasons. The first was to get full information because the participants could tell and explain everything fully when using our mother tongue. They did not have to translate into English when they told me their stories. It helped them to avoid omitting information if they could not find out relevant English words/phrases. They would be more confident and find it easy to talk about personal, emotional issues in Vietnamese. The second reason was to reduce the anxiety during the interview. If I asked them to speak

English, they might feel they were being tested/examined their English proficiency. I wanted to create the most comfortable atmosphere, relaxing and friendly environment to help them feel free to share their stories.

It was more difficult for me and it took me longer time to translate their responses into English. After each interview, I transcribed it myself in Vietnamese language. I read the transcription carefully in order to understand all the information I received. I picked up important themes of the stories of each participant during the interviews. Those themes helped me summarize the stories of each participant. I did not translate everything participants said into English just the summary of their stories the main information and 
quotes from the full stories. It was a challenging job. I tried to focus on what the participants wanted to say, the senses they wanted to make and then tried to find relevant English expressions. Sometimes it was very hard because the participants used idioms, proverbs and so on. For example, when one participant said "tụ thân vận động" is her strategy to solve some problemsand I understood that meant somebody would do everything himself. I speak English as a second language so it was difficult to find an equivalent proverb in English. Furthermore, the challenges came from cultural differences. In Vietnamese it had this meaning but when literarily translated into English, it had another meaning. An example could be when a male student said "Khi được phân công viẹc cụ thể, các bạn sinh viên Châu Á có lòng tụ trọng rất cao để hoàn thành phần việc của mình”. In that sentence, the most important word is "ty trong" and literarily translated into English, it would be "self-esteem" as in dictionary. But, actually, "self esteem" means self-regard, self assurance or self-confidence but there the participant meant "high responsibility" when I came back and asked him about that expression. I was very cautious in order to avoid misinterpreting participants' stories and tried to narrow the gap between the two languages when presenting the stories in English. The English version of the summary of each participant's interview was sent to them. Each participant provided their feedback on their English summary, not Vietnamese interview. I decided to send the participants the English version because I wanted them to know that their stories would be retold in English like that after the interviews in my thesis. I encouraged them to compare their own stories in Vietnamese with the English version and have their opinion on them before I fixed in my written report.

\section{Field notes}

Field notes taking is considered to be one way of composing a field text (Clandinin \& Connelly, 2000) process. Clandinin and Connelly (2002) rate it as "the most important way" of recording the ongoing bits during the field work (p.104). In my research, field notes have been written by the researcher. I wrote down what I heard, thought, saw and experienced during the study especially in interview sessions. I tried to write as much detail as possible. After interviewing I wrote down notes as soon as possible (Groenewald, 2004). I also took notes about how I felt about the interview, the challenges I had faced and 
strategies I had used to do good interviews. When doing transcribing, I recalled my impression of the participants and their stories then, I wrote them down. These field notes were very useful especially because after the first interview I used them to focus on what I would want to explore more in the second interviews. The field notes helped my understanding of my own research journey filled with experiences that I could use in report writing. When I reread my field notes, I could recognize what happened at some important points of time such as in interview sessions, contacting participants, transcribing or translation. These things helped me represent participants' stories clearly and ensure they accurately reflected the participants' experiences. Writing field notes helped me avoid missing information (about how participants responded, what was their favorite topic, what they wanted to keep private...). During two months working in the field, I tried to write frequently so that I had rich information of what was going on in my field trips, about my participants and my own job as a narrative researcher.

\section{Analysis and representation participants' stories}

I started analyzing the transcription (in Vietnamese) by selecting subthemes and key words/phrases for the four main themes. The first was coming to New Zealand, the second was beginning to study, the third was academic life and the fourth one was social life. I selected subthemes such as first assignments, tutorials, first lectures, circle of friends...I then summarized participants' stories. Then, those fragments of their stories would be grouped and named such as "stories of first lectures".

Thematic analysis allowed me to identify the similar categories of fragments that motivated me to shape the participants' stories as episodes (Riessman, 2005). In each big theme, there were episodes shaped by representing the same and the different (opposite sometimes) fragments in which I could compare and contrast across participants. These episodes were rearranged fragments of participants' stories so they were close to what they told in interviews. In responding to the same questions, the participants provided the stories that were the most meaningful to them at that time and that were the valuable sources of information to answer my research questions. 
I next analyzed the episodes and this time I emphasized on the stance that participants took when they talked about themselves and people related to them. That was nature of Positioning theory (Davies \& Harré, 1990); Davies \& Harré, 1998) provided a lense to understand the participants' negotiation and sense making process through their stories. The participants were talking about themselves as well as retelling stories in which other people offered them different positions. This was very important to see which positions the participants took, which they wanted to be in and which they refused because it helped me to decide how to represent each participant's stories in comparison with others. The participants had a tendency to express who they were by using power of language in their stories and their negotiation. For example, in their study in 2007, Arkoudis and Tran used Positioning theory to explore how two Chinese post graduate students' agency where they positioned themselves as well as the academic staff talked about them. Another example is Koehne's 2006 study. In his study, Koehne looked at the power of academic discourse had to "develop subject positions" that were international students talked about themselves.

\section{Representation of four themes of stories}

After grouping fragments of experiences according to the themes and subthemes, I started representing the experiences. I tried to retell the stories as close as possible to the told stories by the participants in reshaping their stories. Each small story of the big theme was an episode of their whole storyline.

\section{Stories of coming to New Zealand}

When I interviewed the participants I realized that the participants talked a lot about their journey to and their first feelings about New Zealand. I selected that theme because I assumed that their first impressions of where they would live and study were very important to them for the rest of their study journey. In literature on international students, many studies address first stage of adjustment (Brown \& Holloway, 2008; Choi, 2006). I developed a list of questions that I used to interrogate the narratives. I wanted to build up coherent episodes for individual participants on themes such as "how did they feel; what were the most frequent words they used to describes their trips/feelings; or how the first week in New Zealand happened". To some students their first experiences would be unforgettable. 


\section{Stories of beginning to study at Victoria University}

I especially focused on looking for detailed information of their orientation sessions at Victoria University and their preparation, the university and the hostel preparation for the students before the academic year. I assumed that these activities were very important to the participants. The six students took part in the orientation week compulsorily but their experiences were not the same. Three students lived in the hostel had chances to share in group of multicultural background students so their experiences were different from the other three students. Their stories also revealed how the university helped to prepare for their both academic life and social life in Wellington.

\section{Stories of academic life}

Academic life of international students is the most concerning issues to not only students themselves but also the institutional staff, educational exporting industry administrators. In my research, I also paid strong attention to these issues by encouraging the participants to talk as much detailed as possible of how their academic life was happening. I categorized the stories of academic life into five groups: first lectures, first assignments, academic English, learning styles, relationship with academic staff; and learning to be an independent learner.

\section{Stories of social life and Yo-yo relationship}

Besides achieving academic success in the host countries, the participants involved in many social activities, communication and relationship which made their life more meaningful.

The stories were represented in episodes consisting of hostel life, relationship with international/Kiwi students, and friendship in Vietnamese student community. In that theme, the stories of participants reflected that their Vietnamese friends were the main sources of support to them in some issues such as accommodations, personal problems or academic issues.

\section{Analysis}

After representing the four big themes stories, I looked for the overarching stories of the participants. I focused on what the meanings that the participants wanted to construct. The 
stories told by the students in the interviews were analyzed to see in what ways the participants constructed the meaning of their experiences of life. By doing the cross analysis of the participants' narratives, I could see how the participants positioned themselves and what positions they wanted to take. The narratives were developed into three "big” stories: "Un-belonging” stories; "Becoming” stories and "Belonging” stories.

\section{Trustworthiness}

Trustworthiness is a term used in qualitative research, which refers to the whether the research results can be trusted or not. In this research, in order to promote trustworthiness I used strategies suggested by Johnson and Christensen (2008). They were "low-inference", participant feedback, peer review, external audit and reflexivity (Johnson \& Christensen, 2008, p.276). I will elaborate on each with following section.

I have chosen the qualitative approach with the lenses of narrative enquiry so that it could help me gain rich information about the problems I wanted to investigate. I endeavored to see that descriptions remain very close to what participants told me in what was called 'low-inference' descriptors as term used by Johnson and Christensen (2008). I tried to translate the participants' quotes into English within the meanings they were referring to.

The most important strategy for establishing trustworthiness in this study was using participant feedback. After I transcribed the first interviews, I summarized the participants' stories and sent them individually via email (the English version). The participants read the summary of their interview and checked what were captured by me were what they wanted to say. I invited their responses, and reminded them that if there was anything they would like to have removed or changed they should let me know. After some days of receiving their summary of their stories, they sent back to me with their words. Four participants were satisfied with the summary of what they shared with me. One participant withdraws a piece of information on a part time job. I then took that sentence out of the transcription. Another participant provided some detailed information on coping strategies. I used those stories to select the questions and stories which I wanted to explore more in the second interview. 
Besides getting the participants' feedback, I decided to use strategies of asking for experts' opinions and peer reviews. I discussed my interpretation of participants' stories with my thesis writing group under the supervision of my supervisor. They are included Kiwi, American and Asian students and they helped by asking questions and sharing their own experiences which really helped me to see clearly what the experiences the participants had in New Zealand. I also talked with my previous lecturer at Victoria University who was very interested in studying international students in New Zealand. She shared with me her own experiences of doing research and encouraged me a lot. Talking to her helped me to compare issues that emerged in her studies with those I was exploring in my own study. Moreover, I discussed about narrative inquiry, positioning theory and telling stories with another academic with a strong background in narrative and constructionism approaches. I learnt more about how to represent stories that were underpinned by my chosen theoretical framework. I discussed with my supervisor every week and after each stage of my research.

However, I am an international student too, as a researcher, I am aware that some of my experiences may affect the research process and results somehow. I always thought that I was listening to the participants' stories, and I had to retell "their" stories in "my" work, and tried to reduce my bias as much as possible in every step of my research such as in asking questions, summarizing, selecting stories and representing stories (Johnson \& Christensen, 2008) 


\section{CHAPTER FOUR: \\ Coming to New Zealand and Beginning to Study}

\section{Coming to New Zealand}

The six students came to New Zealand and bringing with them different prior experiences which would become important in their study journeys. Five students had completed at least seven courses in the Twinning program at the Ho Chi Minh City Campus. They had known who would study with them at Victoria University of Wellington (VUW). They were all excited before travelling. Five students travelled with other Twinning students, while one student travelled alone, from a different city in Vietnam. This student had travelled to New Zealand two years previously so for him the trip was nothing special in comparison to the experience of those coming for the first time. The stories of these students arrival to and settling in New Zealand follow.

In this chapter the focus is on four representative stories. David and T's stories repeated much of what appear in the four narratives here. In chapter five and six I will turn to David and T's stories.

\section{Tom's story: "Where do I get off?"}

Tom came to New Zealand after a long journey with his friends from the Twinning programme in Ho Chi Minh City campus. Travelling with friends would help him a lot. He did not feel lonely and they had fun during the flights. When they had to wait in transit to other flights they went around the different airports and experienced new things together. Compared to other international students, he positioned himself as a lucky person to be travelling with friends. They had shared their preparation for their new study journey together and became close.

Tom was prepared for Wellington to be very windy and cold but he was surprised arriving at midnight to feel the strong and cold wind even "like a storm" and it was the first impression he had when he first set foot in this completely new and strange place. He is from the city without winter so it was hard for him to adapt to changing weather. 
Tom and his friends were welcomed by the Victoria International office staff and taken to their hall or hostel on a shuttle bus. The warm welcome made him feel better. That first night as he traveled in the shuttle bus he tried to see the city but there was nothing impressive. It was so quiet, with dark sea and mountains, narrow roads and none of the traffic jams as he had imagined before coming.

Tom was surprised with the cozy and friendly atmosphere in the Hall, which was managed by a friendly and hospitable lady. It was arranged that Tom would share a room with another international student and they quickly became friends and talked a lot. Tom felt very excited to talk with his new friend and forgot the tiredness of the long flight. They did not sleep that night but talk until the following morning. Tom talked about his new friend as a good and thoughtful person who stayed up late to talk about many things in order to help him feel better and do not miss home too much.

The next morning was enrolment and he felt a little bit tired. He thought he could be very happy with his new friend who helped him to with the enrolment procedure but when he went out to see Wellington, everything was large and strange, and he felt homesick. It was a hard feeling but "truthfully it was normal" he admitted. His feeling of missing home and family did not long last because he had many things to do. Orientation week at the university and the Hall orientation activities made his first weeks busy and he had very little time for his own emotional feeling.

"Going downhill" was how Tom talked about his trips from the hostel to the campus. Travelling by bus, he felt "car sick" for the first time. Roads in Wellington are narrow and driving on the hills with many bends and slopes is a challenge for many new passengers. Tom was no exception. He was confused with traveling on the left hand side. He failed to recognize the bus stops and sometimes missed to get off at the right place.

I was feeling bad travelling by bus. Carsick was the feeling I have never had before coming here. It took me 30 minutes to travel from the hostel to other campuses. First few days I found very hard because I was not sure where I should get off. I did not know how to read the bus routes and felt worried when I got on the bus. But, it happened in two first weeks, and then everything got better. 
No skyscrapers but many beautiful wooden houses on the hills are very impressive. He was completely new in a big space of Wellington especially in his hostel surroundings. Tom was very surprised when seeing many people at different ages walking. The pedestrians are priority on the roads and people are well disciplined. He decided to walk alone in the neighborhood to see how people lived, and his first impressions of seeing the life in New Zealand left him feeling peaceful and happy. People he met were friendly. He got lost on his the second time he walked around. An old lady walked him to the main road, and from there he could easily find him way back. He was impressed by the kindness of people in his community. Then walking became his favorite activity and travelling by bus was no longer a challenge.

\section{Hoang's story: "People are very nice"}

Hoang moved from her hometown to study in the Twinning programme and had nearly two years of living alone in a big city in Vietnam before coming to New Zealand. Hoang is a strong-minded person in her early twenties. She brought to New Zealand her experience of living far away from home.

I moved to Ho Chi Minh City for two years to study and lived alone. I was familiar with the feeling of being alone in different place so now I feel fine to live alone here. I also missed my home, my family, but home sick is not a strong feeling. I can find it different from other students who the first time saying goodbye family and living themselves. Living in a different country is not easy but if you had times to live far from family before, it is better to have some experience for yourself.

Hoang used to travel overseas sometimes so that her journey to New Zealand was somehow the same as what she had done before except for the "too long" flight. It was a three-stop flight without friends so she felt nervous about getting lost and missing the transit flights. In contrast to Tom's experience, Hoang was surprised by the sunlight and high temperatures when she outside at Wellington airport, it was not what she expected.

I came to Wellington in the afternoon and the sun was burning hot, it was not as what as I expected. I had prepared for cold weather with thick coat but that time it made me had a terrible headache. I had been worried many things but when I came, everything was under control. 
Everything in Wellington was new to her and she admitted she liked new things. She realized firstly that the living standard in New Zealand was much higher than Vietnam. First weeks going out to see the city and participating in orientation activities were the time of comparisons. She compared living style, people behaviors and habits between her country and New Zealand. She positioned herself as an "observer" - she enjoyed going out and observing people behavior and actions. Her first impression of New Zealand was of the politeness and kindness of Kiwi ${ }^{3}$ people.

She was too much impressed by fresh air and quiet environment in Wellington, which was totally different from Ho Chi Minh City and a little bit similar with her hometown because it was a coastal city as Wellington. Hoang was impressed with the high standard of public services and of buildings. Hoang felt welcome in New Zealand.

I remembered when I did some shopping on the first week to buy some essential stuff for new life in Welly, I had a very strong impression that shop assistants were very nice. They are patient to wait while I was selecting, explained carefully when I asked and smiled and comforted me when I could not get the thing I wanted. It was very good behavior in trading. I could walk along a street and see people smiling with each other and with me. People say "hello" to everyone even he/she is a foreigner. They helped me feel close. People are very friendly and polite. I felt I liked it.

Hoang observed and learned many new behaviors such as greeting others, travelling by bus and shopping. Her international buddy helped with understanding student life at the university. She positioned herself is a person who just like observing and feeling in her own way then she decided what is suitable and necessary to learn. Though she acknowledged Kiwi people are very friendly and nice to her, she found very difficult to make a conversation with them. Lack of confidence was one of the reasons.

\section{Andy's story: "It was too quiet"}

Andy positioned himself as a lucky person who had a chance to study abroad. He came to New Zealand with a "small cheerful spirit" coming to a new place. He has learnt about

\footnotetext{
${ }^{3}$ Kiwi is another word used to name New Zealander.

${ }^{4}$ Welly is short and informal way of talking about Wellington.
} 
Wellington city through the internet, the twinning lecturers and friends but he was still disappointed when he arrived. "Boring" was the only word he could use to express his impressions when once he left the airport. Like Tom, and contrary to Hoang, Andy experienced and suffered from the cold weather. He was not prepared and was very cold.

My flight landed at midnight in Wellington. It was too cold, colder than I imagined. I had some winter clothes but put in my baggage so I only had one light jacket, which could not keep me warm. I was very cold and felt unwell.

He decided to spend the first week going around the city with his friends. Andy went to see what life was like in Wellington. He went shopping despite his lack confidence in his communication skills. The shop assistant welcomed him; unfortunately, he misheard and misinterpreted what she said was "watching is free" and he misinterpreted and thought she said "nothing is free" that she meant, if he did not buy anything, he was not welcome. He had the embarrassing experience of using English to communicate with native speakers. Then, trying to think, he found that how thoughtful the shop assistant was when she told him that.

After two weeks in Wellington, going around and talking to some both domestic people and foreigners, and doing some shopping Andy thought he "dislikes living there". He was discouraged by that the city was boring and quiet, especially at night. Shops closed at five o'clock, and very few people went out after nine in the evening. He did not know where to go out when he sometimes felt sad and lonely at night. His "cheerful spirit" of a newcomer had left him and was replaced by boredom in the third week.

My first impression of Wellington at night was it was very quiet. It was too quiet and nothing was special and attractive. [...]. On the third week, I started feeling bored and did not like living here. It was more boring than [his hometown]. I used to be familiar with noisy city and public crowded so that I had a feeling of lacking something. I liked busy lifestyle.

Andy knew that he had to try to keep his daily life busy in order to reduce the feeling of boredom. He gathered his friends to chat. Luckily, that feeling did not last for long. He had come to love the peaceful city with friendly people and he started on his new academic life. 


\section{Hai's story: "It was a panic trip"}

Hai flew to New Zealand with three other students. They had to transit twice before reaching Wellington airport. It was the longest trip she had ever been on. Hai was fascinated with the international airport in Singapore because it was modern, convenient and splendid. However, she found herself lost in the huge airport when she was trying to find the gate number for her flight. Hai felt panic.

It was the first time of being in a foreign airport. It was huge and we had such a little time to find the gate for the next flight. We were a little bit panic when trying to find the gate number on the big screen. It was full of numbers, flight destination, hours and gates. And then, after finding successfully, we had run very fast to the other side of the airport in 30 minutes left. I was exhausted and thought of throwing away my hand-luggage.

During the 10-hour flight she had nothing to eat because her air ticket did not include food and drink; she did not buy anything in the air because it was too expensive. While Tom travelled with friends and had a lot of fun, Hai and her friends were exhausted to talk to each other. The thought of coming closer to Wellington made her excited and she felt better about having to transit to another flight landing in Auckland. Her excitement did not last because for the first time when she was in Auckland airport, and found herself in a large space in a new and different city, Hai experience the feeling of loneliness for the first time. With an inquisitive look around she found "a feeling of strangeness surrounded me".

At the capital airport she was anxious about her English. The warm welcome of international officer encouraged her to think positively. As with Tom, Hai had an "unforgettable trip from the airport to the Hall". She found it was much worse than the 22hour flight with two stops. The windy outside and the twisting roads made her dizzy. She was totally worn out and looked forward to a warm bath and comfortable bed but something was wrong when she arrived at the hostel. She was allocated a single room instead of the triple room she had booked before coming. She was angry with that and had to discuss her problem with a student resident. The problem was solved when they found a double room for Hai. 
Hai was not alone in having a problem with accommodation; David had felt "scared" when the Hall staff did not let him in. David was scared that he had no place to stay overnight in a strange city. Finally, they found his name and he could enter his room. Hai and David shared similar experiences but their reactions were different. Hai was worried and scared by the high cost of the room and she chose to be angry and shouted that she would not stay in a single room at that price, so then they found a shared room for her. On the other hand, David did not say anything except to request the staff of the Hall to look for his name on the registration files or anywhere they could. While waiting, he thought of the worst situation and that they had missed his online registration and that he would to need try to contact his friends for help. Luckily, after an hour, they came to apologize because they had not prepared to welcome him. David felt happy soon after that.

I was very scared because it was the first time I went abroad. I was not sure where to sleep after tired journey. I asked them try to check their system because I had booked and paid already (rental fee and bond). Fortunately, they found me. Someone had missed putting my name on and they did not confirm when I would come. So that was not good experience.

\section{Beginning to study at Victoria University}

Orientation sessions are compulsory at Victoria University and that was very busy time. Besides that, students can take part in other optional workshops or seminars at their schools/faculty.

Hai came to New Zealand early and she was waiting for orientation with excited mood. She was so impressed by the Hall orientation week that she told again and again about it. Other three students were living in the Hall/hostel at that time but they did not share the same feeling with Hai. In the common room, students were instructed to participate in different activities. A small group of five students (different origins) gathered to play a game. Hai was impressed by "rapid reaction ability" of Kiwi students. The first time joined a group of Kiwi and other international students; Hai could not hear and understand what they said. They spoke too fast and sometimes used slang. The students were encouraged to make friends in a multicultural environment. 
The hostel staff tried to help students become close to each other. They organized many activities such as sport clubs, a music band or chatting groups. Besides organizing social activities, the hostel staff paid a lot of attention to the academic success of students. Hai remembered that in the second week of the orientation weeks in the hostel, students took part in many activities to build groups. These groups were where students who were studying on the same courses would gather to share their experiences or support each other. The big bulletin board in the common room was the place students could put their name against the relevant courses they were doing or had previously done. Senior students (they were student residents), would share their experience of the courses with the new students such as how they did assignments, how to prepare for tests and exams. There were activities that helped students reduce and coping with stress.

When Hai was worried, she went to the main lounge to talk about her worries and to get suggestions from the other students and this made her feel better. Chatting was an effective way to improve an international student's language. Even more, the Hall staff and student residents tried to create an environment for students that helped them to relax after hard study.

Students could chat about every topic at dinner time. Some students gathered in the main lounge to talk about their daily stress. Other students played music in music room and the most common game in the hostel was hand-soccer and billiard. Students wrote their names on the bulletin board and found their academic groups or sought support when they needed. I enjoyed chatting with other students; it was good way for practicing English. The staff encouraged students to share their feelings of study when they felt stressful or difficult. Asian students tried to participate in many social groups in order to learn Kiwi culture and practice English.

(Hai)

Tom and Hoang also lived in the hostel but they focused on VUW orientation week. They were impressed by the workshops held by Student Learning Support Services (SLSS) such as academic writing, intercultural communication, Excel and time management. Tom remembered those days as very busy. He attended a workshop of academic writing which involved students in different activities. Academic advisors asked students to do some writing at the workshop and then they checked the writing carefully. Attending the session 
on money management was also a very good experience. Other social organizations came to the University to introduce their work or to offer support. Tom was surprised when some police officers came to explain general law and security policies in New Zealand.

I liked workshops in orientation weeks such as Learning Support workshops and time management workshops. They secured me of new academic environment and then I had a feeling of safe and security. I also learnt how to manage my time, set up my study plan to avoid missing and overdue assignments tests or group works.

(Hoang)

Tom had some interesting experiences, saying:

VUW had a separate orientation session for Twinning programme students who had transitioned from level 1 in Vietnam to the Wellington campus. They introduced some services of VUW. SLSS advisors also organized workshops for students to practice our writing or understand about assignment/test/exams preparation and requirement. I knew that I could book to work with academic advisors in SLSS to discuss about my assignments and check my writing and so on. They were very helpful.

$\mathrm{T}$ was the youngest participant who was doing level 100 at the time of the interviews. Orientation weeks for him were the time to make friends, to become acquaintanted with the academic terms of his major and with the academic environment. "It was useful" he admitted. T remembered the day he went to the Victoria International orientation session and was surprised that there were so many international students at VUW. He attended some compulsory sessions but missed some workshops which, according to him, might have been useful. One day he was busy, and on the other days he was lazy. He was contradictory in admitting orientation sessions were useful but in taking advantage of them. The big benefits he got from the sessions he attended were to getting basic information about his school, academic requirements, lifestyle and the study culture. At VUW, students were encouraged and guided to "self-study", they were expected to become self-directed learners. As his experience, many students considered orientation just a time for finishing enrollment and institutional introduction so they did not take advantage of the workshops. 
I saw many international students when attending orientation session held by Victoria International Office. Students were introduced about the VUW, studying environment and living style in Wellington. They also recommended some useful workshops in SLSS and different faculties. International Office also would organize many activities for students taking part in. I knew that but I did not participate because I was busy and sometimes I was lazy. It was not good to miss some useful workshops. 


\section{CHAPTER FIVE: Academic Life}

\section{First lectures}

The six participants came away from their first lectures impressed by the size of the classes; not only the big lecture theatres but also a space full crowded with students. "I have never thought of a big lecture theatre with nearly 300 students studying together. It was really amazing!" - T exclaimed after one trimester in that environment. I could see how excited he was at that moment he talked to me. T remembered entering the lecture theatre and feeling as if he was watching "a movie" on a big screen on a stage.

The other five students who had studied at the Twinning program were also surprised with the organization of the lectures. Tom was taken by the friendliness and creativeness of the lecturers; David was interested in the lecture slides which were full of focused information. Hoang enjoyed the sense of humor of the first lecturer and the fast reaction to questions by the Kiwi students impressed Hai greatly.

Besides these first impressions of the lectures, they had some different reactions to the academic environment both then and as their academic life continued. For example, David found that 50 minutes was not long enough for a class even though the lecturer was good. He did not see many interactions or responses between the lecturer and students.

I had a feeling of shortfall of the lecture duration. 50 minutes were not enough and because we used to be familiar with a lecture from 90 to 120 minutes so I thought I could not do anything in that short period.

Sharing David's view, Hai and T thought it was hard to deal with all the lecture issues in 50 minutes. They expected that the lectures would be two hours long as in the Twinning program.

I found that, a 50-minute lecture was very short, lack of time for practicing and interacting. I had expected the lecturer would interact with student more and stronger but not. He [the lecturer] just explained briefly the core points of the studying tasks. Students did not have time to ask for further explanation. Students needed to read more and more.

(Hai) 
'Challenging' was the word the participants used to describe their first lectures because most had difficulties in understanding the lectures. They came full of enthusiasm but they did not understand the lectures. Most found it "too hard" in their first weeks. They talked about their experience saying things like - "I understood very little", "I did not understand" and even "I completely did not understand" the lectures. Some participants were worried and others were really shocked. The difficulties they faced related to their language proficiency, to different teaching styles and to the accents of the lecturers.

\section{"I do not understand their English"}

During the two first weeks of lectures Andy came to his classes in a bad mood because he did not understand the lectures at all. He used the metaphor of watching a concert but not being able to see where the orchestra stood, nor to hear what the singer was singing. He could not enjoy the performance he just felt very stressed and shocked because he gained nothing from the lectures. He found that the lecturers spoke different types of English. He explained that he spoke poor English and his listening skills were not good enough to understand the lectures.

I was very shocked at first lectures. I completely did not understand anything, because of language and culture. I was very worried because I did not know what to study and focus after the lectures. It looked like I was attending a music performance but it was not enjoyable and relaxing at all.

Like Andy's Hoang, Hai and Tom also felt challenged keeping up with what was happening in the lectures. They admitted that their first lectures were very hard. They had been eager to experience new lecturing styles but the reality did not please them because they understood very little.

It was very, very hard to understand what the lecturers were teaching. I felt stressed because I could not figure out what was important and what I needed to remember. Preparation for each lecture took a lot of time because I even had to read some chapters twice or three times but I was not completely confident with what I had prepared before classes. At the lectures, I sat quietly and tried to listen to the lecturers but I could not gain much. 
Hoang revealed "I know my English is very poor I could not understand the lecturer's words". Tom said he needed three weeks to adapt to the lecturers' accents. Understanding different accents was a major problem for these international students when they studied in New Zealand. David confessed "it was uniting English, not like the English I learnt at home". He said that the lecturers' accents: the local Kiwi accent and Asian English (Indian, Chinese and Japanese) created different accents that puzzled the students. David was the only participant who confidently stated that his English listening skills were good and that he could understand all the lectures from the beginning of the courses. He was "different".

English in New Zealand is uniting English, the different English (not American English but English of different nationalities).Different accents were a big problems. Vietnamese students learnt with Vietnamese lecturers of English so it was difficult to adapt to new accents. My English was a little bit good especially listening skills so that I could understand almost.

After talking to David, I had another chance to talk with T, who also had no difficulty in understanding the lectures. But, the interesting thing was, he did not think that his English was good.

First lectures were a little bit hard because I had tried to be familiar with different accents of lecturers. I knew my English was just enough to understand the content of the lectures. A little bit stressful because doing tertiary education level was time you had to study yourself a lot.

\section{First assignments}

\section{"How can I draw up to 1,500 words?"}

T asked himself the question "How can I draw up to 1,500 words" several times before his first assignment. With no one to remind him of the deadline, no one to push him, he found it a struggle to finish his assignment on time. He used the word "draw" instead of "write" or "compose" or even "type" and it made me think of the critical situation he was in at that time. When reading a question; he was really worried and confused as he tried to figure out the requirements of standard assignment writing. $T$ had not done any courses before at a university and found it a big difference between his high school assignments and 
the university ones. "It was a higher level" he said but what level was it was such a big question. He had no experience of assignment preparation and time management and that was why he was so confused. He chose to go and discuss his assignment with his tutor and lecturer. Though confused about what to write, $\mathrm{T}$ positioned himself as a student who was well aware of plagiarism. But, he had confessed that, the gap between citing and interpreting an author's ideas was very small. "Be careful, otherwise, you will be penalty, even more, you might be obliged to stop that course", T shared. He wrote and then erased many times in order to reach smooth writing but when he brought his writing to the student learning support help desk in library to have it checked, many mistakes were pointed out. T had to stay up all night to edit before submitting. "Luckily, I submitted in time. Then, I passed", T happily said. His story was typical of the students' experiences of doing the first assignment.

\section{"What was going on here?"}

Andy was used to practicing assignments and other academic tasks such as presentations, tests and exams in the Twinning program. He was familiar with writing an essay but was very disappointed when he received his first result. He was confused with the marker's feedback. "I was very shocked", he said. His facial expression still said everything of that day. The feeling was still raw. He did not know what the marking criteria were and felt completely deflated by his tutor's comments and feedback. Andy expressed his negative opinion on the way the tutor had marked his assignments. The moment of receiving his assignment back must have been a terrible moment to him. Andy had the pressure of finishing two assignments on the same day. He tried his best to finish one assignment first and then had only one day for the second. It was not a good plan. He followed the questions but the feedback could not clarify what he needed to improve. The comments he got discouraged him.

I was very shocked when receiving the first assignment result. I got confused of the marking and evaluating criteria. The comment of the tutor really shocked me. I did not understand why he commented like that. I could not explain what was going on there. I was completely disappointed. I could remember one of his comments "I am afraid that I could not understand what you were writing" 
Andy tried to contact the lecturer to clarify his comments. He learnt that his English was one reason he got low grade. Luckily for him, he soon found his way.

Hoang was in more critical situation than Andy because if Andy struggled with the early assignments, Hoang was confused all the time, and she finished the first trimester without finding the most effective strategies to get higher grades. Each assignment/ tutorial task received different critical feedback though it had been done based on the previous feedback. Hoang was depressed with her grades. She stated that she was not good at English and not flexible in thinking but tutor's feedback was really challenging, she said:

I do not know what to do after many times following the comments to improve the next assignments but I could not change. The feedback was fragments which could not help me clarify my weakness that was why I changed after each feedback but it did not help. I was really hopeless.

The participants started an assignment when it was almost due. A common experience was staying up late to work, and submit minutes before the deadline. Most did not have time to double check or to have someone proofread. Only T went to the library help desk and Tom to the Student Learning Support Services to have their first assignments proofread then they stopped using these services. $\mathrm{T}$ and Tom said that they did not have enough time to finish early and book an appointment with the academic advisors to check their writing. Hai and David believed that because of their majors were based on calculations their assignments needed a specific answer that was right or wrong; they did not think the academic advisors could provide a specific answer to students. Together with lack of time, Andy had another explanation that said academic helpers just checked your general English which he could ask his friend to help with.

Hoang surprised me when she said "I did not like rereading my writing, more especially when it was checked by others". She was afraid that if an academic advisor provided suggestions for changes that she could not do then she would be worried for days. She liked submitting right after finishing. Whenever she could, she asked her friend to check her grammar, but that was not often. Students doing Marketing and Management majors had to write essays that were at least 2,000 words and usually from 3,500 to 5,000 words and 
which took them ages to write so even though they wanted to check and recheck before submitting, they did not have enough time.

\section{Learning style and relationship with academic staff}

\section{"Why did I spend thousands of dollar there then I had to self study?"}

There was a significant gap between those Vietnamese students' expectation of what learning at university would entail and what the reality was. There was the sense that their New Zealand counterparts were prepared for a different approach to learn. In the Twinning program in Vietnam the lecturers provided a lot of support and guidance to the students. Time was spent helping the students understand the course material. The lecturers directed the students as to what to focus on, and what to revise. When they did not understand, the lecturers would explain in Vietnamese. In their early weeks at Victoria the students were confused about what and how they were supposed to be learning. There was a gap between the experience on the Twining program and the experience of classes at Victoria University. The classes were big, the lectures were short, and the lecturers did not have time to help the students clarify the lecture content. Another significant difference was that at VUW the lecturers took the role of instructors rather than that of teacher in Vietnam. Students needed to study before and after class. Hai was distressed at the beginning of the first trimester when lecturers just introduced the main contents of the course but explained little else in detail.

I was a little bit disappointed and shocked when the lecturers just introduced some key terms, some specific definitions with very few practical examples. Students had to read a lot, search for information and needed study outside of the lectures. Sometimes, I emailed the lecturers but they did not reply, that made me hurt and thought why did I spend thousands of dollars to self-study?"

The participants shared common perceptions of the ways that lecturers taught at VUW which was, to rapid present slides and without caring whether the students took notes or not. The lecturers introduced the main issues, terms or tasks and then the students had to decide their own ways to get as much information as possible. The lecturers did not ask the students whether they understood or not. At VUW, students were expected to self-study 
and to be "self-regulated learners". The lecturers and text books just provided basic knowledge and the students had to develop their own plans and strategies to complete academic tasks, and build their knowledge.

Before the lectures, I had to read textbook (some chapters), search on the internet to find more information, which helped me understand key terms in the books. If I had any questions, I would search more information to sharpen my understanding, ask my friends, or ask tutor or lecturer but they were not available whenever I needed. After lectures I also did the same things.

(David)

Andy explained the difference between a Vietnamese learning style and a Western style by citing an insight from his previous teacher in Vietnam. His teacher had said, in Western culture, people pay attention to the results; they value the correct results not the way you get those results. In Asian culture, on the other hand, people value the whole process which is expected to follow one format.

T explained self- study meant every student had to set up their own plan, be a good time manager because assessment tasks and dates were fixed and there was to be no excuses if someone missed their tasks such as two assignments due at once, or no time for preparation for group work. The students should be aware that, they chose their courses; they had to be responsible for themselves. "The lecturers played the role of instructor, helper and judge; they do not feed the students. They suggest some ways to get food, finding the food will be the students' job" (T's metaphor).

Despite the perception that lecturers did not care about the students during the lectures, and they did not check their understanding, none the less the lecturers willingly answered questions during and after the lectures. Interestingly in Vietnam, lecturers would provide greater support and explanations in class than happened at VUW but in Vietnam the students were reluctant to question their lecturers and were aware of the hierarchical distance between students and students. At VUW the students felt at ease going to see their lecturers and questioning them. 
Andy's stories started with his memory of a lecture in which students were skeptical and argued with the lecturer. Students felt free to question when they were unsure of something. It was very different from Vietnamese classrooms where teachers asked questions and students answered.

Lecturers are very humorous; they talk about some funny things to help the students reduce stress though they are very strict. They see themselves as helpers so they were always ready to talk to the students after classes. They create a friendly environment and they respect their students.

According to Andy, some lecturers were aware of international students' needs and took care of these students by asking simple, short questions and being encouraging. Whenever he went to see his lecturers, he found them to be friendly, open-minded and helpful.

\section{"Sometime it was demotivating"}

Academic staff-student relationships played an important role in motivating or demotivating these students to study or to seek help. Hoang's stories illustrate this because she had both positive and negative experiences in her relationships with her lecturers and tutors. She was motivated in some lectures because the lecturers were creative, humorous and friendly. The relationships were close. Hoang was interested in the different ways lectures were organised, and in how class activities and assignments were designed, as well as in how lecturers responded to students' questions. She felt eager to go to the lectures in which students contributed to the classroom activities. She positioned one of her lecturers as a "game organizer", who attracted students to participate in different academic activities. On the other hand, she was bored by and had no contact with some lecturers and tutors. In her opinion, these staff was not creative, dynamic nor enthusiastic. Frequent changes of lecturers in some courses put her in a bad mood. She could not develop relationships with the staff because they had no time for the students and just read their lecture slides. The class atmosphere was boring and students felt no connection with others, or the lecturers. In one of Hoang's tutorials, the tutor could not control the group debates and international students felt ignored and unable to contribute any ideas to the group discussions. Hoang said it was a very disappointing experience. 
T often took advantage of opportunities to discuss academic issues, such as assignments, tests and examination preparation, with academic staff. His lecturers and tutors were good listeners and helpers and because their advice was valuable and practical that helped him a lot. He positioned them as fair, friendly and responsible. He felt that the gap between students and lecturers was very small. Sometimes, the lecturers helped the students feel there was no gap between them. It was the opposite of a Vietnamese Confucian educational environment, where students were often afraid of teachers, and did not dare to discuss issues with the teachers and the teachers were always right.

The lecturers/tutors were very helpful and I found easy to talk with them. Students and lecturers seem to be friends. I did not feel scared as before when I had had face-to-face conversations with my Vietnamese teachers.

\section{Learning to be an independent learner}

"I know I am definitely more independent when studying here" was a very positive result of the adjustment process. The participants said they changed from being very passive to more active in their learning. "Passive" was explained by $\mathrm{T}$ as when students waited for lecturers' instructions on what to learn, when and why. Passive learners depended on what was taught by the lecturers and believed that was enough. On the other hand, "active" was defined as the ways students "self-organized" their learning plans, and searched for more information to enlarge what provided, and included questioning lecturers when they found something unclear.

Students have to self-study very hard in order to gain in-depth understanding and expand their knowledge. The tests do not come directly from what we study in textbooks and lectures/tutorials. They require us to think independently in practical issues, your own thinking, not bringing everything from books to your answers.

At VUW, the students did not only follow the required readings but they also needed to do extra readings, they were expected to search for more information in order to improve their knowledge. This new academic environment required the students to be flexible thinkers. Most of the assignments, tests or exams asked students to solve practical problems. "That means I have to think flexibly, apply the knowledge to deal with real situations, not simply 
repeat a definition of a term"- Hoang commented and her lecturer advice: "do not rewrite what you read."

All of the participants commented that they were encouraged to develop their creative ability in studying and doing assignments. They were expected to be self-regulated learners and to manage their own time.

"No lecturers/academic staff force you to study, it was your choice, you have to finish responsibly otherwise you will get bad results. You have to know your purpose and do your best to reach it."

(Andy)

\section{Academic English}

\section{"Don't beat around the bush!"}

Andy, a Marketing student told me detailed stories about his writing. His expectation was that with his IELTS scores, he could be confident with his English but that was not the reality. In his first months in Wellington, he faced difficulties in participating in oral communications and with academic writing. Early on Andy had two assignments due on the same day and spent too much time on the longer essay (5,000 words) and this left barely half of a day for the 1,500-word-assignment. He was shocked and confused when he received the results: a low grade for the long essay. He was not satisfied with the mark and decided to ask his Kiwi friend's opinion of his assignment. The friend found that his writing repetitious and ramble. He met his course coordinator to discuss his concerns. The lecturer asked him to point out the important points in his writing and to explain how Andy had thought of them. Andy was more than confused when he did not know what the main points were though he had stated many sub-themes. The lecturer then listed Andy's weak points and asked him to try to improve if he wanted to get higher grades when writing similar assignments. Andy used the same expression of a participant in a study by Arkoudis and Tran (2007) "Don't beat around the bush" after he met the lecturer.

The problems that challenged Andy related to language and academic writing. The first thing was his poor grammar. His syntax and tenses were not good enough for standard writing and weak skills of building an argument. He introduced many subthemes without 
thesis sentences and relevant evidences to support his arguments. The lecturer pointed out that, he made the mistake of stating issues and then leaving them without critically discussing. After that, the lecturer advised Andy to improve his critical thinking skills as these were vital to improving his writing skills.

He said I made a lot of grammar mistakes, used inappropriate words and phrases. He pointed at some paragraphs and asked me what I was discussing and asked me to find the thesis sentences of each paragraph, I failed. Moreover, he also figured out some repetitions what made my writing as a mess with similar passages and lack of evidences which could prove my arguments. He said I should focus on some main themes then discuss, argue and develop, don't beat around the bush. Sometimes, the readers could not see what I was discussing in a long paragraph.

\section{“Deeper or broader?"}

T had a similar experience to Andy and he talked about critical thinking skills. He was sure that his English grammar was standard and that so did his lecturers and tutors because he received very few comments on mistakes in grammar. According to him, he struggled with his reading comprehension and with developing ideas in writing. He said that it was hard to criticize another's work because this is not often done in Vietnam. Criticism had been something very negative for him. Then he learnt that, criticism was not "criticize" but "compliment" then it meant to find both strong and weak points in any work.

But it is not easy as said to find strengths and weakness when reading something. The question is how you know this is strong or weak; I mean how you prove your critiques. My lecturers and tutors also advised me to think deeper, read between the lines. It was very philosophical. Even, I was wondering "deeper or broader", it is frustrating.

T struggled with ordering his ideas in writing with repetitions, or missing important ideas. After one trimester, $\mathrm{T}$ concluded that structure of writing was a very important element which madehis writing smooth. The lecturers looked for what the students were going to write and how they developed what they planned from beginning of writing. If students knew how to organize their writing then it would be easier to find information to build up their structure. 


\section{"Appropriate or inappropriate?"}

Tom moved to VUW after finishing his first year courses (level 100) and EPP course at VUW in Vietnam. So he had some experience with using English for academic language. He said that writing a long essay was not only a struggle for international students but also for domestic students. The challenges he faced originated from the differences between oral and academic English. English was a contextual language and he used words or expressions in the wrong contexts.

I knew what I wanted to write but the problem was, sometimes, I use inappropriate words. I used words in wrong contexts so my writing looked like it was transforming spoken talk into a written form. The marker's feedback was about how I presented my ideas, and sometimes about my grammar.

\section{"Do not take notes on everything said by the lecturer"}

The participants mentioned note taking was other English language related issue in their academic life. The notes were to self-study of the students as David affirmed. However, note taking was really challenging for these international students.

Hoang, a management student was often required to write long essays, and notes are needed to revise lectures. These notes could help in knowing what needed to be enlarged with more information so that the student could extra search. However, how to take good notes was definitely a difficult challenge. Hoang recognized that, because of her poor listening skills she could not get the main points of the lectures. She did not know what was important to capture. She was not sure what the lecturer was saying so her notes were very poor.

Because of my poor English, I could not take notes often. I heard and guessed what the lecturer was talking about but my spelling was not good either, so that I wrote down wrong words, then, these words did not make any sense. In some lectures, I tried to listen carefully to understand then had no time to take any notes. I tried to recall after the lectures but it did not help very much.

Tom said that for two thirds of the first trimester, his note books were filled with words, phrases and questions because he wrote down everything he caught during lectures and tutorials. He could not use those notes in writing assignments or revising for tests. There 
was a negative consequence that because he spent most of the lecture time writing, he did not understand clearly what the lecturer was emphasizing. After that, he learnt that, the test questions were similar to the examples given by the lecturers and tutors. The important information was explained carefully within or outside of the lecture slides. He changed his approach and he achieved some positive results.

After that, [...] I just took notes on those examples, questions raised by lecturers/tutors and things I was not sure because I needed to search and read more.

(Tom)

$\mathrm{T}$ found that though he was not overly dependent on his notes, rather he only wrote down what he thought to be important or difficult. He first paid attention to understanding the lectures, then, if some points were not clear, he would take some notes. "If you want to take a good note, never write down everything you hear in the lecture," he said.

Hai and David did finance and accounting so that their notes were numbers, calculation formulas and sometimes extra explanations of these formulas. They specially took notes to revise at home those issues that they were unclear or unsure about.

\section{"I read the text book at least twice."}

Reading the textbook before classes was challenging to the participants. Sometimes they had to read more than two chapters to prepare for the following lecture. It took a lot of time and sometimes they had to search for further information from internet to understand the content but sometimes they could not understand at all.

I had to read a chapter twice even three times to make the content clear but it did not always help because sometimes after reading many times I could not understand. That was why when domestic students around me going out or relaxing I had to spend time in the room reading.

(Hai)

T also shared that he spent much of time on reading course materials and sometimes he had to read again and again a paragraph to make sure that he understood. 
Sometimes with important paragraphs or definition I had to read and reread many times to understand. If I could not, I would search for further information on the internet (using google search) to make it clear.

With the assignments or assessment instructions, the participants also had to read more than twice to understand what the lecturers wanted them to do. The participants had different additional strategies besides reading until they understood. "When after reading but I could not make it clear, I came to ask tutors or lecturers about that" (T said).

\section{Class participation}

Language very much affected the class participation of these international students. These six participants' personal stories illustrated their level of participation in both big lectures and in tutorial groups.

David was the participant who understands most of the lectures but in these lectures, he rarely participated in classroom activities such as answering questions, stating his concerns or asking a lecturer for an explanation. He gave all his attention to the lecture slides in order to gather valuable information but he had no ideas to share. In his experience, Asian students always kept silent in the lectures and it was just domestic students who actively answered the questions or requested further explanations. When I asked why that was he replied "because I am a little bit shy." In a big lecture theatre, he was afraid of speaking out, he was afraid of making mistakes. Andy felt similarly, and he wondered when he talked about something whether or not the lecturer and students could understand him so he chose to be quiet.

I was afraid of no one could understand me; they might laugh at my ideas. Another reason was that my accent was very different; pronunciation was not good enough to explain what I wanted to say so I did not participate in answering or asking questions during the lectures.

David was very quiet in his lectures, but more active in tutorials. He found it easier to speak within a small group. In his favorite tutorials, he participated in all the group activities such as discussions, arguing and presenting his own ideas. Sometime he felt shy but he tried to break it. 
In my favorite tutorials, I actively participated in discussing within my group and with tutor. In a small classroom with fewer students, it seemed that I was not very scared of talking out to share my opinion. I saw domestic students were very open so I could argue with them some points.

Hoang and Hai said that, in Vietnam students just kept quiet and they too tried to keep quiet in their classrooms. They brought their traditional learning styles to New Zealand, and this combined with their lack of English fluency hampered participation. In contrast according to Hai, Kiwi students and other English as the first language students were "rapid reactors".

It took a longer time for me and other student like me to think and form our ideas into language (first in Vietnamese then translated into English) in my brain when I was sure enough to talk about it, the Kiwi or other English speaking students had it earlier than me. That was why I did not talk in my lectures.

T explained that lack of participation was because of his laziness. Sometimes he thought he could contribute to the discussion or argument in groups but he was lazy. "I was lazy sometimes, I just listened to others while they were discussing", he revealed.

The six students acknowledged that the degree of their classroom participation depended on whether or not a course was a personal favorite, whether there were supportive lecturers or tutors, the difficulty level of the content, and their own English proficiency level. Hoang was one student who encountered problems from a tutor and from Kiwi group members. In some tutorial and shared tasks with Kiwi students that she had been part of she was very upset when the other group members ignored her.

They did not care that I was in their group. They tried to speak at every point; they used slang, and spoke too fast. That made me think they did not want me to know what they were talking about. I did not know what to do, I was doing nothing. I asked myself why I had been there to face these bad things. I skipped sometime.

Hoang did not have "any turns" in the discussions and she felt excluded. She admitted that, though her English was not good enough, she could understand everything and she had her own opinions that she wanted to share but she could not. It was sad experience. 


\section{CHAPTER SIX: Social Life}

\section{New and international friends}

Tom was very happy because he was arranged to share a hostel room with a student who had arrived earlier. Tom was impressed by his new friend's enthusiasm. This first friend took him around the city to buy household goods and accompanied him during the orientation weeks.

Tom made friends with other international students living in the hostel. He found it easiest to talk with other Asian students from China, Japan, Thailand and other Indochina countries.

I lived in the hostel and there were both Kiwi and international students. I joined a group of Asian students. We chatted at dinner time. We played sports every Tuesday night. We also went out sometimes. We became friends.

Hai was very sociable and participated in all the social activities held in her hostel. She tried to talk about things within an international students' group. She realized that international students were open when they gathered in their group.

I found easy to participate in social activities in the hostel such as playing table soccer, watching movies, going on a picnic and chatting in academic groups. International students were closer to each other than to the Kiwi students. I found it easy to take part in social groups and chat with other international students.

In contrast, $\mathrm{T}$ was a private person and he confessed that he did not like making friends with non-Vietnamese students. He lived with a New Zealand family for some months and his relationship with that host family was good but he had no international friends as in the true meaning of friendship. He found it difficult to set up new relationships especially with people from a different cultural background.

They [Kiwi family] treated me as one of their children. They took care of me and I felt comfortable with them. Then I moved out to share a flat with other Vietnamese students. I 
don't have international friends because I don't want to. I feel it's hard to make friends and be in harmony with people who come from a different culture.

\section{"I was happy when talking with him"}

Andy was one of the participants who had very close international friends although he did not take part in the social activities as in the hostel. He said that it was very interesting to have international friends. His friends were other Southeast Asian students; one shared the apartment with him. Andy found it easier to make friends with Asian students, than with other students.

Kiwi students were not as friendly, as I had thought. I had a [nationality] friend, and we talked a lot. He was friendly and kind. I felt very comfortable to talk with him. We went to the cinema, dined out or played games together. The good thing was a feeling of security when sharing with him some personal affairs. He did not know my Vietnamese friends, he kept secret what I told him then I also did the same to him.

Andy's international friend was helpful and they often helped each other especially with academic and language issues. Andy could practice English with his friend because the friend was bilingual. Sharing Asian cultural roots, they became friends easily.

He helped me with English because he spoke better than me. I could help with academic issues such as preparing for assignments or preparing for tests. He learnt some Vietnamese and I learnt his national language. It was fun.

All the participants found it very hard to make friends with Kiwi students. They would talk sometimes but just like classmates not friends. They talked to Kiwi students in academic contexts such as in lectures, tutorials or group work. Some host students were helpful and co-operative in group works but some were not.

We studied marketing strategies and the lecturers gave examples of New Zealand companies so working in a group with Kiwis was good. My group mates were very helpful and knowledgeable. They shared their understandings with us and explained when we asked them. However, I knew some Kiwi students did not co-operate with Asian students to solve the group tasks. They dominated with their ideas and did not want to work in groups with Asian students. 


\section{There was still a gap}

Hoang was the only one participant who joined the buddy programme ran by university support services. This programme offered by the Institute of Language, Victoria University. First year students can register as a language buddy or as an international buddy. The most important purpose of the program is matching one international student with one domestic student so that the international student can practice English with their buddy. Hoang was matched with a female Kiwi student. That was the first Kiwi with whom she developed a relationship and who she shared her first experiences of Kiwi culture. They met at least once a week to chat about daily matters such as food and drink, transportation people as well as academic issues. Most of the time they talked to help Hoang practice her English. Hoang stated her English was not good and her international buddy helped her whenever they had a chance to meet.

We talked about everything. She encouraged me to talk more and talk slowly to communicate clearly because I spoke badly. She suggested some topics when we chatted. If we were free, we met twice a week.

When Hoang felt more comfortable with her buddy, she asked her to check her written language. Hoang felt more confident to speak in English and happy because there was a person ready to listen to her. This was the main benefit she received from the programme. But, she felt that they were not really close because of cultural differences and Hoang's English. Sometime she felt that the international buddy was just doing a voluntary job, and not wanting to build a friendship.

She was a good listener. Though we talked a lot about ourselves, it seemed that there was a gap between us. I did not know exactly what it was but I thought we were not true friend as its meaning. I thought because I was shy, my English was not good and we came from different cultural background so we were not really close to each other though she was friendly and helpful. 


\section{Circles of Friends}

The participants had enlarged their circle of friends and some were setting up relationships with local students. Though they knew that making friends with Kiwi students could offer good experiences, they paid more attention to their Vietnamese friends.

$\mathrm{T}$ and David were two of the participants who preferred being with Vietnamese friends. They did not make friends with Kiwi students though they regarded most Kiwi students as friendly. David was active in the Vietnamese Students Association in Wellington (VSAW). He joined most of the activities organized by VSAW. He had a group of close friends and they cooked and went out together.

I like to keep a small circle of friends. My friends are all Vietnamese. Most of us used to study in the Twinning and were studying in commerce faculty so we met very often. We could go out or cook together on the weekend. Sometimes we played sports.

Similarly to David, T chose to spend his time with Vietnamese friends. They acknowledged that, they could easily engage in multicultural groups but they did not want to.

I know that Kiwi and many other international students are very friendly. They are good classmates. I respect their friendly behavior but I don't think I will choose them as my close friends because we are basically different. I treat them as my classmates and schoolmates but I never join them out of school.

Although other participants had some Kiwi or international student friends they focused on their close friendships with other Vietnamese students. They felt safe and relaxed with their

friends. Vietnamese friends were a source of support. Tom explained that, he could study with his Vietnamese friends and share private problems.

I had a big circle of Vietnamese friends at Victoria. I had three close friends and we could talk to each other about everything. Besides that, I always joined of a group of friends who did the same major with me to study, we prepared for tests or exams. We met often and played together. 
In contrast, $\mathrm{T}$ and David said they gathered with Vietnamese friends often but never studied at home with their friends. David explained that if some members did not prepare their contribution to the group, it would be very risky.

I did not like group study to prepare for tests or exams. I like studying by myself, to be responsible to myself. I am afraid if - for example one member did not prepare his/her part, the rest would be affected. I could discuss with friends but not studying together.

$\mathrm{T}$ and his flat mate studied together but working on different courses:

My flat mates and I studied together (stayed up late to study) but we did separate things. We talked and ate when felt tired and sleepy but we did not know what each studied which. I do not like two friends working one task together or exchanging exercises or homework.

Hai only shared academic issues such as doing assignments, exchanging materials or discussing tutorial tasks with her international friends. She had her Vietnamese friends for sharing emotional and personal concerns. Though she described her international friendships as good, she only trusted her Vietnamese close friends and chose them to share with when she had personal worries.

I could only share my private stories with my Vietnamese friends. They were also ready to offer practical help. I could not explain things to my international friends because of language difficulties and cultural differences.

\section{She is my secretary}

Andy was one of the most sociable participants who quickly enlarged his circle of friends. He was part of the wider Vietnamese student circle and developed close relationships with two "special sisters". He thought he was lucky to know them. They supported each other in every aspect of life such as academic, language and daily issues. Andy would ask one of his "sisters" to check his writing as well as his English speaking skills.

I finished one assignment and submitted then started the next one when it was due within 8 hours. I could not finish the second one with minimum word counts and I had to ask my sister to read my writing. Then she advised me which needed more information, evidence or discussion. She also checked grammar for me before I submitted. 
They were close and he could share his thinking with her. Andy felt confident when she helped him with language issues. He said that he could not correct his English errors (grammar, spelling, pronunciation) himself. He needed someone to point out what his mistakes were and how to use English correctly. He stated that his sister's English was very good. She commented both on academic and oral language.

His other "sister" was not only available whenever he needed help but she also assisted him to set up his academic schedule. They enrolled and registered in the same courses and tutorials. She had discussed and made suggestion about the selection of courses and they studied together. She reminded him of important dates such as when assignments were due, tests, or tutorial tasks. They always prepared for tests and exams together.

She was very kind to me. She also set up an academic plan for the trimester that we follow together. She was like my "special secretary" who kept my study timetable, sometimes she pushed me to work.

\section{Yo-yo relationship with Kiwi students}

Though the relationships between participants and Kiwi students were not true friendships, they brought them many interesting experiences. They set up their relations in academic contexts such as in tutorials. Working in groups with Kiwis helped them to learn about Kiwi learning styles, culture and language.

\section{"They were co-operative students"}

Hai was impressed with the work styles of Kiwi students who worked with her in tutorial groups. She preferred to work with Kiwi students rather than just with Vietnamese students or Asian students. Hai always chose group mates who were Kiwi because they were disciplined and responsible students who were always on time. Kiwi students reacted rapidly to issues so that they could complete their projects in good time. It was very different from working in a group of all Vietnamese. Besides that, the Kiwi members could explain things related to the New Zealand economy.

They [Kiwi students] were disciplined and good contributors to the group tasks. They shared their experiences and understanding about the New Zealand economy, accounting 
system and many other practical issues. They also helped me learn about Kiwi youth learning styles such as they did not depend too much on textbooks but searching on the internet or learning from others.

Like Hai, Tom was fascinated with the many experiences with kiwi companies that the Kiwi students who brought to their group tasks. Tom wanted to join groups with Kiwi students. He tried to invite Kiwi students to join his group. He felt that Kiwi students were not open to international students but most were helpful in academic contexts. Kiwi students helped with learning about New Zealand customer behavior. Tom felt all members had been treated equally in his groups. Kiwi student's writing because they needed to check each member's contribution which would affect the group's results.

I liked working with Kiwis in tutorials because I could learn from them about academic writing, and expressing my ideas. They supported me with language issues and I could ask them about cultural aspects that affect their business behavior. They also talked about lifestyles of Kiwi people when they talked about practical issues in doing assignments.

\section{They are more critical than me}

Andy asked his Kiwi classmates about academic writing. His difficulty was that how to write arguments, and one of his Kiwi classmates explained the weakness in his writing.

One of my Kiwi classmate said that my writings lacked critical argument. He advised me not to select every theme in the textbook to present in my writing to, just selected some, discussed deeply and evidence to support my argument.

Andy found Kiwi students did not buy textbooks. They read online, searched and downloaded key chapters and read. This was different from him and his friends; they tried to buy the text books and needed time to read them. Taking notes, searching on the internet and discussing with others were their learning strategies. Andy's Kiwi classmate shared his strategies for writing assignments and for presenting.

He said he just spent four days before deadline to do assignment (about 2-3,000 words): one day for reading, two days for writing and one day for checking and editing. To prepare for a presentation, he outlined the main content, built up the outline with detailed information and developed a power point and checked. He did not practice too much but 
he advised me to do some practice before presenting in class because I needed to speak fluent English.

Though they were real friends and did not meet outside of classes but some Kiwi students were ready to talk about academic issues and shared their experiences with Andy. A few students sent articles to Andy for extra reading. But, their conversations were limited to the academic context.

\section{Outside of school relationship}

\section{"Working there was very harsh!"}

T had been far away from his parents at a young age and was very independent. He found a part-time job to support his personal expenses. He was in charge to be filling shelves in a supermarket. At first, he thought it was the simplest job in the world but after two weeks he found that it was very stressful. It did not require many skills but it required a person to be meticulous. He tried to work hard and learn from the senior staff in his department but it was not easy.

I knew I had to perform well to satisfy the person who helped me to be employed and to keep my job. I tried a lot and did everything but I was under high pressure all the time. The boss was very tricky and often pushed the staff though everything looked good. He wanted everyone to keep working every minute and second.

At the end of each work day $T$ felt tired and stressed. The staff need to hurry otherwise they would be criticized for not working hard enough. He remembered a year earlier when he was with his parents; he had no worry. Then in new country, he had to do everything himself and had no one to support him when he was depressed. He thought he needed to be "stronger". He talked to his friends who were international students in other countries and they shared everything.

I had friends who were studying in other countries to share my all troubles. After that I thought, study abroad was not a very big thing like I used to think-super big thing even I could change the world. I decided to be stronger and kept trying. 
Though that job was not as easy as he had expected, it brought him good experiences. He had chances to talk with customers and to practice his English and learn about shopping behaviors. It helped him be more open-minded to unfamiliar people; he could talk with them about different topics. The job did not only have negative effects on T's feeling but also brought some positive experiences. The biggest benefit he experienced was learning how to work in a high pressure workplace, something that would be very important in the field of economics.

My English has improved very much. I felt more confident when talking with others. I also learnt to control my emotions at work. At the work place productivity was important, and as they paid money they had the right to require me and other staff to work harder and harder. Nothing was easy; I had to try a lot.

Like T, David found a job after two months in Wellington where the boss was a Cambodian-New Zealander. He was lucky because he had his friend's help. He started the job eagerly because he thought he should try to satisfy the boss but he failed. The boss was too greedy and paid his employees very little but required them to do overtime every day. He felt tired then he decided to stop.

He was greedy; it was cruel to ask employees to work least 30 minutes after our shift finished but the salary was very low. Not only me but other staff were exploited. I had a very bad impression of him. I stopped after some months.

David also acknowledged that, in a competitive business environment, getting a job was not easy but he could not continue working because he could not balance his time. Though working there for a short time, he noticed some good things he had undergone such as language improvement, the true value of money so that he learnt to highly appreciate the money earned by working very hard.

\section{"Working was relaxing."}

Andy was working hard and his boss sometimes pushed but he did not feel stressed. He thought working brought him more positive experiences than negative ones. Whenever he went to work, he did not think about his study and tried to work hard. He came to talk with the other staff members and the customers. When they learned he was Vietnamese, many 
customers expressed their love of Vietnam. He would talk and joke with many people and felt that helped him relax.

I considered that was relaxing time. I knew that, we wanted to get salary, the boss had to pay money to employ us, so he pushed us and that was understandable. I had to react quickly to customers' orders, and run sometimes; it was good for my health. I was very happy with what I was doing.

At his place of work, people were friendly and helpful. They assisted each other to finish their jobs. His English was better after four months working there. He earned some money for travelling around New Zealand and for his own expenses. Besides that, he learnt Kiwi slang, sped up and spoke more clearly when chatting with customers.

The staff at my place of work were co-operative. The seniors guided the novices and I learnt a lot about how to do my job well. I also learnt many new English words, Kiwi slang and idioms. I could answer the phone, and take the customers' orders. I am very happy about that. I think my progress is going well, that is what I want. 


\section{Chapter Seven: Three "Big" Stories of Participants}

After representing the participants stories of their experiences in four big themes (Chapter Five, Six and Seven); I then reanalyzed the interview summaries and the stories I has presented to look for whether there bigger stories of adjustment underpinning the fragments, episodes and stories told by the participants and storied by me.

I identified three underlying storylines that ran across the participants narratives of the adjustment experiences. I saw these storylines as being "Belonging”, "Becoming” and "Unbelonging", which I then used to reshape the participants' narratives but in ways that were close to how the participant lived their story. Within each of the big stories I show that there are different meanings and the meanings were based on what the participants wanted to express.

In the storyline of "Becoming" the participants feel themselves as having changed in some way. They may feel that they have become more independent, to have become Westernised, or becoming more open and interested in exploring New Zealand or the world, or maybe becoming acclimated or adapted to their new context.

In the storyline of "Belonging" - the participants position themselves in relation to context and to community. Their stories illustrate belonging - belonging in Vietnam, or being included and belonging in New Zealand, or belonging to the world as an explorer. Some saw themselves as belonging to the Vietnamese student community in Wellington, others to a community of international students. Tom's stories illustrate these types of "belonging".

"Belonging " has a counter narrative of "Unbelonging", which is different to not feeling welcome, it is a clear sense of not belonging in New Zealand, that this new context is not home nor do some students want it to be. In their stories they position themselves as here for as short a time as possible and of disinterest in building relationships or becoming involved in the local culture. "Unbelonging" is knowing that you do not belong and not wanting to belong because you belong in Vietnam. 


\section{Stories of "Belonging"}

Similar to others Tom experienced difficulties and challenges in studying and living in Wellington but in his interviews he focused on the excitement, and the advantages. The challenges from language, the different culture and academic context did not discourage him from enjoying his life in Wellington.

Tom positioned himself as an open and friendly person and he made friends with many international students and shared many experiences with them. An international student was the first person who helped him when he came to New Zealand. His international friends and they treated each other as a family, he said:

I joined a big group of international students, learnt their language, played sports and chatted when I felt bored and stressed. We always organize outdoor activities so we can understand each other and become close. One friend in the international student group was sick; so we bought fruit, food and flowers to visit and encourage him to recover soon. We are like a family.

Moving from feeling stressed and worried about the results of his study, Tom became a confident student with many new academic skills. In his experience, New Zealanders are friendly, environment fresh, and the society safe and fair. Public services and transportation were convenient, and all these things made him feel comfortable to live in New Zealand. He even liked Kiwi food and weather. Tom felt happy and included in New Zealand.

I can say that my life in Wellington is pretty good up to now, not easy but not very challenging. It has brought to me many new experiences which I could have never had if I studied in Vietnam. It is precious to me when I have new chances to develop my skills in learning, behaving and working in a dynamic and competitive market.

\section{Stories of "Becoming"}

Three participants, Andy, Hai and Hoang told stories of their transitions I reshaped their stories around the storyline of "becoming". The three told different stories in their interviews but their stories had in common the ways they became accustomed to the new environment and changed their perspectives on New Zealand and themselves. Their 
common story was that of first being in shock at the new environment, and not knowing what to do. With time this changed to the environment being more familiar, and the students' feeling a greater sense of 'becoming' an independent student and becoming to feel more positive about New Zealand and living here.

In his first weeks Andy thought Wellington was "terribly boring" even more boring than his home town. Hoang and Hai shared the same thoughts from their first weeks in New Zealand and they quickly found it was good environment.

Andy found that as his language improved he caught up with the learning process quickly.

I see that I am "Westernizing". The biggest barrier was language that was solved and I now know how to learn well. Better language was the great progress that I made which really helped me become more confident to communicate, and my studying life is easier.

If in the first lectures, Kiwi students ignored him, after one trimester, Andy had had many Kiwi students share study strategies such as how to write an assignment, how to develop standard academic writing or what to do to prepare for an oral presentation.

Andy overcame his view that Wellington was cold and boring and become a person who liked travelling. He found that the landscapes in New Zealand were magnificent. Andy positioned himself as a "traveler", someone who wanted to travel, and that New Zealand was attractive stop-over in his journey. Though he found that New Zealand to be a good place it was not his final destination. He had begun to love the country but it was not his "promising land".

I am a traveler and am finding the new environment good to experience new things. New Zealand is as beautiful as in many movies I have ever seen, that were why I have come to love it. I am not feeling too strange, and it is not difficult to live here. My advice for students who are going to study here is that go out, do everything yourself, be social and open, relaxed, don't be too ambitious and do be optimistic.

Hoang came to New Zealand to study without the pressure of expectations for high academic achievement. Her family encouraged her to find a balance between studying and relaxing; they wanted her to just pass the exams and to experience a new life in a different 
country. Though the initial difficulties challenged her and were similar to those of the other participants such as language deficiency, the changing weather, a different education system and the Western learning context, she felt "pretty fine".

I think that my studying process is going well; everything is fine though there are some difficulties but I am getting well with everything. I did not find things too challenging and did not have to struggle too much. I have learnt and know many new and good things in New Zealand. It will be very meaningful period of my life.

Hoang was depressed by her English speaking skills but she had improved a lot. After trimester one struggling to work out effective learning strategies, she had learnt from her classmates, lecturers' and tutors' feedback. She was interested that, New Zealand society encouraged their youth to develop their social skills together with achieving academic success. She liked the way a secondary graduate did not have to choose to study in a university but could travel and work to earn their living. She wanted to experience that.

Hoang was a private person with few close friends but she had her own ways of relaxing and adapting to the Wellington life style. Instead of joining a big group of friends to share feelings and experiences of cultural differences, Hoang wanted to keep to herself and observe other people [the ways they act, treat, behave and solve problem in daily life]. She positioned herself as an "ideal city seeker" and she had found that Wellington attracted her more and more.

I must say that I am seeking a good city for me to live. I am seeking a place where I belong to, that is where I can live and enjoy my life. This study journey is also an ideal city seeking journey. Up to now, I know that it is not completely ideal place for me but I begin to love it and hopefully I will find more good things.

Hai described herself as "shocked" during the first few weeks of experiencing the new environment; shocked at the short lectures, the teaching strategies, and speed of the spoken language, and with the cultural shock.

I used to have a feeling of cultural shock but it has not happened in a long period. After some weeks I felt better and step by step adapted to New Zealand culture. Moreover, I got 
some benefits from sharing with Kiwi students such as how to refuse something (an invitation or suggestion), defending my opinion, being sociable and so on.

At first the different academic environment challenged Hai. But after some weeks, she found that the Western academic environment had some benefits. The biggest advantage she took from the experience was "self-study" that is learning to be a self-regulated learner, learning before, after classes and constantly "self-studying" that helped her to become an independent learner.

I realized that self-study was very important for every student. I felt more confident and lucky that I was familiar with the academic environment here. I could reach my aim and continue doing well. Mid-term and mid-year breaks were wonderful time for me to relax, socialize and learn new things from Kiwi culture. I adapted very quickly.

Hai was a hardworking young student; her study took up most of her time and energy. She positioned herself as a "victim" of her own academic ambition. In the peaceful and quiet city of Wellington, many times she felt bored, lonely and sad. She has changed her opinion of life just studying was priority important but relaxing with friends is important too. Hai was also an optimistic person who always thought and saw to the positive side whenever she had a problem.

I could say that New Zealand was a fair and safe country. I was lucky when studying here. My living experience has been improved very much. Sometimes I felt stressed with assignments, tests and exams but I tried to be successful and there were chances for me. I found that everything was under my control and was getting better.

Hai applied for a part time job to earn her living expenses as well as working experiences. She came alive after she joined programme offered by the International Office which were social activities for both international and domestic students and created opportunities for international students to intercultural change with each other. She also planned to join some volunteer groups and all those activities helped her practice her English, enrich her cultural competence which were really important for a successful academic achievement.

Victoria International office was a good place for sharing my experiences and practicing English. I met a lot of people, exchanged academic both academic and social experiences. 
I felt more dynamic and active when taking part in those kinds of activities and voluntary events. It made my life here more meaningful and the study less stressful. I also wanted to take advantage of exchange programs of Victoria University to experience in another different country and academic environment.

\section{Stories of "Unbelonging"}

David and T were two participants who were very confident of their English, from very beginning of the study journey. David positioned himself as "an adaptable person" who had easily adapted to his new environment but he was clear that "I don't belong to this place". He saw his future in Vietnam.

I liked the natural environment in Wellington; it was fresh, clean and beautiful. In general, Kiwi students and people are very friendly and helpful but it is very difficult to make friends with them. In my own experiences, there were many cultural differences between the two countries that created big gaps between the host students and international students like me. I could easily recognize the differences but I did not try to minimize the gaps because I did not think it was very important to me. I will return home right after I graduate.

David did not want to build social relationships with Kiwi students because the relationships would end soon after the courses. I knew that [New Zealand] was a good place for living and studying, I tried a lot to adapt and enjoy my time but I still felt I don't belong to this place. The lack of relationships with local students did not affect his life in Wellington.

He spent all his time and energy on study in order to shorten his time in Wellington as much as possible. He missed his family, friends and noisy city in home country.

I missed everything- that was mine since I was born; my family, friends, noises of the neighborhood, food, traditions and customs. I chose to do four papers per trimester instead of three in order to finish my study soon so that I can save money and time. Furthermore, I want to graduate soon, get a job and earn money to take care of my parents. I need to go back to Vietnam. 
David's initial difficulties did not affect his academic life much because he had his own opinion that "For me, the knowledge I gained was more important than the grades I received". He did not force himself to learn about every difference in Kiwi culture so that he did not feel stressed. After one trimester, he used only one word to describe his life in Wellington and that was "boring". He had some happy moments with friends or when finishing a paper but that was not enough to cheer him up without family and friends.

$\mathrm{T}$ has not been in the Twinning programme and was the youngest participant.He thought Kiwi and other international students were friendly and helpful; and they were supportive in group work. But outside of class, he did not join them. His friends were Vietnamese. He positioned himself as "not an adaptable person".

I never participated in international students groups or activities which shared by the Kiwi. I did not want to and I had a feeling that I could not adapt to their group. I could not easily join their activities because I don't like their habits, customs or lifestyles. I only talked to Kiwi students at school and when we worked together to finish academic tasks. I saw the huge cultural differences between us.

$\mathrm{T}$ said he felt very uncomfortable living in New Zealand and could not adjust to Kiwi society. He could not find his support sources around him and felt lonely most of the time. The Kiwi life style was very different for him:

I did not like the very quiet atmosphere in the evening and at night. Every shop was closed at 4.00 or $5.00 \mathrm{pm}$. The streets were nearly empty after $9.00 \mathrm{pm}$ on weekdays. There were no public activities at night, just some bars but the students do not have enough money to enter those places. I did not know what to do and how to relax except by gathering with some Vietnamese students but they were also busy.

T said that, before coming to New Zealand, he had prepared himself for facing loneliness, language challenging, different academic environment and cultural gaps but he still felt the "short fall". He did not have to worry about financial issues, his studying was going well, he had income from part-time job but he did not think he belongs to "this place. Like David he missed much from Vietnam and questioned what he was doing in New Zealand. 
I missed everything in my home town, my family and friends. I missed the noisy mornings and crowded streets at the rush hours. In Wellington, I could study what I wanted; I enjoyed my freedom but many times I was awake in the mornings and I asked myself "why am I here?" it was one of the worst feelings of staying in New Zealand. 


\section{CHAPTER EIGHT: Discussion and Conclusion}

\section{Discussion}

In this chapter I present and discuss the findings. I begin with a summary of my findings, and then I discuss the findings in relation to each of my research questions.

I have tried my best to reflect the authentic and colourful stories of six Vietnamese international students who were studying at VUW in an undergraduate program. The students shared me many interesting stories of their adjustment experiences These stories conveyed the initial challenges faced when they first came to New Zealand and set up their new life. The challenges came from academic life and social life, with problems arising from language difficulties and cultural differences. English language proficiency affected their academic adjustment in multiple ways including being able to think critically about course content and texts, writing reports and essays and also in participating in class discussions which required social skills such as communication skills, relationship building and problem solving skills.

Their cultural background and prior educational experiences contributed to a mismatch between their expectations of their courses and staff and the expectations of academic staff. Some participants felt isolated, or not welcome at particular times and contexts. The participants prioritized academic life because, achievement was more important than making friends. The participants applied different strategies to cope with their difficulties. The most common source of support was family and friends. These participants knew about the support services but they rarely used them.

I identified three overarching stories to the participants narratives, which I restored as "Stories of belonging"; "Stories of unbelonging', and "Stories of becoming". These stories were retold based on how the participants positioned themselves in relation to their new context or were positioned by the others such as staff, or classmates. 


\section{Stories of adjustment}

In their stories the participants talked about their first feelings of coming to New Zealand, their struggles, joys and new experiences.

Starting their journey with the feeling that Wellington was a boring and "nothing special" city of their first days the students could see the advantage of living in this place. It was quiet, fresh, peaceful and beautiful. Walking around they saw Kiwi people who were friendly and helpful.

After seven months, Tom had moved from feeling stressed with the academic environment to becoming confident with many academic skill such as note taking and writing. After an initial feeling of being "terribly bored" and "homesick", Tom felt his life in New Zealand was more comfortable and his study was "not very challenging". He especially liked Kiwi

food and Wellington weather. He said "I am very happy to be here". He renegotiated who he was and said "I am an explorer" and he was having a "good explorative trip" which brought new knowledge about the nature and society in New Zealand. Tom's stories were similar with some students in Holmes (2004) where they said they love the country New Zealand.

The greatest changes for the participants were in their academic life, language and communication. They were adapting to the academic demands such as academic writing disciplines and becoming more independent learners who could ask the lecturers about course issues. They confirmed that their English was better than the day they came especially their listening and speaking skills. They were familiar with Kiwi accents and confidently communicated with non-Vietnamese people.

\section{Students experience their academic life, language and communication issues and social interaction in New Zealand}

In order to answers for this question How do these students experience their academic life, language and communication issues and social interaction in new Zealand, I represented their stories around four big themes which were in chapter five, six and seven. The participants talked about the challenges in their academic life. Their language and 
communication skills affected their academic and social life. That finding was in line with many previous studies such as in Do (2006), Lee (2007), Townsend and Poh (2008) or Zhang and Mi (2009).

Most participants did not take part in class discussions because of a lack of confidence in their use of English language. David said that this was because "I am a little bit shy" and he was afraid of "making mistakes" when he talking in front of many people. Previous research has indicated that international students may feel anxious in speaking in class because of a perceived lack of English proficiency, and this means they do not participate fully in class learning activities (Do, 2006; Lee, 2007). My participants referred to Asian students not giving their opinions or asking questions. Here they were positioning themselves as Asian students, not as Vietnamese students, and as different to the Kiwi students. Asian students were different from the other students. From my own experience and the students stories there is an awareness of the difficulty of moving from an educational culture in which it is not acceptable to question those in authority, to one in which students are expected to question lecturers.

The participants had difficulties with understanding the lecturers' instructions, course materials and assessment requirements. "I had to read a chapter twice or even three times to make the content clear but it did not always help because sometimes after reading many times I could not understand. That was why when domestic students around me going out or relaxing I had to spend time in the room reading”. Hai's story was in the line with findings in the study done in 2008 by Townsend and Poh which explored the difficulties that international students encountered in a regional area of Australia.

The participants found writing a challenge especially writing an argument. The students received feedback suggesting that a of lack critical thinking in their writing led to many mistakes such as repetition, a lack of thesis sentences and of relevant evidence when they argued something. Andy's advice for other Vietnamese students was "Don't beat around the bush", and to avoid repetition and grammar mistakes and in order to make a clear and strong argument. The students' stories are in keeping with previous research findings on Asian international students writing in a Western academic context (e.g., .Arkoudis and Tran, 2007(). There is a danger that in discussing Asian students and the issue of critical 
thinking in academic writing that this ends up as an inference that most Asian students lack critical thinking skills. In the stories of these Vietnamese students they are struggling with the combination of the language demands of their courses alongside encountering radically different writing tasks. They desperately try to work out what is expected in academic writing.

$\mathrm{T}$ made the point that Vietnamese do not criticize the works or others in schools, in Vietnamese culture, criticism is something "negative”. T was confused when asked to evaluate the "weakness" and "strengths" when reading. A typical mistake made by the participants was not providing evidence to support their arguments and their critiques. They were learning a new way of writing, and about different expectations of what a good student should do. Holmes, (2004) study of Chinese students in a New Zealand university had similar findings.

English language proficiency affected setting up relationships with domestic students. The participants did not feel confident in talking with Kiwi students and admitted that making friends with the Kiwi classmates was not easy, something that found in other studies of the international student experience (e.g., Ward \& Kennedy, 1993). Being able to form friendships with domestic students has been identified as one of the predictors of successful adjustment (Cross, 1995). Earlier I shared the story of Hoang whose international language buddy was a Kiwi female student. They were 'buddies" in the programme, but when the Kiwi student moved away their connection ended.

Although the participants had found local students to be friendly and helpful they struggled with making friends except $T$ and David two students who did not want to do so; they were only interested in friendships with Vietnamese students because they found too many differences with domestic students. Their stories provide insights into why the international students may limit their relationships to their own cultural or ethnic groups. The participants gained experience of domestic students as being friendly and helpful differs from some international research. For instance, Mori (2000) found international students with limited English skills who were unfamiliar with the education system in the United States faced challenges in gaining the respect and trust of their American classmates. However, in my study, the participants reported that while their Kiwi peers were not active 
in initiating communication with international students when approached by international students they were good classmates. In their narratives Kiwi classmates welcomed their contribution to group discussions or work. This differs Hsieh (2007) study in which American classmates negatively evaluated and did not accept Chinese participant.

In the participants' stories they positioned themselves, and saw themselves as being seen by their friends and lecturers as hardworking, well-disciplined and highly motivated students in class. That was also very positive comments of the lecturers on their Asian students in Kingston and Forland (2008) study. Hoang described how the class had a task, Asian students usually started first and they worked really hard on it. Sometimes they had to actively remind the Kiwi students to gather to start the group work.

\section{The problems and benefits they experience at VUW}

The most common problems the participants talked about were language issues, and these impacted on their adjustment and that Wellington was boring. These have been discussed previously in this chapter. Besides the participants experienced other problems or negative experiences.

The participants" friends and families were far away from them and they felt homesick. These findings are in a line with the previous study (Hechanova- Alampay et al., 2002 cited by Andrade, 2006). When they found their study stressful they often felt homesick.

The participants were affected by the changes of the educational system, assessment forms, diverse English accents, learning styles and classroom discourse and these findings confirmed the previous studies such as Arkoudis and Tran (2007); Kingston and Forland (2008); Lee (2007) or Tait (2010). For their first week they even felt "shocked" when did not understand what the lecturers said because of "different" accents. Their expectation of the lectures were not satisfied that one-hour lectures and the lecturers explained briefly the core content of the lectures. The participants realized that they had to self study too much, before and after the classes. Many times they struggled with how to study to master the knowledge and meet the course demands. 
Surprisingly, the participants stated that they did not have any financial difficulties while they were in Wellington. They said that their parents supported enough and they were learning to spend money effectively. It was contrary to the findings of Do (2006) where the Vietnamese students complained very much about their financial problems in the US.

Besides their struggles, the participants experienced benefits from their study journey. One of the biggest benefits was "maturing" or "growing up". These young students confidently acknowledged that after one trimester studying and living away from home they had grown up. They had learnt to manage their time, money and plan their study. As well, the students were aware of learning to control their feelings and how to behave with friends and people in a new setting. For example Hai said "I am growing up, I know how to behave in different relationships and I am not childlike". Though all the participants of my study talked about their maturity but it is not plausible to suggest that every international student makes progress with psychological maturity.

Not only had the students left Vietnam, but they were living independently for the first time. The independent life brought them positive benefits including that they could make their own decisions of how to live and how to study. All the participants talked about how they had learnt to live independently. Without their parents' care, they had learnt to take care of themselves. At the same time they knew that study cost a lot of money, and they had become more aware that their parents had had to work very hard to support their education. David said: I then knew how hard my parents had to work to support my sister and I; I love them very much". The participants experienced a number of academic stressors such as what they referred to as "too much self-study too", assignment deadlines, workload, as well as participation in group work and tutorials. In contrast to their prior educational experiences in Vietnam, the students were expected to work independently a great of the time, and they struggled with this and referred to it as "self-study'. At times the students felt they did not know what they should be doing. In their stories it sometimes seemed as if they felt this unfair. Hai had questioned why she had paid thousands of dollars to "self study". Despite complaining that they sometimes felt very tired all admitted they were becoming independent learners. 
By the second interviews it appeared that as the students became familiar with the local teaching styles and course demands, they realised that they had to actively study outside of the class and needed to set up a study plan for themselves. The new educational environment required them to be more flexible, independent and practical than was expected in Vietnam.

Previous research has focused on the general benefits that international students gain from host countries such as their academic credentials and international certificates or language skills (Butcher \&McGrath, 2004). In this study, the participants focused on the "practical benefits" which were meaningful to them and they saw clearly changes in their life.

\section{Coping with their problems}

Coping strategies were explored in many studies (e.g., Beaver \& Tuck, 1998; Choi, 2006 and McClure, 2007) and these international students applied various strategies in their adjustment process. In order to investigate the six participants' coping strategies, I asked the participants to tell me about their experiences, in their stories they told me some difficulties and then I encouraged them to remember how they overcame these. The participants provided a variety of coping strategies.

The most common strategy was to search further information and self study using "google search". They searched for extra readings, definitions of key terms, example of exercises or journal articles. They used "wikipedia" search tools to find what they wanted. Tom said "I can search on Wikipedia for the Vietnamese translation version of the documents (definitions, explanations of terms or phenomena and so on) that help me to understand the content quickly”.

The participants believed that "working hard" was a good strategy for them to meet the demands of the program. Hai was one of the six participants who spent most of the day in her studying room after the lectures and tutorials. That finding was consistent with Choi's (2006) and Hellsten (2002) studies. Especially to deal with language issues, the student chose to work hard such as practice listening and speaking everyday and spending hours on reading textbook before lectures. 
Three participants (Andy, David and T) worked part time. The work place created a good environment for practicing English especially listening and speaking skills. They talked with customers and staff; they were familiar with Kiwi accents and it helped in their academic environment. The participants tried to talk with Kiwi and other international students. Hai and Tom joined a group of multicultural students to practice English and learntabout language, customs and traditions. The participants tried to deal with personal problems (homesick, lonely or stressed) themselves. This accounts with previous studies (Choi, 2006; Do, 2006 and McClure, 2007). The participants became more independent in learning (as discussed above). They did not use counselling services because they thought "the counselors may not be able to help me and I could not explain my problem clearly in English" as Hai said.

Furthermore, "extra studying" was important to them. That was consistent with the findings in Beaver and Tuck (1998). Besides that, in order to pass the tests and final exams, the participants chose previous questions to practice again and again so that they could learn the form of the questions, the ways to answered and sometimes they learnt by heart for the short answer questions. These findings once again confirmed the findings in Tait's (2010) study about Chinese students in New Zealand.

\section{Support sources}

In their stories of adjustment experience, the participants talked about their families and Vietnamese friends. They went to close friends to share their feelings of homesickness, loneliness or difficulties in studying. They trusted their friends. They prepared for tests and exams together, cooked together when they missed Vietnamese food, took care of each other when they were sick. If the friends were source of help, their families were big sources of encouragement. These findings were consistent with previous studies (Do, 2006). Their family's support was important to them. Some felt more connected with their families and understood how much their parents' care for. That finding was contrary to the previous study (Holmer, 2004) where the researcher found the students thought their parents did not understand them and denied to discussion with them about their problems. It was different from David and T of this study who did not want to discuss with their parents too much about their problems (except about finance, general information of the courses or 
their Visa problem) because they avoided worrying their parents, they only wanted to "assure mom and dad that I was ok" as T said.

With general issues such as selecting courses, renewing Visa or insurance they seek the support from the Victoria International officers. Though there was available support at VUW and they knew that but the students did not take the advantage of these service. Except David and H, other four students worked with learning support services once or twice then they stopped because of various reasons. These students said because of not having enough time, complicating process, not being effective to them. These findings may extend the findings in Khawaja and Dempsey (2008) which found why international student denied coming to both academic and social support services at the universities.

\section{Conclusion}

\section{Narrative of the study}

This study used narrative inquiry to explore the adjustment experiences of six Vietnamese students who had come to study in New Zealand. The study explored the adjustment experience of these undergraduate students in their five to twelve months of study at Victoria University of Wellington. The participants shared their experience of encountering a new environment with its difficulties and challenges. I have retold their stories of academic life, the benefits they received, and the strategies they used to cope with their challenges and their sources of support in order to create the adjustment story of being international students from Vietnam in New Zealand.

This study was carried out because of the following reasons. Firstly, my personal interest arising from my own experiences as an international student. I wanted to explore how other international students experienced their life at VUW and in Wellington. Secondly, I found there were very few studies looking at the experience of Vietnamese students in New Zealand. I conducted this study in the hope that it would help readers to understand how a group of Vietnamese students experienced studying and living in New Zealand. Five of the six participants were part of the VUW twinning programme and transferred to Wellington from the Ho Chi Minh City Campus. I hope the study will help VUW administrators, lecturers and other staff to understand more about students' lived experience of the 
Twinning program. Moreover, the findings may help academic staff understand what the students should be prepared for before transitioning to VUW Wellington campus.

I chose narrative inquiry as my methodological approach and Positioning Theory as my theoretical framework. I interviewed six participants twice in Vietnamese. I transcribed the interviews then summarized each transcript (in English) and sent the summary to each participant for their feedback. I used thematic analysis to identify common patterns across the students' narratives. Following the thematic analysis I represented the students' narratives first as episodes or stories of the individual student adjustment experience under three big themes (Coming to New Zealand and Beginning to study at VUW, and Academic life and Social life). Then using cross analysis of the participants' episodes and positioning theory helped me to identify and develop three "big stories" which reflected their adjustment process at VUW. The stories were "Belonging", "Becoming" and "Unbelonging”.

The study found that the participants faced challenges in studying in a second language which very much affected their academic and social adjustment. The participants were unfamiliar with academic environment at VUW. The learning and teaching styles were different to their expectations so for some weeks they felt a "short fall" and were "stressed". The participants revealed that they had difficulties with academic writing especially with writing an argument. Making friends with Kiwi students was more difficult than they expected. The main coping strategy of the participants was to trying themselves to deal with their problems. Friends and families were sources of support especially with personal problems such as being home sick, or experiencing loneliness or problems in their relationships with others. The participants were aware of support services provided by VUW but they rarely took advantage of these. That was likely to be because of cultural differences and many other reasons such as time and language barriers.

Narrative inquiry enabled me to gather and explore the detailed stories of the students' experience through interviews. Using open-ended questions, I encouraged the participants to tell their stories in detail. I could come back to their stories to clarify points that could not be done if I used another approach. Each interview was like a storytelling time, with the participants free to talk about what they wanted. By listening to their stories, I could 
understand their experiences of adjusting to a new and different context, and at different points of times and how they were creating their lives in this new context.

\section{Difficulties}

As with most studies, this study had difficulties. The first difficulty was that of time. I had to finish this study within one year (including developing my proposal, gaining ethical approval, recruiting participants, collecting data, analyzing and writing the thesis). Moreover, I had to working around the participants tough study schedules, their part-time employment and their social activities, and this was challenging because I depended on having time to meet with them. Some students had wanted to participate in my study but could not arrange a time to meet. The second difficulty was that of transcribing and translating. Narrative interviewing brought me long and detailed stories. I conducted two interviews with each of participants and in total I recorded between 90 minutes and 150 minutes of storytelling per participant. It took considerable time to transcribe all the interviews into written text. The interviews were in Vietnamese language as were the transcriptions. I translated a summary of each interview, and chose the themes and translated them into English. This was not easy because of the differences between the two languages and cultures. The third difficulty was that of managing research bias. I am an insider in the Vietnamese International student experience. I had to remind myself all the time that I was listening to the participants' stories that I wanted their stories, and that I needed to avoid leading them to tell stories I wanted to hear. I tried a lot to reduce my bias in asking open questions, and in reflecting their stories.

\section{Limitations}

This study was designed as a small scale narrative study and the participants were from one faculty in one university so that while the findings should be thought of as a good source of insights into the adjustment experiences they cannot be generalized to the population of all Vietnamese international students. The six participants were not necessarily representative of other Vietnamese undergraduate students. The participants were doing an undergraduate degree in only Faculty of Commerce and the stories they told me might be different from those of students in other faculties, at other universities and from those of postgraduate 
students. That was why this study cannot claim to provide the full picture of the adjustment experience of Vietnamese international students in New Zealand.

Collecting stories through in-depth interviews was a useful approach with rich data. However, such interviewing has weaknesses. The participants were asked to tell their stories of experiences and when telling stories people may forget things, it is possible that they may make up parts of stories or avoid telling something So while I felt that the participants told their stories in detail I had no way to check if the stories were exactly happened in their life.

\section{Implications}

The findings of this study have implications for Victoria University of Wellington, for both the campuses in Wellington and in Ho Chi Minh City) and for future research. The findings show that the participants had difficulties in adjusting to the academic environment at VUW even though they had done one third of the programme in Vietnam before coming to New Zealand. Their challenges included language and communication issues. When the participants studied at the Ho Chi Minh City campus they mostly studied with Vietnamese lecturers who did not speak English as their first language. The participants were familiar with their Vietnamese lecturers' accents so they were disconcerted by the diverse and different accents of lecturers at the Wellington campus. It may be advantageous to provide more opportunities for students to practice English with first language lecturers from the very beginning of the program in Vietnam. While there may be resource and fee implications, Victoria University could consider options to increase the students' prior exposure to kiwi and other accents such as by sending more lecturers (especially lecturers who teach Basic English) to the Ho Chi Minh City campus to help students before they transfer to New Zealand. The university may prepare good orientation programme that will help new students be familiar with the university environment, regulations and policies. The university may think of providing more practice support services and helping the students to understand about the services and use those services when they have any concerns. 
The study also suggested some ideas for the future research. Future studies could explore the experiences of students studying at different levels of tertiary education, e.g., postgraduate students. Each group of the students faces different difficulties. Future research could focus on the longitudinal process of adjustment. By doing that, it may provide insights into how the stories (and the lives) of the students change as time passes and the students become more familiar with their new environment. Other research could focus on the effectiveness of support services and the reality of using these services for the students at VUW. That suggestion was arose because I found that most of the participants did not use support services at VUW; they either did not know about or did not want to use them. So perhaps both the reasons for this and the provision of culturally appropriate services need to be investigated.

\section{Personal reflection}

Before starting my study I wrote my own narratives of my experiences as a Vietnamese postgraduate student studying in new Zealand and at the moment of finishing the study as I look back at my narratives and see that a lot has changed. My "lived by stories" reflected two storylines that existed in paralled in my life during the time of the research. One storyline was that of being an international student, continued with many new experiences. The other one developing one was that of "a novice researcher".

The research was the second part of my study journey in New Zealand and it has brought to me many valuable experiences. I was very happy to listen to other Vietnamese students' stories. I could share many experiences with them which were lively and meaningful to them. The participants were much younger than me but I thought they were very brave in leaving their families and their home country to study in a different country. Talking with them I learnt that, my difficulties in being an international were "normal" and that other students faced similar difficulties to me. During the time of my field work the Vietnamese Student Association of Wellington organized many activities to gather the Vietnamese students in Wellington. I had the feeling of being in a big family in which all the students could ask after and share with each other things about our study and life. Most of the members of the association were undergraduate students; they were very humorous and 
friendly. I have realized that I shifted from feeling strange and excluded to participating in many activities and belonging to my community.

A new storyline has been formed and exists in my life from the many fragments of experiences from doing this research. The research journey was very interesting and meaningful to me. I started this journey with a "feeling of being lost". Though I had studied a course on methods in educational research, I felt worried about not knowing what I could and would do. That was a very stressful time. I was confused about where to start and I struggled with issues that needed to be clarified in my research such as my methodological approach, what it was that I wanted to explore, what was my theoretical framework. These things made me "crazy" but my supervisor step by step helped me to deal with these struggling moments by providing advice. Every day I tried to write something, at least 10 sentences of what I was thinking and reading about my topic.

I was proud to say "I am doing my thesis research" to people I met in the thesis writing group, workshops, symposium sessions or, at a conference. It cheered me up when people recognized that I was from Vietnam and I had tried a lot to adapt to New Zealand academic environment. Though I was welcome every time I found I was a brand new to the scientific research field and I knew very few things. I tried to share my stories with my friends and other researchers whenever I had chances in order to learn more about their research experiences. Similar to many research students, I was nervous as I waited for the result of the review of my proposal, for ethics approval, my research grant and for the participants' replies. These days made me live through different emotional moments that I will never forget: worried, stressful, frustrating, happy, excited and finally satisfied.

Using narrative inquiry as a methodology of my research, I became more familiar with storytelling skills. Every day, we live with our stories, retell and create new stories that we also live. Developing my understanding of the nature of narrative I found how important stories are to our lives. That was the time I realized people might not recall what their experiences of life was but they could retell every moment of their experiences in the form of story that captured the experience. Furthermore, Positioning theory was a powerful tool that helped me see the valuable positions of myself and other people who shared their 
stories with me. I shifted between the position of an international student, a research student and that of novice researcher during that period.

The Faculty of Education provided me the opportunity to attend the Australian Association of Educational Researchers (AARE) Conference. The five days of the conference brought me many exciting moments which now are still lively in my mind. I had chances to attend sessions and workshops on narrative inquiry research and on international student education topics. I was a research student among many researchers and found that what I had known was very small and I needed to learn more and more. My journey as a researcher and as a gatherer and teller of stories continues.

\section{Final reflection on stories of the adjustment process}

The students left Vietnam and travelled thousand of kilometers hoping for a good education environment and wanting to learn about Kiwi culture and expecting to make friends with local students. They were confident that they were well prepared for this new life. They had learnt (more or less) about life in New Zealand. Those from the Twinning program had chances to study with lecturers from Wellington and to practice with VUW assignments and test/exams. They were familiar with some forms and had had access to the course materials, journal articles and books from the VUW library. Before coming these students were confident they would be able to cope with the English language demands of their courses. They expected living in New Zealand would help develop their English language skills. When the students landed in New Zealand, they realized they had arrived in a new and very different place. Initially, all were surprised that this Western city was so quiet and empty, "nothing special; one side is the sea, the other the mountain." It seemed so boring. Their initial impression of New Zealand was that it was boring.

They expected with their English language preparation that they would be able to understand their lecturers and Kiwi classmates but in those first weeks, most did not understand "anything". There was the challenge of diverse English accents, what one student referred to as Kiwi "uniting" English. The students struggled to understand what to expect from lectures and what was required of them. Lectures were much shorter than expected, and rather than providing all the course content only provided some core points, 
and students were expected to do a lot additional work in order to know and understand a topic. They came from a much more structured educational environment and struggled to work out what was expected of students in this new environment. In the Twining programme each lecture took two hours and lecturers provided clear explanations and gave the students guidance on specific additional sources. Whereas, at Victoria, students had to try by themselves to understand the material through whatever means they could. There was no time to ask lecturers for more explanation; one asked, "Why did I spend thousands of dollars to study all by myself?"

Before the students came, they expected that they could make friends with Kiwi students when they studied at Victoria; it was not easy at all. Kiwi students were friendly but they could not be "true" friends as the students hoped. Some of the students set up a good relationship with Kiwi students but some did not, they just thought the Kiwi students were simply their classmates. They found it easier to make friends with other international students from other Asian countries. The students had prepared for the differences between two cultures and when they lived in New Zealand, they realized there were cultural gaps but the students were not affected too much because they were open to learn new things. They still had good experiences of living in a different culture. They found that they were adapting to New Zealand culture: some daily customs and habits. They felt safe and security to live in Wellington where people were friendly and helpful.

However, other students felt isolated and longed for the day when they go back to Vietnam. They had a high regard for the educational benefits but they wanted to shorten their time. They could not be happy in a environment in which they were lonely and bored. They compared Vietnam with New Zealand and found that they were not comfortable; there were so many differences that they could not live in harmony in this new country. 


\section{REFERENCES}

Adrian-Taylor, S. R., Noels, K.A., \& Tischler, K. (2007). Conflict between international graduate students and faculty supervisors: Toward effective conflict prevention and management strategies. Journal of Studies in International Education, 11(1), 90117.

Altbach, P. G. (2004).Higher education crosses borders: Can the United States remain the top destination for foreign students? Change: The Magazine of Higher Learning, $36(2), 18-25$.

Ali, S., Rohindra, D. \& Coll, K. R. (2008).Student perceptions of a culturally diverse classroom environment. Research in Science \& Technological Education, 26(2), 149-164.

Andrade, M.S. (2006). International students in English-speaking universities: Adjustment factors. Journal of Research in International Education, 5(2), 131-154.

Arkoudis, S. \& Tran, L. T. (2007). International students in Australia: Read ten thousand volumes of books and walk ten thousand miles. Asia Pacific Journal of Education, 27(2), 157-169.

Asteris, M. (2006). British universities: The "coal exporters" of the $21^{\text {st }}$ century. Journal of Studies in International Education, 10(3), 224-240.

Ballard, B. \& Clanchy, J. (1991).Teaching students from overseas: A brief guide for lecturers and supervisors. Melbourne: Longman Cheshire.

Beaver, B. \& Tuck, B. (1998). The adjustment of overseas students at a tertiary institution in New Zealand.New Zealand Journal of Educational Studies, 33(2),167-179.

Birrel, B. (2006). Implications of low English standards among overseas students at Australian universities, People and Place, 14(4), 53-64. 
Brown, L. \& Holloway, I. (2008). The initial stage of the international sojourn: Excitement or culture shock? British Journal of Guidance \& Counselling, 36(1), 33-49.

Brown, L. (2009). A failure of communication on the Cross-cultural campus. Journal of Studies in International Education, 13(4), 439-454.

Burrell, K.I., \& Kim, J. D (1998).International students and academic assistance: Meeting the needs of another college population. In L. P, Dwinell and J. I, Higbee (Eds.): Developmental Education: Meeting the diverse student needs, (p.81-96): Morrow, GA: NADE.

Butcher, A. (2002).A report on the Demographic, Social and Economic Impact of International Students on North Shore City, Albany: School of Social and Cultural Studies, Massey University.

Butcher, A. \& McGrath, T. (2004). International students in New Zealand: Needs and responses. International Education Journal, 5(4), 540-551.

Caligiuri, P.M. (2000). Selecting expatriates for personality characteristics: A moderating effect of personality on the relationship between host national contact and crosscultural adjustment. Management International Review, 40(1), 61-80.

Casey, K. (1995). The new narrative research in education. Review of Research in Education 21, 211-252.

Chalmers, D., \& Volet, S. (1997). Common misconceptions about students from South-East Asia studying in Australia. Higher Education Research and Development, 16(1), 87-98.

Chase, S.E. (2005). Narrative inquiry: Multiple lenses, approaches, voices. In N.K. Denzin \& Y.S. Lincoln (Eds.).The Sage Handbook of Qualitative Research $\left(3^{\mathrm{rd}} \mathrm{ed}\right)$, p. 651679.Thousand Oaks. CA: Sage 
Cheng, D., Leong, F.T.L., \& Geist, R. (1993). Cultural differences in psychological distress between Asian and American college students. Journal of Multicultural Counselling \& Development, 21, 182-189.

Choi, T. (2006).Asian international students' academic adjustment in a US graduate school and Stanton-Salazar's framework. Pacific Asian Education, 18 (2), 51-68.

Clandinin, D. J., \& Connelly, F. M. (2000). Narrative inquiry: Experience and story in qualitative research. San Francisco: Jossey-Bass

Crabtree, D.R. (2008). International education (research).Student service (International aspects).Michigan Journal of Community Service Learning, 15(1), pp.15.

Creswell, J.W. (2007). Qualitative inquiry and research design: Choosing among five approaches $\left(2^{\text {nd }} e d\right)$. Thousand Oaks, CA: Sage.

Creswell, J.W., Hanson, W.E., Clark, V.I.P., \& Morales, A. (2007). Qualitative research designs: Selection and implementation. The Counseling Psychologist, 35(2), 236264.

Cross, S (1995). Self-construals, coping and stress in cross-cultural adaptation. Journal of Cross-cultural Psychology, 26(6), 673-697.

Davies, B. (1991).The concept of agency: A feminist post-structural analysis. Social Analysis, Special Issue, Postmodern Critical Theorizing, 30, $42-53$.

Davies, B. (1993). A poststructuralist analysis of classroom practice. Geelong, Victoria, Australia: Deakin University Press.

Davies, B., \& Harré, R. (1990).Positioning: The discursive production of selves. Journal for the Theory of Social Behavior, 20(1), 43-63.

Davies, B., \& Harré, R. (1998).Positioning and personhood. In R, Harré \& L, V. Langenhove (Eds.), Positioning theory: Moral contexts of intentional action (pp. 32-52). Malden, MA: Blackwell. 
Deem, R., \& Brehony, K.J. (2010). Doctoral students' access to research cultures- are some more equal than others? Studies in Higher Education, 25(2), 149-165.

Do, T. (2006). East meets West: The adaptation of Vietnamese international students to California Community Colleges. Journal of Southeast Asian American Education and Advancement, 2(1), 1-30.

Eid, M.T. \& Jordan-Domschot, T. (1989).Needs assessment of international students at Eastern Oregon State College.(ERIC Document Reproduction Service No. ED 326098).

Ellis, J. (1993). Japanese students abroad: Relating language ability in class and in the community. Thought Currents in English Literature, 66, 45-82.

Erichsen, E, A. (2011). Learning for change: Transforming international experience as identity work. Journal of Transformative Education, 9(2), 109-133.

Foot, J. R. (2009).Exploring international student academic engagement using the NSSE framework. Unpublished Doctoral Dissertation Missouri-Columbia University, Columbia.

Freeman, M. (1992). Self as narrative: The place of life history in studying the life span. In T. Brinthaupt \& R. Lipka (Eds.): The self: Definitional and methodological issues (p. 15-43). Albany: State University of New York Press.

Groenewald, T. (2004). A phenomenological research design illustrated. International Journal of Qualitative Methods, 3(1), 1-27.

Harré, R. \& Langenhove, L. V. (1999).Positioning theory. (Eds.). Oxford. Blackwell.

Harré, R., Moghaddam, F.M., Cairnie, T.P., Rothbart, D., \& Sabat, S.R. (2009). Recent advances in Positioning Theory. Theory \& Psychology, 19(1), 5-31. 
Heggins, W.J \& Jackson, J. F.L (2003).Understanding the collegiate experience for Asian international students at a Midwestern research university. College Student Journal, 37(3), 379-391.

Hellsten, M. (2002). Students in transition: Needs and experiences of international students in Australia. Paper presented at the $16^{\text {th }}$ Australian International Education Conference, Hobart, Tasmania. http://www.idp.com/16aiecpapers/program/wednesday/teaching/Hellsten_p.pdf

Ho, E.S., Holmes, P., \& Cooper, J. (2004). Review and evaluation of international literature on managing cultural diversity in the classroom. Report for Ministry of Education and Education New Zealand, Wellington.

Ho, S. E., Li, W., Cooper, J. \& Holmes, P. (2007). The experiences of Chinese international students in New Zealand. Report for Education New Zealand, March 2007.University of Waikato.

Hoang Thuy (2011). Most of the teachers of English are under the standard (Đa số giáo viên ngoại ngữ chưa đạt chuẩn) http://vnexpress.net/gl/xa-hoi/giao-duc/2011/10/daso-giao-vien-ngoai-ngu-chua-dat-chuan/

Hodza, F. (2007).Managing the student-supervisor relationship for successful postgraduate supervision: A sociological perspective. South African Journal of Higher Education, 21(8), 1155-1165.

Hollway, W. (1984).Gender differences and the production of subjectivity. In J. Henriques, W. Hollway, C. Urwin, L. Wenn, \& V. Walkerdine (Eds.), Changing the subject: Psychology, social regulation and subjectivity (pp. 227-263). London: Methuen.

Holmes, P. (2004). Negotiating differences in learning and intercultural communication: Ethnic Chinese students in a New Zealand university. Business Communication Quarterly, 67(3), 294-307. 
Hsieh, M.-H. (2007). Challenges for international students in higher education: one student narrated story of invisibility and struggle. College Student Journal, 41(2), 379-391.

Hussin, V. (2007).Supporting off-shore students: A preliminary study. Innovations in Education and Teaching International, 44(4), 363-376.

Johnson, K. A. (1993). Q-Methodology: Perceptions of international student services in higher education. (ERIC Document Reproduction Service No. ED363550)

Johnson, B. \& Christensen, L. (2008). Educational research: Quantitative, qualitative and mixed approaches $\left(3^{\text {rd }}\right.$ ed). Los Angeles: Sage.

Josselson, R. (2007). The ethical attitude in narrative research: Principles and practices. In Clandinin, D. J (Eds.). Handbook of narrative inquiry (p.538-566). Thousand Oaks, CA. Sage.

Kaur, D. (2006). International students and American higher education: A study of the academic adjustment experience of six Asian Indian international students at a research level II school. Unpublished Doctoral dissertation. The University of North California at Charlotte, Charlotte, CA.

Khawaja, N. G. \& Dempsey, J. (2008).A comparison of international and domestic tertiary students in Australia. Australian Journal of Guidance \& Counselling, 18(1), 30-46.

Kingston, E. \& Forland, H. (2008).Bridging the gap in expectations between international students and academic staff. Journal of Studies in International Education, 12(2), 204-221.

Knight, J (2007). Internationalization: Concepts, complexities and challenges. In Forest, J.F.J \& Altback, G.P (Eds.).International Handbook of Higher Education, 207-227.

Koehne, N. (2006). (Be)coming, (be)longing: Ways in which international students talk about themselves. Discourse: Studies in the Cultural Politics of Education, 27(2), 241-257. 
Kuo, I. (2006). Addressing the issues of teaching English as a lingua franca. English Language Teaching Journal, 60 (3), 213-221.

Kvale, S (2007). Doing interviews. London. Sage.

Lacina, J.G. (2002). Preparing international students for a successful social experience in higher education. New Directions for Higher Education, 117, 21-27.

Larcombe, M., McCosker, A., \& O’Loughlin, K. (2007). Supporting education PhD and MEd Students to become confident academic writers: An evaluation of thesis writers' circles. Journal of University Teaching \& Learning Practice, 4(1), 1-12.

Lassegard, P. J. (2008). The effects of peer tutoring between domestic and international students: The tutor system at Japanese universities. Higher Education Research and Development, 27(2), 357-369.

Lee, E. L. (2007). Linguistic and cultural factors in East Asian students' oral participation in US university classrooms. International Education Journal, 36(2), 27-47.

Lewthwaite, M. (1996).A study of international students' perspectives on cross-cultural adaptation. International Journal for the Advancement of Counselling, 19(2), 167185.

Li, G., Chen, W., \& Duanmu, J-L. (2010). Determinants of international students' academic performance: A comparison between Chinese and other international students. Journal of Studies in International Education, 14(4), 389-405.

Lysgaard, S. (1955). Adjustment in a foreign society: Norwegian Fulbright grantees visiting the United States. International Social Science Bulletin, 7, 45-51.

Manathuga, C (2011). Intercultural postgraduate supervision: Post-colonial explorations and reflections on Southern positioning. In Keynote presented at Stellenbosh University Postgraduate Supervision Conference, Stellenbosh, 2011. 
Marshall, C. \& Rossman, G.F. (2006).Designing qualitative research ( $4^{\text {th }} \mathrm{ed}$ ). Thousand Oaks, CA: Sage.

McClure, J. W. (2007). International graduates' cross-cultural adjustment: Experiences, coping strategies, and suggested programmatic responses. Teaching in Higher Education, 12(2), 200-227.

McLeod, M. \& Wainwright, P. (2009).Researching the study abroad experience. Journal of Studies in International Education, 13, 66-71.

Merriam, S. B. (1998). Qualitative research and case study applications in Education (2 ${ }^{\text {nd }}$ ed). San Francisco: Jossey-Bass.

Merriam, S.B. \& Associates (2002). Qualitative research in practice. San Francisco: Jossey- Bass.

Moen, T. (2006). Reflections on the narrative research approach. International Journal of Qualitative Methods, 5 (4), p 56-69.

Montgomery, C. (2010). Understanding the international student experience. London: Palgrave Macmillan.

Mori, S. (2000).Addressing the mental health concerns of international students. Journal of Counselling and Development, 72(8), 137-144.

Nieto, C., \& Booth, Z.M. (2010). Cultural competence: Its influence on the teaching and learning of international students. Journal of Studies in International Education, 11(4), 406-425.

Oberg, K. (1960). Cultural shock: Adjustment to new cultural environments. Practical Anthropology, 7, 177-182.

Osmond, J. \& Roed, J. (2010). "Sometimes it means more work": Student perceptions of group work in a mixed cultural setting. In E, Jones (Eds.).Internationalization and the student voice, (p.113-124). New York: Routledge. 
Personal Narrative Group. (1989). Interpreting women's lives. Feminist theory and personal narratives. Bloomington: Indiana University Press.

Polkinghorne, D. (1995). Narrative configuration in qualitative analysis. In J. Hatch \& R. Wisniewski (Eds.), Life history and narrative (p. 5-23). Lewes: Falmer.

Poyrazli, S. \& Grahame, M.K. (2007). Barriers to adjustment: Needs of international students within a semi-urban campus community. Journal of Instructional Psychology, 34(1), 28-45.

Poyrazli, S. \& Kavanaugh, R. P. (2006). Marital status, ethnicity, academic achievement and adjustment strains: The case of graduate international students. College Student Journal, 40(4), 767-780.

Rai, S. (2002).Gender and the political economy of development: From nationalism to globalization. Cambridge: Polity Press.

Ramsay, S., Barker, M. \& Jones, E. (1999). Academic adjustment and learning processes: A comparison of international and local students in first year university. Higher Education Research \& Development, 18(1), 129-144.

Riessman, C.K. (1993). Narrative analysis. Newbury Park, CA: Sage.

Riessman, C.K. (2005). Narrative, Memory \& Everyday life. University of Huddersfield, Huddersfield.

Riessman, C.K. (2008). Narrative methods for the human sciences. Thousand Oaks, CA: Sage.

Rizvi, F. (2005).International education and the production of cosmopolitan identities. Paper presented at the March $4^{\text {th }} 2005$ Transnational Seminar Series at the University of Illinois: Urbana-Champaign.

Robertson, S.L. (2012). Stories of young migrants' cross-cultural educational transitions. Unpublished Master dissertation. Victoria University of Wellington: Wellington. 
Rotter, J.B. (1954).Social learning and clinical psychology. New York: Prentice Hall.

Rotter, J.B. (1982).The development and applications of social learning: Selected papers. New York: Praeger.

Ryan,E. M. \& Twibell, S, R. (2000). Concerns, values, stress, coping, health and educational outcomes of college students who studied abroad. International Journal of Intercultural Relations, 24, 409-435.

Schneider, L. J., \& Spinler, D.G. (1986).Help-giver preference patterns in American and international Asian students.(ERIC Document Reproduction Service No. ED272794).

Sikes, P. \& Gale, K. (2006). Narrative approaches to education research. Faculty of Education, University of Plymouth.

Smith, L. M. (1994). Biographical method. In N. Denzin, \& Y. Lincoln (Eds.).Handbook of qualitative research (pp. 286-305). Thousand Oaks, CA: Sage.

Storch, N. \& Hill, K. (2008). What happens to international students' English after one semester at university? Australian Review of Applied Linguistics, 31(1), 4.1-4.17.

Stoynoff, S. (1997). Factors associated with international students' academic achievement. Journal of Instructional Psychology, 24(1), 56-68.

Tait, C. (2010). Chinese students' perceptions of the effects of Western University examination formats on their learning. Higher Education Quarterly, 64(3), 261-275.

Taylor, E. W. (1994). A learning model for becoming interculturally competent. International Journal of Intercultural Relations, 18(3), 389-408.

Townsend, P. \& Poh, J, H. (2008).An exploratory study of international students studying and living in a regional area. Journal of Marketing for Higher Education, 18(2), 240-263. 
Tran, N. L. (2009). An acculturation dilemma for Asian international students in Australia: The case of Vietnamese international students. Paper presented at the $20^{\text {th }}$ ISANA International Education Conference, The Gap, Queensland, Australia, 4061. Retrieved March 05, 2012 from http://proceedings.com.au/isana2009.

Tran, T.L. (2011).Committed, face-value, hybrid or mutual adaptation?The experiences of international students in Australian higher education. Educational Review, 1, 79-94.

Tran, T.L (2007). Journey of adaptation of Chinese and Vietnamese international students to academic writing practices in higher education. Unpublished Doctoral Dissertation, University of Melbourne.

Victoria University of Wellington: Student services. Retrieved on May, 12 ${ }^{\text {th }}, 2012$ from: http://www.victoria.ac.nz/st_services/slss/whatweoffer/international.aspx

Victoria University of Wellington. International Prospectus 2012-2013.

Walliman, N. S. R. (2001). Your research project: A step-by-step guide for the first time researcher. London: Sage.

Ward, C. (2001). The impact of international students on domestic students and host institutions: A literature review. Prepared for Export Education Policy Project. Wellington: Ministry of Education.

Ward, C. \& Kennedy, A. (1993). Where's the "culture" in cross-cultural transition? Comparative studies of sojourner adjustment. Journal of Cross-cultural Psychology, 24(2), 221-249.

Webber-Bosley, G. (2010). Beyond immersion: Global engagement and transformation through intervention via student reflection in long-term study abroad. In E. Jones (Eds.) Internationalization and the student voice. New York: Routledge.

Winslade, J. (2005). Utilising discursive positioning in counselling. British Journal of Guidance and Counselling, 33(3), 353- 364. 
Ying, Y. W. (2003). Academic achievement and quality of overseas study among Taiwanese students in the United States. College Student Journal, 37, 470-480.

Zhang, Y. \& Mi, Y. (2009).Another look at the language difficulties of international students. Journal of Studies in International Education, 14(4), 371-388.

Zhao, K. (2007). The impact of adjustment problems on academic achievement of international undergraduates at West Virginia University. Unpublished Master's Dissertation. West Virginia University. 


\section{APPENDICES}

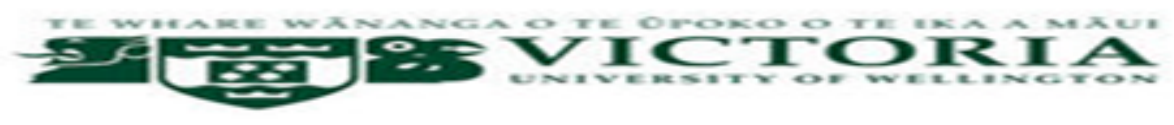

\section{RESEARCH INFORMATION SHEET}

Invitation to participate in a research study the "Vietnamese international student adjustment experience in a New Zealand University: A narrative case study".

\section{Researcher}

I am $\mathrm{Ha} \mathrm{Vu}$, a master student in the School of Educational Psychology and Pedagogy, Faculty of Education, Victoria University of Wellington. This research is a requirement for the dissertation of my master degree.

\section{Purpose of the research}

This research explores the adjustment experiences of Vietnamese international students in a New Zealand university. I particularly want to listen to students' stories of their experiences, coping strategies and the support they receive. In my study, I will focus on three issues of adjustment, which are language and communication, academic experiences and social relationship experiences.

\section{Involvement of the participants}

Two interviews will be conducted with each participant during the research. The first interview will be between 60 and 90 minutes in length and the second interview will be about 60 minutes in length. The interviews will be audio taped and transcribed by the researcher. I will write field notes as sources of data.

\section{Participant's rights}

Participation is voluntary. If you accept my invitation to participate you have the following rights:

- To withdraw at any time you want without explanation (just let me know that you do not want to continue) up until s week following the second interview.

- To refuse to answer any questions and require me not to use any information that you do not wish to be used in my research

- To ask any questions about the study at any time

- To be sure that your identity will be protected and you will able to select your pseudonym

- To select the time and place of the interviews

- To be provided with transcripts of your interviews 
- To be given access to the summary and findings of the research when it is finished

\title{
5. Protecting your privacy
}

I will audio-tape the interviews and transcribe them myself. The tapes and transcriptions will be stored safely and will be kept in locked a cabinet or stored on password protected computer files and the data will be destroyed after three years, only my supervisor and I will read the transcripts.

\section{How the interview data will be used}

Initially, the data will be used in writing my master thesis. Subsequently, data may be used to write academic articles or present the findings at academic conferences. The Victoria University's Faculty of Education's Human Ethics Committee has approved this study.

This study is guided and supervised by Dr Stephanie Doyle a senior lecturer at school of Educational Psychology and Pedagogy, Faculty of Education, Victoria University of Wellington. You can contact her at stephanie.doyle@vuw.ac.nz or (04) 463 6657 for more information. At any time you can contact me at vhlove04@yahoo.com or (04) 4635233 ex 9401 if you have any questions.

If you have issues or concerns about the research you may contact Dr Allison Kirkman the chairman of University Human Ethics Committee

\author{
Dr Allison Kirkman \\ Room MY 1013, Murphy Building \\ Kelburm Pde, Kelbum Campus \\ Phone: (04) 4635676 \\ Email: allison.kirkman@vuw.ac.nz
}

If you would like to accept this invitation to find out more about the research, and possibly to participate in the research please complete the expression of interest form and send it to me.

The researcher

$\mathrm{Ha} \mathrm{Vu}$ 


\section{EXPRESSION OF INTEREST}

Dear Ha,

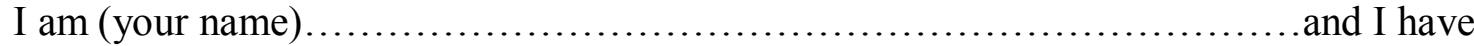
read the research information sheet carefully and I am very interested in your project. I would like to talk about it. We can arrange a time to meet and discuss.

You can contact me at (email)

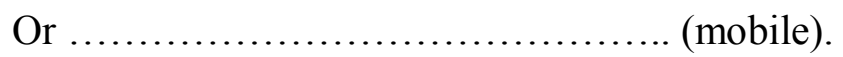

My preferred time/day

Yours sincerely 


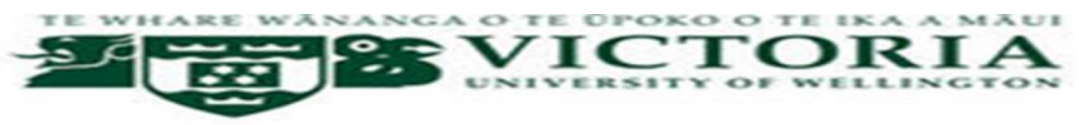

\section{CONSENT FORM}

Re: Vietnamese international student adjustment experiences in a New Zealand University: A narrative case study.

\section{Please tick}

I have read and understood the information sheet and the researcher has explained the research clearly. My questions have been answered to my satisfaction.

I understand what participating in the research involves and that we can ask for further information.

I understand that I do not have to take part in this study and can withdraw at any time up until one week after the second interview.

I understand that my name will not be used, and a pseudonym will be used.

I understand that I can refuse to answer any particular question in the interviews.

I understand that I will have the opportunity to read my interview transcript and to remove any information that I do not want to be used in the research.

The information will be used only for a Master's thesis, publications and presenting at academic conferences.

I agree to take part in this research project and am happy to work with the researcher.

I would like to be emailed a summary of the research findings.

Signed:

Name:

Email address: 
